\title{
Flammable Gas Safety Program: Actual Waste Organic Analysis FY 1996 Progress Report
}

Technical Task Leader: J. A. Camphell
S. A. Clauss
J. Rau
K. E. Grant
R. Steele
V. Hoopes
K. H. Wahl
G. M. Mong

September 1996

Prepared for the U.S. Department of Energy under Contract DE-AC06-76RLO 1830

Pacific Northwest National Laboratory Operated for the U.S. Department of Energy by Battelle

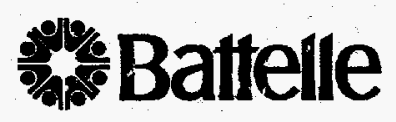




\title{
DISCLAIMER
}

This report was prepared as an account of work sponsored by an agency of the United States Government. Neither the United States Government nor any agency thereof, nor Battelle Memorial Institute, nor any of their employees, makes any warranty, express or implied, or assumes any legal liability or responsibility for the accuracy, completeness, or usefulness of any information, apparatus, product, or process discloseò, or represents that its use would not infringe privately owned rights. Reference herein to any specific commercial product, process, or service by trade name, trademark, manufacturer, or otherwise does not necessarily constitute or imply its endorsement, recommendation, or favoring by the United States Government or any agency thereof, or Battelle Memorial Institute. The views and opinions of authors expressed herein do not necessarily state or reflect those of the United States Government or any agency thereof.

\author{
PACIFIC NORTHWEST NATIONAL LABORATORY \\ operated by \\ BATTELLE \\ for the \\ UNTED STATES DEPARTMENT OF ENERGY \\ under Contract DE-AC06-76RLO 1830
}

Printed in the United States of America

Available to DOE and DOE contractors from the

Office of Scientific and Technical Information, P.O. Box 62; Oak Ridge, TN 37831; prices available from (615) $576-8401$.

Available to the public from the National Technical Information Service, U.S. Department of Commerce, 5285 Port Royal Rd., Springfield, VA 22161

This document was printed on recycled paper. 


\section{Flammable Gas Safety Program:}

\section{Actual Waste Organic Analysis FY 1996 Progress} Report

Technical Task Leader: J. A. Campbell

Report contributors:
S. A. Clauss
K. E. Grant
V. Hoopes
G. M. Mong
J. Rau
R. Steele
K. L. Wahl

September 1996

Prepared for the U.S. Department of Energy under Contract DE-AC06-76RLO 1830

Pacific Northwest National Laboratory Operated for the U.S. Department of Energy by Battelle 


\section{DISCLAIMER}

Portions of this document may be illegible in electronic image products. Images are produced from the best available original document. 


\section{DISCLAIMER}

This report was prepared as an account of work sponsored by an agency of the United States Government. Neither the United States Government nor any agency thereof, nor any of their employees, makes any warranty, express or implied, or assumes any legal liability or responsibility for the accuracy, completeness, or usefulness of any information, apparatus, product, or process disclosed, or represents that its use would not infringe privately owned rights. Reference herein to any specific commercial product, process, or service by trade name, trademark, manufacturer, or otherwise does not necessarily constitute or imply its endorsement, recommendation, or favoring by the United States Government or any agency thereof. The views and opinions of authors expressed herein do not necessarily state or reflect those of the United States Government or any agency thereof. 


\section{Abstract}

This report describes the status of optimizing analytical methods to account for the organic components in Hanford waste tanks, with particular emphasis on tanks assigned to the Flammable Gas Watch List. The methods that have been developed are illustrated by their application to samples obtained from Tanks 241-SY-103 (Tank SY-103) and 241-S-102 (Tank S-102). The analytical data are to serve as an example of the status of methods development and application. The primary purpose of this report is to provide a summary of the organic analytical results.

Samples of the convective and nonconvective-layer samples from Tank SY-103 were analyzed for total organic carbon (TOC). The average TOC value obtained for the nonconvectivelayer samples from Tank SY-103 was $9,400 \mu \mathrm{g} \mathrm{C/g}$. The average TOC value obtained from both the convective and non-convective layer samples of Tank 241-SY-101 (SY-101) was 11,000 $\mu \mathrm{g} \mathrm{C/g}$. The average value for the TOC of the convective-layer samples from Tank SY-103 was $7,400 \mu \mathrm{g} \mathrm{C} / \mathrm{g}$. Chelators and chelator fragments in Tank SY-103 samples were identified using derivatization gas chromatography/mass spectrometry (GC/MS). Organic components were quantified using GC/flame ionization detection. Major components in both the convective- and nonconvective-layer samples include ethylenediaminetetraacetic acid (EDTA), nitrilotriacetic acid (NTA), succinic acid, iminodiacetic acid (IDA), citric acid, and ethylenediaminetriacetic acid (ED3A). Results also indicate the presence of $\mathrm{C} 16$ and $\mathrm{C} 18$ carboxylic acids in the nonconvective-layer sample. Oxalic acid was one of the major components in the nonconvective layer as determined by derivatization $\mathrm{GC} /$ flame ionization detection.

A cation exchange step has been assimilated into the sample preparation procedure for analyzing tank waste to minimize radioactivity levels before organic analysis. Previous results showed that using cation exchange to reduce the radioactivity levels did not introduce or reduce any organic carbon for samples from Tank SY-101. However, organic carbon appears to be slightly reduced in eluting convective-layer samples from Tank SY-103. In addition, the radioactivity level of $137 \mathrm{Cs}$ was reduced by a factor of approximately 200 , and the level of $90 \mathrm{Sr}$ was reduced by a factor of 10 to 15 in convective-layer samples from Tank SY-103.

Analytical support was also provided for the studies being conducted to determine gas generation rates in order to estimate the extent of thermal and radiolytic degradation in samples from the convective layer of Tank SY-103. The results of analysis of samples heated at $60^{\circ} \mathrm{C}$ indicate the concentrations of IDA, NTA, and ED3A increased, and EDTA decreased. The same trends were noted for the samples heated to $120^{\circ} \mathrm{C}$.

Several techniques have been evaluated for directly analyzing chelator and chelator fragments in tank wastes. These include matrix-assisted laser desorption/ionization time-of-flight (MALDITOF) MS and liquid chromatography with ultraviolet (UV) detection using copper complexation. Although not directly funded by the Flammable Gas Program, the success of these technologies has implications of simplified organic analysis for both the Flammable Gas and Organic Tanks Safety programs.

As a direct result of work on the Flammable Gas Safety Program, one manuscript has been accepted for publication and two others have been submitted for peer review. 


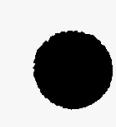

- 


\section{Summary}

This report describes the status of analyzing samples and developing analytical methods to account for the organic constituents in Hanford waste tanks. Particular emphasis was placed on those tanks that have been assigned to the Flammable Gas Watch List. The methods that have been developed are illustrated by their application to samples obtained from Tank 241-SY-103 (SY-103). The capability to account for organic carbon in Tank 241-SY-101 (Tank SY-101) samples has been improved significantly by improving techniques for isolating organic constituents relatively free from radioactive contamination and by improving derivatization methodology. The methodology has been extended to the analysis of samples from Tank SY-103, and the results are documented in this report. The results from analyzing heated and irradiated SY-103 samples (Gas Generation Task, Sam Bryan, Task Leader) and evaluating methods for analyzing tank waste directly for chelators and chelator fragments will be also be discussed. The results reported here are from the most recent organic analyses.

\section{Tank SY-103 Results}

The convective layer and nonconvective layer-samples were analyzed using derivatization gas chromatography/mass spectrometry (GC/MS) for chelator and chelator fragments. The major components in the convective layer include ethylenediaminetetraacetic acid (EDTA), ethylenediaminetriacetic acid (ED3A), iminodiacetic acid (IDA), nitrilotriacetic acid (NTA), citric acid (CA), and succinic acid (SA). Chelators and chelator fragments were quantified using gas chromatography/flame ionization detection (GC/FID). In addition, low-molecular-weight acids were quantified using liquid chromatography with conductivity detection. The results were similar to those obtained by the 222-S laboratory (Rice 1995). Table S.1 summarizes the data for low-molecularweight acids, chelators, and chelator fragments of samples from Tank SY-103. For comparison, Table S.2 contains previous results from analyses of samples from Tanks SY-101 (Campbell et al. 1994). The data represented in Table S.2 are average values obtained for the convective- and nonconvective-layer samples. These component types constitute the majority of the carbon accounted for by speciation.

Table S.1. Carbon (mg C/g) Accounted for by Chelators, Chelator Fragments, and LowMolecular-Weight Acids in Tank 241-SY-103 Convective and Nonconvective Layer Samples

\begin{tabular}{|c|c|c|c|}
\hline Sample & Chelators(a) & $\begin{array}{l}\text { Low-Molecular- } \\
\text { Weight Acids(b) }\end{array}$ & $\begin{array}{c}\% \text { TOC } \\
\text { Accounted For }\end{array}$ \\
\hline Convective & $3.2(43 \%)^{(\mathrm{c})}$ & $1.9(28 \%)$ & 71 \\
\hline Nonconvective & $1.7(18 \%)$ & $7.6(81 \%)$ & 99 \\
\hline
\end{tabular}

(a) Includes chelators, chelator fragments, nitrosated chelator material, and several carboxylic acids.

(b) Low-molecular-weight acids include acetic, glycolic, oxalic, and formic.

(c) Parentheses give percent of TOC accounted for by analyte category. 
Table S.2. Carbon Accounted for by Chelators, Chelator Fragments, Low-Molecular-WeightAcids in Tank 241-SY-101 Samples (mg C/g sample)

\begin{tabular}{|c|c|c|c|}
\hline Sample & Chelators(a) & $\begin{array}{l}\text { Low-Molecular- } \\
\text { Weight Acids(b) }\end{array}$ & $\begin{array}{c}\% \text { TOC } \\
\text { Accounted For }\end{array}$ \\
\hline Convective & $4.8(44 \%)(c)$ & $3.7(35 \%)$ & 79 \\
\hline Nonconvective & $2.9(26 \%)$ & $6.3(57 \%)$ & 83 \\
\hline
\end{tabular}

(a) Includes chelators, chelator fragments, nitrosated chelator material, and several carboxylic acids.

(b) Low-molecular-weight acids include acetic, glycolic, oxalic, and formic.

(c) Parentheses give percent of TOC accounted for by analyte category.

The chelators and chelator fragments comprise $43 \%$ and $18 \%$ of the total organic carbon (TOC) in the convective and nonconvective-layer samples from Tank SY-103, respectively. In contrast, the chelators and chelator fragments constitute $44 \%$ and $26 \%$ of the TOC in the convective and nonconvective-layer samples from Tank SY-101, respectively. Low-molecular-weight acids comprise $28 \%$ and $81 \%$ of the TOC in the convective and nonconvective-layers samples from Tank SY-103, respectively. For samples from Tank SY-101, low-molecular-weight acids make up 35\% and $57 \%$ of the convective and nonconvective-layer samples, respectively. The TOC accountability is $78-$ 99\% for the convective and nonconvective-layer samples from Tank SY-101 and the nonconvectivelayer sample from Tank SY-103. Organic speciation of the convective layer from Tank SY-103 accounted for $91 \%$ of the material remaining after cation exchange and $71 \%$ of the original material, indicating the loss of some organic carbon by adsorption on the resin.

Samples were eluted through a cation exchange resin to remove radioactivity. This additional step to the sample-preparation procedure was probably the single most important factor in increasing the \%TOC accounted for. With this step, samples could be dried and derivatized in a fume hood; parameters important for increased derivatization yields could be better controlled and monitored. The difference in TOC results for the nonconvective layer from Tank SY-103 before and after cation exchange was not statistically significant, but the difference in the convective-layer sample was approximately $30 \%$. This indicates that some organic carbon in the convective-layer sample may have adsorbed to the cation exchange resin. This may also be a possible explanation for the apparent lower TOC accountability. The radioactivity level of $137 \mathrm{Cs}$ was reduced by a factor of approximately 200 , and the level of $90 \mathrm{Sr}$ was reduced by a factor of 10 to 15 in the convective-layer samples from Tank SY-103. For the nonconvective-layer samples, the $137 \mathrm{Cs}$ was reduced by approximately a factor of 900 , and the level of $90 \mathrm{Sr}$ was reduced by a factor of 13 . In addition, apparently no organic carbon was introduced or removed from the nonconvective-layer samples.

Results from analyzing the convective- and nonconvective-layer samples from Tank SY-103 were compared with previous analyses from Tank SY-101. The accountability for carbon in the convective layer sample from Tank SY-103 was somewhat lower compared to samples from Tank SY101. This may be because the dried sample from Tank SY-103 was an extremely hard, impervious solid (the samples from SY-101 were softer and more amenable to derivatization), which may have inhibited the derivatization reaction. In addition, the excess $\mathrm{NaOH}$ used to elute the cation exchange column may have consumed a majority of the derivatizing reagent. The primary extractables 
(organically soluble carbon) from SY-101 were normal paraffin hydrocarbon and its related compounds, but those from SY-103 were styrene and styrene polymers.

\section{Tank S-102 Results}

The results from analysis of Tank S-102 are to be considered preliminary. The major components identified using derivatization with subsequent MS analysis included oxalic acid, succinic acid, citric acid, NTA, sulfur, N-butylbenzenesulfonamide, palmitic acid, and stearic acid. Other chelators such as EDTA, IDA, and ED3A were very low in concentration. A summary of the preliminary estimates is shown in Table S.3.

Table S.3 Approximate Concentrations of Analytes in Tank 241-S-102

\section{Analytes}

\section{Chelators}

(NTA, EDTA, ED3A, citric acid, succinic acid)

Low molecular weight acids

(oxalic acid)

Others

(sulfur, stearic acid, palmitic acid, n-butylbenzenesulfonamide)
Approximate Concentration $(\mu \mathrm{g} / \mathrm{g})$

\section{Gas Generation}

Samples from the convective layer of SY-103 were heated for 800 hours at $60,75,90,105$, and $120^{\circ} \mathrm{C}$ as part of the Gas Generation Studies Task (Sam Bryan, Task Leader). Major differences exist between samples heated at 60 and $120^{\circ} \mathrm{C}$. As the temperatures rose, the chelators degraded and the concentration of EDTA decreased, but the concentrations of IDA, NTA, and ED3A increased. The analytical results of samples heated at 75,90 , and $105^{\circ} \mathrm{C}$ indicated the concentrations of derivatized products varied widely, and the differences in concentration were small, within experimental uncertainty. Derivatization GC/FID may not be capable of detecting small changes in concentration, and the salt characteristics of the sample may have prevented full derivatization. Further discussions are contained in the Gas Generation Task Report (Bryan 1996).

\section{Degradation}

To estimate the extent of degradation of organics in the tanks, fill histories have been compared with actual analyses. The results are significantly different, indicating that chemical processes over time have changed the chemistry of the tanks. For example, the fill history of SY-101 indicates that $0.008 \mathrm{mg} / \mathrm{g}$ of oxalic acid was initially in the tank, but analysis results revealed approximately $15 \mathrm{mg} / \mathrm{g}$. For EDTA, the fill history lists a concentration of $12 \mathrm{mg} / \mathrm{g}$; the concentration determined by analysis was $4.2 \mathrm{mg} / \mathrm{g}$. Further comparisons between the fill history and actual analysis are needed to estimate the amount of degradation of the organic constituents. 


\section{Alternative Techniques}

Because derivatization GC/FID (which was used for these analyses) is time-consuming, expensive, and heavily dependent of the nature of the dried material, ion-pair liquid chromatography with ultraviolet detection of the copper complex is being evaluated for analyzing tank waste directly. Studies with simulated and real wastes look very promising. Another technique evaluated for analyzing chelators and chelator fragments directly is matrix-assisted laser desorption ionization/timeof-flight mass spectrometry. This technique has the advantage of very little sample preparation, small sample size, and little or no additional waste produced.

During FY 1996, there has been an increased collaboration between the Flammable Gas and Organic Tanks Safety Programs. Methods developed under one program have been used successfully to analyze organics under the other program. In addition, the question of aging of the organics is being examined under both programs.

\section{References}

Bryan, SA, CM King, LR Pederson, SV Forbes, and RL Sell. 1996. Gas Generation from Tank 241SY-103 Waste, PNL-10978, Pacific Northwest National Laboratory, Richland, Washington.

Campbell, JA, SA Clauss, KE Grant, FV Hoopes, BD Lerner, RB Lucke, GM Mong, JK Rau, and RT Steele. 1994. Flammable Gas Safety Program. Analytical Methods Development: FY 1993 Progress Report. PNL-9062, Pacific Northwest National Laboratory, Richland, Washington.

Rice, A. D. 1995. 216-Day Final Report for Tank 241-SY-103, Push Mode-Core 62. WHC-SDWM-DP-074, Rev. 0, Westinghouse Hanford Company, Richland, Washington. 


\section{Acknowledgments}

The authors would like to acknowledge the support of Westinghouse Hanford Company. Battelle is supported by the U.S. Department of Energy under Contract DE-AC06-76RLO 1830. The authors would also like to thank Dr. Harry Babad of Westinghouse Hanford Company for years of support and challenging dialogue. In addition, the authors would like to thank Georgia Ruebsamen and Wayne Cosby for assistance in preparing this report. 


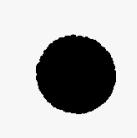

○ 


\section{Glossary}

$\begin{array}{ll}\text { BF3 } & \text { boron trifluoride } \\ \text { CA } & \text { citric acid } \\ \text { CI } & \text { chemical ionization } \\ \text { DSC } & \text { differential scanning calorimetry } \\ \text { ED3A } & \text { ethylenediaminetriacetic acid } \\ \text { EDTA } & \text { ethylenediaminetetraacetic acid } \\ \text { EI } & \text { electron impact } \\ \text { FT } & \text { Fourier transform } \\ \text { GC/FID } & \text { gas chromatography/flame ionization detection } \\ \text { GC/MS } & \text { gas chromatography/mass spectrometry } \\ \text { FY } & \text { fiscal year } \\ \text { HEDTA } & \text { N-(2-hydroxyethyl)ethylenediaminetriacetic acid } \\ \text { HPLC } & \text { high performance liquid chromatography } \\ \text { HRMS } & \text { high resolution mass spectrometry } \\ \text { IC } & \text { ion chromatography } \\ \text { IDA } & \text { iminodiacetic acid } \\ \text { IR } & \text { infrared } \\ \text { LC } & \text { liquid chromatography } \\ \text { LCMS } & \text { liquid chromatography/mass spectrometry } \\ \text { LSC } & \text { liquid scintillation counting } \\ \text { LMWA } & \text { low-molecular-weight acid } \\ \text { MALDI/TOF } & \text { matrix-assisted laser desorption/ionization time-of-flight } \\ \text { NED3A } & \text { n-nitrosoethylenediaminetriacetic acid } \\ \text { NIDA } & \text { N-nitrosoiminodiacetic acid } \\ \text { NMR } & \text { nuclear magnetic resonance } \\ \text { NTA } & \text { nitrilotriacetic acid } \\ \text { NPH } & \text { normal paraffin hydrocarbons } \\ \text { PFK } & \text { perfluorokerosene } \\ \text { PFTBA } & \text { perfluorotributylamine } \\ \text { SA } & \text { succinic acid } \\ \text { S-EDDA } & \text { symmetrical ethylenediaminediacetic acid } \\ \text { TBP } & \text { tributyl phosphate } \\ \text { TOC } & \text { total organic carbon } \\ \text { U-EDDA } & \text { unsymmetrical ethylenediaminediacetic acid } \\ \text { UV } & \text { ultraviolet } \\ & \end{array}$




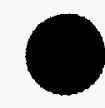

○ 


\section{Contents}

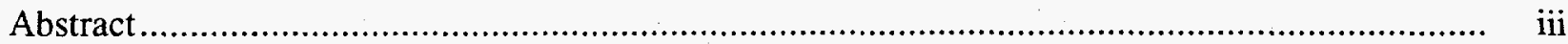

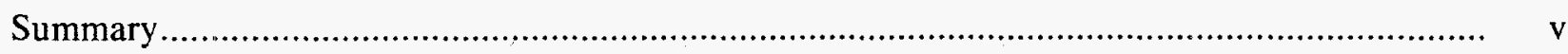

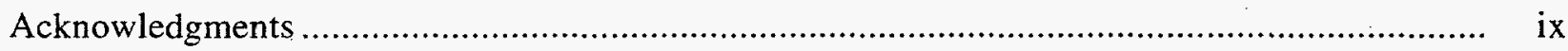

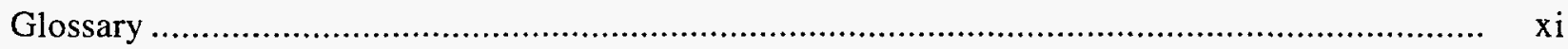

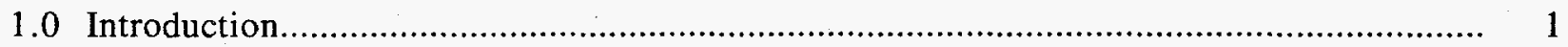

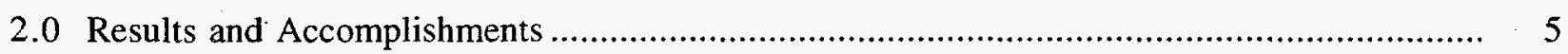

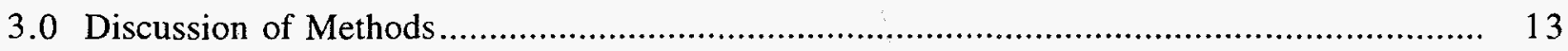

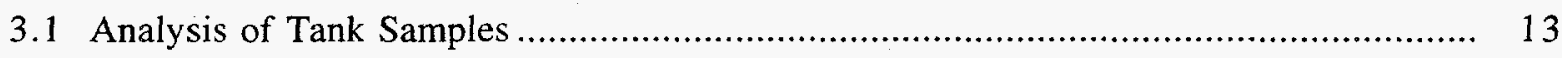

3.1.1 Sample Preparation .................................................................... 13

3.1.2 Cation Exchange for Reduction of Radioactivity Levels............................. 15

3.1.3 GC/MS and GC/FID for Chelators and Chelator Fragments ....................... 17

3.1.4 LC and IC for Low-Molecular Weight Acids......................................... 22

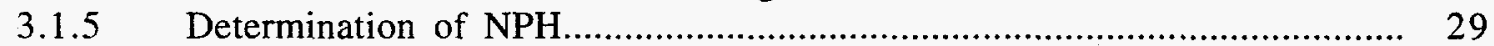

3.2 Analysis of Heated Samples from Tank SY-103 ............................................. 32

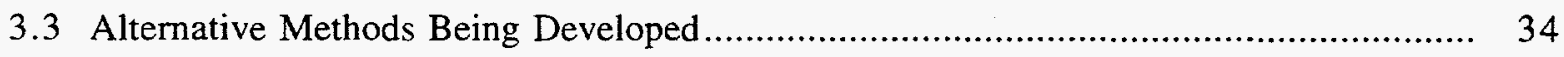

3.3.1 Organic Functional Group Screening Development .............................. 34

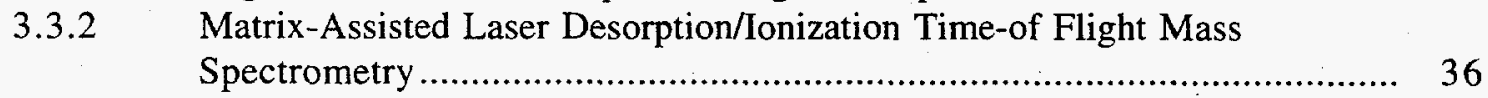

3.3.3 Ion-Pair Chromatography for Chelators and Chelator Fragments................ 37

3.4 Degradation of Organics in Flammable Gas Tanks ........................................ 43

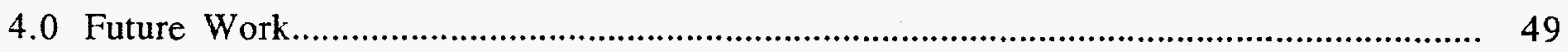

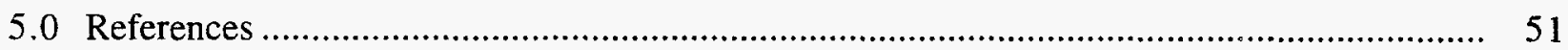

Appendix A Qualitative Determination of Low-Molecular-Weight Organic

Acids in Mixed Hazardous Wastes Using Thermospray Liquid

Chromatography/Mass Spectrometry.

Appendix B Determination of Chelators and Their Degradation Products in

Mixed Hazardous Wastes from Tank 241-SY-101 Using

Derivatization GC/MS.

Appendix C Activity Reduction of Radioactive Mixed Wastes for Subsequent

Carboxylate Determinations

C. 1 


\section{Figures}

3.1 Schematic Illustrating Sample Preparation and Analyses .................................... 14

3.2 Total Ion Chromatogram (GC/MS) of Derivatized Tank SY-103 Sample...................... 18

3.3 Gas Chromatography/Flame Ionization Detection Chromatogram of

Connective-Layer Sample From Tank SY-103.

3.4 Gas Chromatography/Flame Ionization Detection Chromatogram of

Nonconvective-Layer Sample From Tank SY-103 ................................................... 20

3.5 Total Ion Chromatogram (GC/MS) Indicating Myristic Acid as Tracer.......................... 22

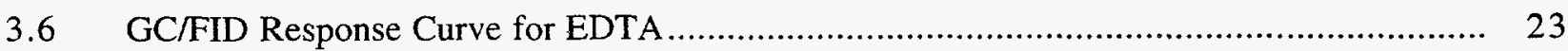

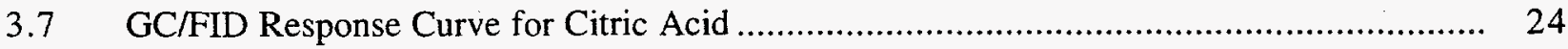

3.8 LC Chromatogram for Determination of Oxalate ............................................... 26

3.9 LC Chromatogram for Determination of Acetic, Glycolic, and Formic Acids ................ 26

3.10 LC Chromatogram of Low-Molecular Weight Acids Standards (Not in Presence of Simulant) with UV Detection................................................................ 27

3.11 LC Chromatogram of Spiked Low-Molecular Weight Acids with UV Detection in Simulated Waste Sample

3.12 IC Chromatogram of Organic Acids Standard (Not in Presence of Simulated Waste)

3.13 IC Chromatogram of a Simulated Waste Using

Conductivity Detection

3.14 Total Ion Chromatogram (GC/MS) of the Chloroform Extract of

Tank SY-101 Sample.

3.15 Total Ion Chromatogram (GC/MS) of the Chloroform Extract of

Tank SY-103 Sample.

3.16 Total Ion Chromatogram (GC/MS) and Mass Spectra of

Styrene-Related Compounds.

3.17 Accurate Mass Data

3.18 Results from Analysis of the Original Sample and $120^{\circ} \mathrm{C}-\mathrm{Heated}$

Sample from Tank SY-103.

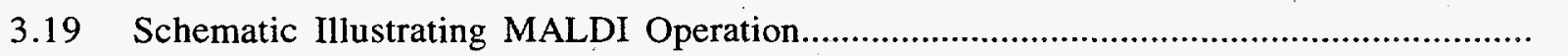




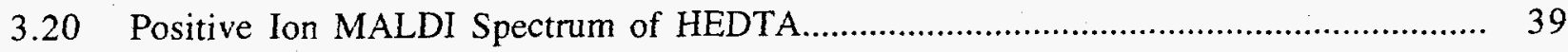

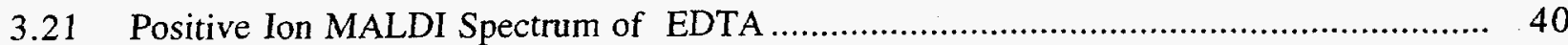

3.22 Positive Ion MALDI Spectrum of NTA .............................................................. 41

3.23 Negative Ion MALDI Spectrum of Citric Acid with Gentisic Acid Matrix...................... 42

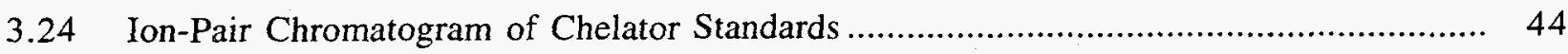

3.25 Ion-Pair Chromatogram of Simulated Waste .................................................... 45

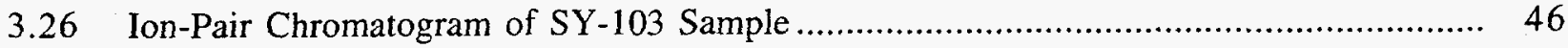

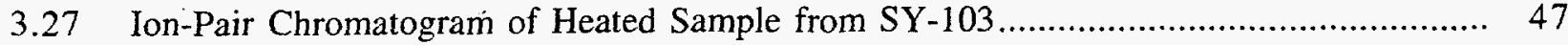




\section{Tables}

S.1 Carbon (mg C/g) Accounted for by Chelators, Chelator Fragments, and Low-Molecular-Weight Acids in Tank SY-103 Convective and Nonconvective Layer Samples

S.2 Carbon Accounted for by Chelators, Chelator Fragments, Low-MolecularWeight-Acids in Tank SY-101 Samples (mg C/g sample)

S.3 Approximate Concentrations of Analytes in Tank 241-S-102.

1.1 Summary of Actual Tank Waste Sample Preparation and Analysis

1.2 History of Analytical Methods Availability for Real Tank Waste Analysis

2.1 Summary of Results from Analyses of Tank SY-103 Samples for Chelator and Chelator Fragments (mg C/g) Using Derivatization GC/FID

2.2 Summary of Results from Analyses of Tank SY-103 Samples for Low-Molecular Weight Acids (mg C/g)

2.3 Results of Derivatization GC/MS Analyses on Tank SY-101 Window E Core Segment Samples.

2.4 LC Results for Oxalic, Formic, Glycolic, and Acetic Acids (mg C/g Sample) for SY-101 Window E Core Segment Samples

2.5 TOC Measurements of Tank SY-101 Samples Before and After Cation Exchange

2.6 Total Organic Carbon (mg C/g) Measurements Before and After Cation Exchange for Samples from Tank SY-103

2.7. Results from ${ }^{137} \mathrm{Cs}, 90 \mathrm{Sr}$, and Gross Alpha Analyses in Tank SY-103 Samples Before and After Use of Cation Exchange for Radioactivity Reduction....

2.8 Concentration of Normal Paraffin Hydrocarbon $(\mu \mathrm{g} / \mathrm{g})$ and Styrene-Related Organic Components in Tank SY-103 Samples

2.9 Concentration (ppm) of Normal Paraffin Hydrocarbon in Tank SY-101 Core

Segment Samples

2.10 Summary of Analyses of Samples from Tanks SY-101 and SY-103

2.11 Average Concentrations (mg C/g) of Components from Heated SY-103 Samples Using GC/FID 
3.1 Ions Observed for the Analytes by MALDI-TOF in the Positive or Negative Ion Mode. 


\subsection{Introduction}

In this task, tank wastes are analyzed under the auspices of the Flammable Gas Safety Program to identify proposed mechanisms for generating gas and to provide analytical support for the Gas Generation Studies Task (Sam Bryan, Task Leader). This report documents progress at Pacific Northwest National Laboratory ${ }^{1}$ during FY 1996 in 1) analyzing Tank 241-SY-103 (Tank SY-103) waste, 2) analyzing heated samples from the Gas Generation Task, 3) analyzing irradiated samples from the Gas Generation Study, 4) quantifying organic constituents using gas chromatography/flame ionization detection (GC/FID), 5) analyzing samples from Tank 241-S-102 (Tank S-102), and 6) optimizing analytical methodology for analyzing tank wastes directly for chelators and chelator fragments.

Organic constituents and quantities play a key role in gas composition and generation and provide the source material for some flammable gases. Studies in the Flammable Gas Program increase our understanding of the role organics play in how gas is generated, what types of gases are generated, and the quantities of potential or actual flammable gases. We need a better understanding of organics in tanks other than SY-101 and SY-103 to adequately address the Flammable Gas Safety issues. While generic organic analytical capabilities may exist elsewhere, this program provides the unique Pacific Northwest National Laboratory equipment, talent, and experience with actual waste analysis to satisfy the safety-issue needs described previously.

A history of methods development and analysis of tank wastes will be summarized. Only $10-$ $20 \%$ of the water-soluble organic carbon could be accounted for by derivatization gas chromatography/mass spectrometry (GC/MS) and liquid chromatography (LC) at the beginning of FY 1993, as reported in the FY 1993 Progress Report (Campbell et al. 1994a). All of the samples were prepared in the hot-cell facilities (this includes derivatization for chelator analysis). At the beginning of FY 1993, a set of eight core segment composite samples of Tank SY-101 from the window $E$ sampling period were being analyzed for chelators, chelator fragments, and carboxylic acids. Four samples were from the convective layer, and four were from the nonconvective layer. Throughout FY 1993, the composite samples were used to refine the analytical methods. Simulated wastes were not as beneficial as real wastes for developing certain methods; many of the properties of real waste were not duplicated in simulated wastes. Subsamples were used to determine the best sample size to reagent ratio in derivatization GC/MS and to evaluate procedures for removing a major portion of the radioactivity (without loss of organic carbon) so samples could be derivatized in the fume hood. Subsamples were also used to perfect LC methods for low-molecular-weight acids (LMWA). After the analytical procedures were in a final stage of development, additional subsamples of the composite samples were requested from the hot-cell facilities to perform analyses with the refined methods. These core segments were analyzed using the improved analytical methods, and the results were reported in the FY 1993 Progress Report (Campbell et al. 1994a). Questions regarding the presence or absence of nitroso compounds in the waste samples remained unanswered at that point, and total organic carbon (TOC) accountability was not as good as hoped.

Efforts in FY 1994 were focused on 1) developing a new sample preparation procedure to include the use of cation exchange for reducing the levels of radioactivity (Campbell et al. 1994b), 2) improving TOC accountability, and 3) verifying or refuting the existence of nitroso compounds in

1 Pacific Northwest National Laboratory is operated for the U.S. Department of Energy by Battelle under Contract DE-AC06-76RLO 1830. 
real waste samples. Removing most of the radioactivity with cation exchange without loss of organic carbon material permitted derivatization in a fume hood. Using a fume hood to prepare samples made it much easier to control reaction temperature and sample dryness; both of these parameters are critical for the derivatization procedures. A much smaller sample could be derivatized by using the fume hood. This improvement in the method allows the ratio of reagent to sample to be high enough to maximize the recoveries and minimize the matrix effect. The results not only gave much higher concentrations of derivatized components in the samples, but produced analyses that revealed sharp differences in component concentrations with depth in the waste tank. Studies were initiated to determine the radionuclide species and amounts removed during the process. In addition, studies were started to compare the sodium and hydrogen forms of the cation-exchange material.

A method was developed to identify water-insoluble organics, such as normal paraffin hydrocarbon (NPH), that may be present in the waste. In this method, the basic waste was extracted with methylene chloride and subsequently analyzed by GC/MS. An LC/MS technique using a basic mobile phase was developed to analyze waste samples to determine whether nitroso compounds existed in the waste or were artifacts of the derivatization procedures. This technique was performed under strictly basic conditions to analyze the samples directly and not under acidic conditions where nitroso compounds can be formed. Results from this study indicate that nitroso compounds are formed during the derivatization procedure, a reaction of nitrite in the waste with organic components having an active nitrogen bound to hydrogen such as iminodiacetic acid (IDA) and ethylenediaminetriacetic acid (ED3A).

During FY 1994, significant progress was made in the amount of TOC accounted for in samples from Tank SY-101 and in analytical methods development. However, problem areas still existed. As a result, efforts in FY 1995 were primarily focused on using developed methods to analyze samples from Tank SY-103. Other areas included 1) using deuterated internal standards with GC/MS analyses for samples from Tank SY-101 for recovery studies, 2) extending the application of cation exchange to reduce radioactivity levels in samples from Tank SY-103, 4) using ion chromatography (IC) to analyze LMWA in simulants, 4) estimating reproducibility for the analytical methods, 5) using an analytical technique to determine surfactants long-chain carboxylic acids, and 6) analyzing simulated and actual wastes for the Gas Generation Task (Sam Bryan, Task Leader).

The above discussion is summarized in Tables 1.1 and 1.2. Table 1.1 summarizes the chronology of actual tank waste sample preparation and analysis. Table 1.2 lists the history of analytical methods development for actual tank wastes.

This report describes the progress made in FY 1996 in 1) analyzing samples from Tank SY103,2 ) analyzing heated and irradiated samples from Tank SY-103 (Gas Generation Studies, Sam Bryan, Task Leader), and 3) developing more effective procedures for separating and preparing samples, for isolating and derivatizing components, and for identifying components. In addition, samples from Tank S-102 were also analyzed for organic constituents. This report will also discuss preliminary data from alternative methods for the direct analysis of chelator and chelator fragments; these methods require no derivatization prior to analysis. The method optimization was not funded directly by the Flammable Gas Safety Program but has important implications to the Tank Safety Program. If successful, the cost of analyses could be greatly reduced. 
Table 1.1. Summary of Actual Tank Waste Sample Preparation and Analysis

\begin{tabular}{|c|c|c|c|c|c|c|}
\hline$\underline{F Y}$ & Samples & $\underline{\text { Sample Prep }}$ & $\begin{array}{c}\begin{array}{c}\text { Cation } \\
\text { Exchange }\end{array} \\
\end{array}$ & $\begin{array}{l}\text { Chelator } \\
\text { Recovery Yield }\end{array}$ & $\underline{\text { LMWA }}$ & $\begin{array}{c}\% \mathrm{TOC} \\
\text { Accounted For }\end{array}$ \\
\hline 1993 & SY-101 & hot cell(a) & no & 54 to $60 \%$ & no & 10 to 20 \\
\hline 1994 & SY-101 & fume hood(b) & yes & 80 to $90 \%$ & yes & $73-93$ \\
\hline 1995 & SY-103 & fume hood(b) & yes & 90 to $95 \%$ & yes & 51 to $99(c)$ \\
\hline 1996 & SY-103 & fume hood(b) & yes & & yes & $\begin{array}{c}90 \%(\mathrm{~d}), 71 \%(\mathrm{e}) \\
99 \%(\mathrm{f})\end{array}$ \\
\hline 1996 & \multicolumn{2}{|c|}{ SY-103 Heated } & yes & N/A & yes & \\
\hline 1996 & \multirow{2}{*}{\multicolumn{2}{|c|}{ SY-103 Irradiated }} & yes & N/A & (g) & \\
\hline 1996 & & & yes & N/A & (g) & \\
\hline
\end{tabular}

(a) Sample preparation including derivatization performed entirely in hot cell

(b) Derivatization performed in fume hood

(c) Results based on partial data

(d) $90 \%$ refers to comparison to original sample of convective layer

(e) $71 \%$ refers to comparison to material after cation exchange

(f) $99 \%$ refers to nonconvective layer

(g) Analysis in progress

Table 1.2. History of Analytical Methods Availability for Real Tank Waste Analysis

$\underline{F Y}$

1993

1994 Derivatization GC/MS

1995 Derivatization GC/MS

1996 $\mathrm{LC}(\mathrm{f})$ LC/MS(h)

Derivatization GC/FID(i)

IC

Method

Derivatization GC/MS(a)

Derivatization GC/MS

Derivatization GC/FID

IC and LC

MALDI-TOF $(\mathrm{j})$ and LC
Analytical Focus

Chelators and Chelator Fragments HEDTA,(b) EDTA, (c) NTA, (d) IDA(e)

Chelators and Chelator Fragments LMWA $(\mathrm{g})$

Oxalate, Formate, Acetate

Qualitative Determination of LMWA

Qualitative Determination of Chelators and

Chelator Fragments

Quantitative Determination of Chelators and

Chelator Fragments

Quantitative Determination of LMWA

Chelators and Chelator Fragments

Quantitative Determination of Chelators and

Chelator fragments

Quantitative Determination of LMWA

Direct Analysis of Chelators
(a) gas chromatography/mass spectrometry
(b) N-(2-hydroxyethyl)ethylenediaminetriacetic acid
(c) ethylenediaminetetraacetic acid
(d) nitrilotriacetic acid
(e) iminodiacetic acid
(f) liquid chromatography
(g) low-molecular-weight acid
(h) liquid chromatography/mass spectrometry
(i) gas chromatography/flame ionization detection
(j) matrix-assisted laser desorption/ionization time-of-flight 


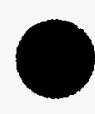

$\bullet$ 


\subsection{Results and Accomplishments}

The techniques developed and successfully applied to samples from Tank SY-101 were extended to the analysis of convective and nonconvective-layer samples from Tank SY-103. The convective-layer samples were primarily liquid with very little solids present. In contrast, the convective-layer samples from Tank SY-101 contained very little liquid and were primarily solids. The drainable liquids from segments 2-7 were composited to comprise the convective-layer sample from Tank SY-103. The nonconvective-layer sample was composed of solids from segments 10-14. Total organic carbon (TOC) values were determined by the hot persulfate method for the convective and nonconvective-layer samples from Tank SY-103. The TOC value for the nonconvective layer was $9,400 \mu \mathrm{g} \mathrm{C} / \mathrm{g}$, which was very similar to TOC results from Tank SY-101. The average value for TOC for the convective layer sample was $7,400 \mu \mathrm{g} \mathrm{C} / \mathrm{g}$. It should be noted that the hot persulfate method is not a good technique for acetone, butanol, NPH, benzene, and solid hydrocarbons (Baldwin et al. 1994).

\section{Tank SY-103 Results}

Samples from Tank SY-103 have been analyzed for organic constituents. The chelators and chelator fragments were quantified using GC/FID. The chelator of highest concentration was EDTA in both convective and nonconvective samples. The concentration of oxalic acid, normally obtained by LC, was determined using GC/FID. Oxalic acid was approximately $60 \%$ of the organic carbon in the nonconvective layer sample as expected, due to solubility limits; oxalic acid was not detected in the convective-layer sample. In addition, the results indicate that the chelators, chelator fragments, and oxalic acid comprise approximately $80 \%$ of the total organic carbon. The concentration for citric acid (CA) is somewhat higher in the convective-layer sample from Tank SY-103 than SY-101. Table 2.1 summarizes the data for chelator and chelator fragment analyses, and Table 2.2 summarizes the data for LMWAs of samples from Tank SY-103. The results for LMWAs are similar to those obtained by the 222-S laboratory (Rice 1995). Table 2.3 summarizes the data from chelator analysis of samples from Tank SY-101, and Table 2.4 summarizes the data from LMWA analyses of samples from Tank SY-101 (Campbell et al. 1994a) and are included here for comparison. The concentrations of organic components in samples from Tank SY-101 are represented as average values for both the convective and nonconvective layers.

The chelators and chelator fragments comprise $43 \%$ and $18 \%$ of the TOC in the convective and nonconvective-layer samples from Tank SY-103, respectively. In contrast, the chelators and chelator fragments constitute $44 \%$ and $26 \%$ of the TOC in convective-layer samples from Tank SY101. Low-molecular weight acids comprise $28 \%$ and $81 \%$ of the TOC in the convective and nonconvective-layers samples from Tank SY-103, respectively. For samples from Tank SY-101, LMWAs make up $35 \%$ and $57 \%$ of the convective and nonconvective-layer samples, respectively. The TOC accountability is $78-99 \%$ for the convective and nonconvective-layer samples from Tank SY-101 and the nonconvective-layer sample from Tank SY-103. Based on the analytical results, the concentrations of some of the analytes in samples from Tank SY-101 are apparently different from those in Tank SY-103. As an example, the concentration of IDA in the nonconvective-layer sample is approximately five times higher in samples from Tank SY-101. The concentration of EDTA in the convective-layer sample is approximately 2.5 to 3 times higher than in the nonconvective-layer samples from Tank SY-101. These results are similar to those obtained by 
Table 2.1. Summary of Results from Analyses of Tank SY-103 Samples for Chelator and Chelator Fragment (mg C/g) Using Derivatization GC/FID

\begin{tabular}{|c|c|c|c|c|c|c|c|c|c|}
\hline$\underline{\text { Sample }}$ & $\underline{\mathrm{DA}}$ & NTA & $\underline{\mathrm{CA}}$ & $\underline{\mathrm{ED}_{3} \mathrm{~A}^{(b)}}$ & EDTA & HEDTA $^{(\mathrm{c})}$ & $\underline{\mathrm{SA}}$ & Total & $\begin{array}{c}\% \text { TOC } \\
\frac{\text { Accounted }}{\underline{\text { For }}}\end{array}$ \\
\hline & 1.36 & 0.32 & 0.62 & 0.25 & 0.73 & 0.03 & 0.02 & 1.49 & 43 \\
\hline NC & 0.16 & 0.16 & 0.56 & 0.16 & 0.65 & nd & 0.02 & 1.71 & 18 \\
\hline
\end{tabular}

Table 2.2. Summary of Results from Analyses of Tank SY-103 Samples for Low-Molecular Weight Acids (mg C/g)

$\begin{array}{lclllll}\text { Sample } & \text { Oxalic } & \text { Glycolic } & \frac{\text { Acetic }}{\text { Weight Acids }(\mathrm{mg} \mathrm{C} / \mathrm{g})} & \text { Formic } & \frac{\text { Total }}{\text { \% TOC }} & \begin{array}{c}\text { Accounted For } \\ \text { C }\end{array} \\ \text { nd } & \text { nd } & 0.6 & 1.2 & 1.8 & 28.1 \\ \text { NC } & 6.0 & \text { nd } & 0.7 & 0.9 & 7.6 & 80.9\end{array}$

$\mathrm{NC}=$ Nonconvective
$\mathrm{C}=$ Convective
nd $=$ not detected

Table 2.3. Results of Derivatization(a) GC/MS Analyses on Tank SY-101 Window E Core Segment Samples Concentration of Major Components (mg C/g Sample) TOC \% TOC

$\underline{\text { Sample IDA NTA }} \underline{\text { CA ED3A(b) EDTA HEDTA(c) SA Accounted For (d) Accounted For }}$

$\begin{array}{llllllllll}\mathrm{C} & -1.04 & 0.33 & 0.32 & 0.30 & 2.23 & - & 0.07 & 4.9 & 44 \\ \mathrm{NC} & 0.82 & 0.22 & 0.31 & 0.28 & 0.80 & - & 0.05 & 2.9 & 26\end{array}$

\footnotetext{
(a) Derivatization performed in fume hood

(b) Assuming response similar to EDTA

(c) HEDTA was found in window E composite samples, but not in the segment subsamples.

(d) Total includes minor components not included in this summary table.

C Convective layer

NC Nonconvective layer
}

Barney with solubility experiments (Barney 1994). However, the EDTA concentrations are practically equal in the convective and nonconvective-layer samples from Tank SY-103.

By removing most of the radioactivity with cation exchange (in most cases without loss of organic carbon material), samples could be derivatized in a fume hood. Table 2.5 shows the 
Table 2.4. LC Results for Oxalate, Formic, Glycolic, and Acetic Acids (mg C/g Sample) for SY-101 Window E Core Segment Samples

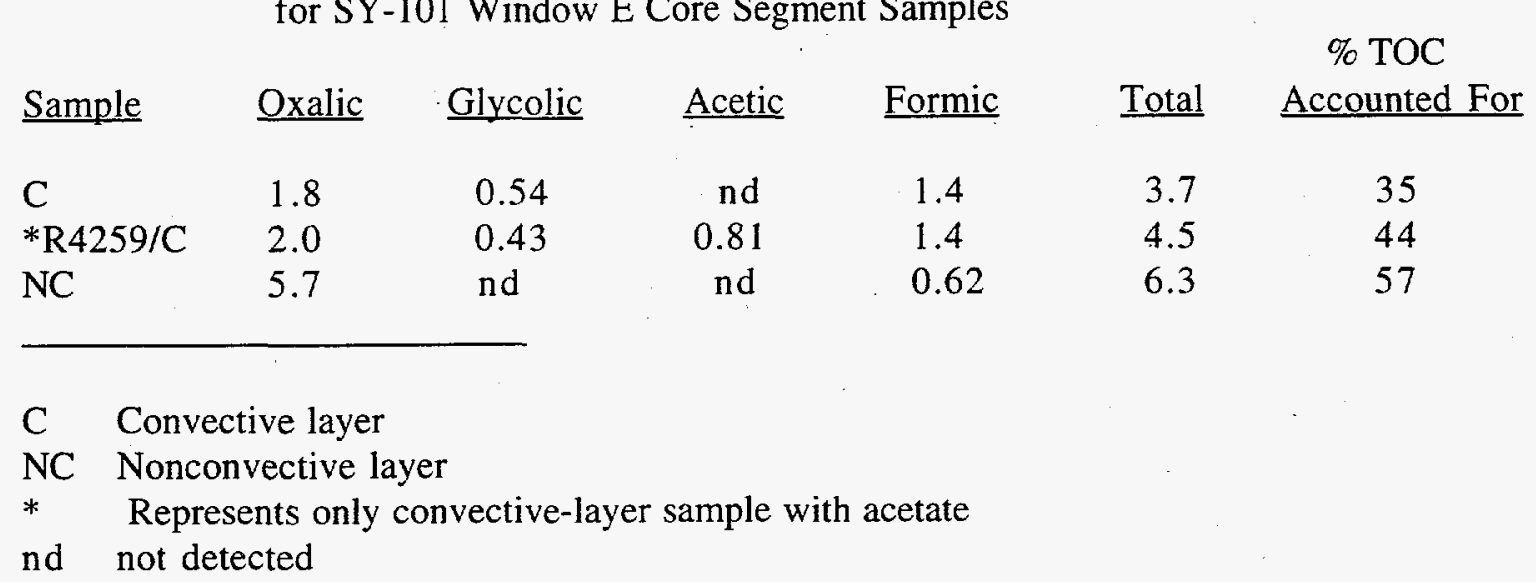

Table 2.5 TOC Measurements of Tank SY-101 Samples Before and After Cation Exchange

Sample

\begin{tabular}{lcc} 
& Trial \#1 & Trial \#2 \\
\cline { 2 - 3 } & & \\
Waste Sample & 2100 & 1995 \\
After separation thru $\mathrm{Na}^{+}$form & 2200 & 2170 \\
After $^{+}$form & 470 & 490 \\
${\text { Blank } \mathrm{H}^{+} \text {form }}$ & 9.5 & 8 \\
Blank $\mathrm{Na}^{+}$form & $<0.5$ & $<0.5$
\end{tabular}

results from studies of the cation exchange material with samples from Tank SY-101. Similar results were obtained with samples from Tank SY-103. For the nonconvective-layer samples, the TOC value obtained before cation exchange was $9400 \mu \mathrm{g} \mathrm{C} / \mathrm{g}$ and after was $8500 \mu \mathrm{g} \mathrm{C} / \mathrm{g}$. The values of TOC obtained from the convective-layer samples are somewhat confusing. The results of TOC measurements are shown in Table 2.6. If the original sample contained small amounts of sludge, the TOC numbers might be much higher than after the cation exchange. Further experimentation is underway with the convective layer to determine if any TOC is really lost. Preparing samples in a fume hood made it much easier to control reaction temperature and sample dryness; both of these parameters are critical for the derivatization procedures. With the fume hood, a much smaller sample could be derivatized. This improvement in the method allows the ratio of reagent to sample to be high enough to maximize the recoveries and minimize the matrix effect. The results not only gave much higher concentrations of derivatized components in the samples, but produced analyses that revealed sharp differences in component concentrations with depth in the waste tank. Analysis of samples from Tank SY-103 showed that the radioactivity level of $137 \mathrm{Cs}$ was reduced by a factor of approximately 200 , and the level of $90 \mathrm{Sr}$ was reduced by a factor of 10 to 15 . The results are shown in Table 2.7 for SY-103 samples. 
Table 2.6. Total Organic Carbon (mg C/g) Measurements Before and After Cation Exchange for Samples from Tank SY-103

$\begin{array}{lcc}\text { Sample } & \text { Before } & \text { After } \\ \text { Convective Layer } & 7.4 & 5.4 \\ \text { Nonconvective Layer } & 9.4 & 8.5\end{array}$

Table 2.7. Results from ${ }^{137} \mathrm{Cs}$, ${ }^{90} \mathrm{Sr}$, and Gross Alpha Analyses in Tank SY-103 Samples Before and After Use of Cation Exchange for Radioactivity Reduction

$\begin{array}{lccl}\text { Sample } & \text { Isotope } & \text { Before }(\mu \mathrm{Ci} / g) & \text { After }(\mu \mathrm{Ci} / \mathrm{g}) \\ \text { Nonconvective } & 137 \mathrm{Cs} & 260.8 & 0.29 \\ & 90 \mathrm{Sr} & 4.75 & 0.033 \\ & \text { gross alpha } & 0.002 & 0.0000143 \\ \text { Convective } & 137 \mathrm{Cs} & 273 & 1.23 \\ & 90 \mathrm{Sr} & 6.92 & 0.55 \\ & \text { gross alpha } & 0.007 & 0.0000061\end{array}$

Table 2.8 shows the concentration of normal paraffin hydrocarbon (NPH) and styrenerelated components in samples from Tank SY-103. The concentration of styrene-related components was $40 \mu \mathrm{g} / \mathrm{g}$ in the convective layer and $130 \mu \mathrm{g} / \mathrm{g}$ in the nonconvective layer. These organics were not in the Tank SY-101 samples. A small amount of NPH was identified in these Tanks SY-103 samples. Normal paraffin hydrocarbon was also identified in chloroform extracts of Tank SY-101 waste samples; the concentrations varied from 20 to $1440 \mathrm{ppm}$. The concentration of NPH varies with depth of the sample as expected. Table 2.9 shows the concentration of NPH found in Tank SY-101 waste samples (Campbell et al. 1994b) for comparing with NPH in Tank SY-103 samples. Table 2.10 summarizes the data from analyses of samples from Tanks SY-103 and SY-102.

\section{Gas Generation}

Waste samples were analyzed for the Gas Generation Task (Sam Bryan, Task Leader). Samples from the convective layer of Tank SY-103 were heated at $60,75,90,105$, and $120^{\circ} \mathrm{C}$ for 800 hours. Even at $60^{\circ} \mathrm{C}$, EDTA underwent thermal degradation. The concentrations of IDA, NTA, and ED3A increased with respect to the original sample. These observations are consistent with Toste (1989) who found that even at room temperature, the chelators in waste simulates degraded considerably. The differences between the concentrations of EDTA, NTA, ED3A, and IDA in the original sample and the sample heated at $120^{\circ} \mathrm{C}$ are significant. At $120^{\circ} \mathrm{C}$, essentially all of the EDTA disappeared, and the difference in concentration of $\mathrm{CA}$ is within experimental uncertainty. Table 2.11 lists the concentration of analytes in the original sample ( $\mathrm{mg} \mathrm{C} / \mathrm{g}$ of sample), the $60^{\circ} \mathrm{C}$-heated sample, and the sample heated at $120^{\circ} \mathrm{C}$. The results represent the average of four separate analyses. The estimated experimental deviation is approximately 15 to $20 \%$. These results are discussed in more detail in the Gas Generation Task Report (Bryan et al. 1996). 
Table 2.8. Concentration of Normal Paraffin Hydrocarbon $(\mu \mathrm{g} / \mathrm{g})$

and Styrene-Related Organic Components in Tank SY-103 Samples

$\begin{array}{lcc}\text { Sample } & \text { NPH } & \text { Styrene-Related } \\ \text { Convective } & 15 & 40 \\ \text { Nonconvective } & 10 & 130\end{array}$

Table 2.9. Concentration (ppm) of Normal Paraffin Hydrocarbon in Tank 241-SY101 Core Segment Samples

$\begin{array}{lcr}\text { Sample } & \text { Segment \# } & \text { NPH } \\ \text { R4258 } & 4 & 1440 \\ \text { R4259(a) } & 6 & \\ \text { R4260 } & 9 & 410 \\ \text { R4261 } & 11 & 670 \\ \text { R4262 } & 16 & 20 \\ \text { R4263(a) } & 17 & \end{array}$

(a) Insufficient sample remaining to determine concentration of NPH.

Table 2.10. Summary of Analyses of Samples from Tanks SY-101 and SY-103

\begin{tabular}{lcccc} 
& \multicolumn{2}{c}{ Convective $(\mathrm{mg} \mathrm{C} / \mathrm{g})$} & \multicolumn{2}{c}{ Nonconvective (mg C/g) } \\
Analyte & $\frac{\mathrm{SY}-101}{1.04}$ & $\frac{\mathrm{SY}-103}{1.36}$ & $\frac{\mathrm{SY}-101}{0.82}$ & $\frac{\mathrm{SY}-103}{0.16}$ \\
IDA & 0.33 & 0.32 & 0.22 & 0.16 \\
NTA & 0.32 & 0.62 & 0.31 & 0.56 \\
Citrate & 0.30 & 0.25 & 0.28 & 0.16 \\
ED3A & 2.23 & 0.73 & 0.80 & 0.65 \\
EDTA & $\mathrm{nd}$ & 0.03 & nd & nd \\
HEDTA & 0.07 & 0.02 & 0.05 & 0.02 \\
Succinate & 1.9 & nd & 5.7 & 6.0 \\
Oxalate & 0.48 & tbd & nd & tbd \\
Glycolate & 1.4 & 1.2 & 0.62 & 0.9 \\
Formate & 0.81 & 0.6 & nd & 0.7 \\
Acetate & 800 & 15 & 20 & 10 \\
NPH(a) & $28600(b)$ & & & 15000 (c) \\
OH & & & &
\end{tabular}
(a) $\mathrm{ppm}$
(b) $\mu \mathrm{g} / \mathrm{mL}$
(c) $\mu \mathrm{g} / \mathrm{g}$
nd not detected 
Table 2.11 Average Concentrations ${ }^{(a)}(\mathrm{mg} \mathrm{C} / \mathrm{g})$ of Components From Heated SY-103 Samples Using GC/FID

\begin{tabular}{lccc} 
Analyte & $\underline{\text { Original }}$ & $\underline{60^{\circ} \mathrm{C}}$ & $\underline{120^{\circ} \mathrm{C}}$ \\
\cline { 2 - 3 } NIDA & 1.36 & 4.93 & 6.37 \\
Citrate & 0.62 & 0.97 & 0.57 \\
NTA & 0.32 & 1.15 & 1.49 \\
ED3A & 0.25 & 0.68 & 1.16 \\
EDTA & 0.73 & 0.38 & 0.06
\end{tabular}

(a) Represents the average of four analyses

Tank S-102 Results

Table 2.12 lists the preliminary results of analyses of samples from Tank S-102. The sample was obtained from segment 4 . This sample was to be used as a preliminary investigation prior to heating and irradiation studies performed by Sam Bryan. These results are to be considered preliminary. Additional samples need to be analyzed. Organically soluble carbon was extracted using chloroform and analyzed using GC/MS. Components typically found in samples from SY-101 and SY-103, including tributyl phosphate (TBP), NPH, or styrene-related organics, were absent. However, siloxane-related organics were present; these may simply be the result of contamination. The major components identified using derivatization with subsequent MS analysis included oxalic acid, succinic acid, citric acid, NTA, sulfur, N-butylbenzenesulfonamide, palmitic acid, and stearic acid. Other chelators such as EDTA, IDA, and ED3A were very low in concentration. A summary of the preliminary estimates is shown in Table 2.12. Samples will also be analyzed using LC with copper complexation. In addition, additional S-102 samples will be analyzed in conjunction with the Gas Generation Task. The preliminary results indicate that the chelator concentration is lower than observed for SY-101 and SY-102.

\section{Degradation}

We have estimated the extent that organics have degraded in flammable gas tanks by comparing the fill history with the composition of the organics as determined by speciation. As an example, we have compared the fill history of Tank SY-101 with the results obtained by organic analyses. For oxalic acid, a common degradation product, the fill history estimates the concentration to be approximately $0.0008 \mathrm{mg} / \mathrm{g}$ of samples ${ }^{(1)}$, but actual analysis indicates a concentration of approximately $15 \mathrm{mg} / \mathrm{g}$. Another example is CA with an initial concentration of $3.5 \mathrm{mg} / \mathrm{g}$ from fill history compared to $0.8 \mathrm{mg} / \mathrm{g}$ from speciation. It may be possible to indirectly prove that waste solids do contain energetic species by comparing the amount of degradation of CA compared to the increase in oxalic acid. Citric acid appears to be less reactive than either HEDTA and EDTA; these results have been confirmed by Camaioni et al. (1996) and by analyzing the heated SY-103 samples (Bryan et al. 1996).

\section{Alternative Techniques}

Derivatization GC/MS for analyzing chelators and chelator fragments is time consuming, produces artifacts, and is costly. As a result, several techniques have been evaluated, including

(1) Agnew, SF. 1995. Updated estimate for SY-101 Fill History. E-mail Message 8/31/95 to Dr. Harry Babad. 
Table 2.12. Approximate Concentrations from Analysis of S-102 Sample

Analyte
EDTA
ED3A
citric acid
palmitic acid
NTA
oxalic acid
succinic acid
sulfur
stearic acid
N-butylbenzenesulfonamide

$$
\begin{array}{r}
\text { Concentration } \\
<10 \mu \mathrm{g} / \mathrm{g} \\
<10 \mu \mathrm{g} / \mathrm{g} \\
160 \mu \mathrm{g} / \mathrm{g} \\
80 \mu \mathrm{g} / \mathrm{g} \\
10 \mu \mathrm{g} / \mathrm{g} \\
2300 \mu \mathrm{g} / \mathrm{g} \\
20 \mu \mathrm{g} / \mathrm{g} \\
450 \mu \mathrm{g} / \mathrm{g} \\
50 \mu \mathrm{g} / \mathrm{g} \\
140 \mu \mathrm{g} / \mathrm{g}
\end{array}
$$

matrix-assisted laser desorption/ionization time-of-flight (MALDI-TOF), LC with copper complexation and ultraviolet (UV) detection. Both of these methodologies allow the sample to be analyzed directly, without prior derivatization. Even though not directly funded by the Flammable Gas Program, the development of these techniques may have implications for the program. These techniques will provide faster and cheaper direct methods for the analyses of chelators and chelator fragments. Positive ion MALDI-TOF spectra of EDTA, HEDTA, NTA, and IDA have been obtained. Negative ion spectra of phosphate, sulfate, nitrate, and nitrite have also been obtained. These techniques will be described in more detail in the discussion of methods section.

One publication regarding LC/MS for the qualitative analysis of LMWAs has been accepted in the Journal of Radioanalytical and Nuclear Chemistry (Grant et al. 1996a, see Appendix A) Two other manuscripts entitled "Determination of Chelators and Chelator Fragments in Samples from Tank 241-SY-101 Using Derivatization Gas Chromatography"(Grant et al. 1996b, see Appendix B) and "Cation Exchange for the Reduction of Radioactivity in the Analysis of Tank Wastes" (Mong et al. 1996, see Appendix C) have been submitted for publication. A MALDI-TOF paper describing the analysis of low-molecular-weight organics is also in preparation. 


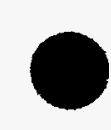

-

- 


\subsection{Discussion of Methods}

\subsection{Analysis of Tank Samples}

\subsubsection{Sample Preparation}

Tank waste materials are generally very basic; the $\mathrm{pH}$ is usually greater than 12 . For samples that we have encountered, it is not necessary to add base to the samples to ensure that carboxylate moieties remain soluble in the matrix. However, for samples that display a $\mathrm{pH}$ less than 10 , adding sodium hydroxide can ensure the analytes remain in solution. The samples are highly radioactive and contain high molar concentrations of nitrate and nitrite.

For highly radioactive wastes, e.g., 3 to $11 \mathrm{R} / \mathrm{h}$, a hot-cell facility was used. This room has thick concrete walls (approximately $1.3 \mathrm{~m}$ ) equipped with a sample entry port, viewing windows (leaded glass, oil-filled), and remote manipulators, which are operated by a highly trained specialist. When a radioactive sample is remotely handled in the hot cell, the procedure is time-consuming and difficult, requiring special abilities. Turnaround time is much longer. Wastes with a low to moderate total radioactivity level, $<1 \mathrm{R} / \mathrm{h}$, may be prepared and analyzed more quickly in a radiation hood or glove box. The radiation levels that determine whether the work can be performed in a laboratory, glove box, or hot cell is usually based upon local practice or the judgment of the resident health physicist.

Approximately 2 grams of the solids from the actual waste composite sample were stirred overnight with $20 \mathrm{~mL}$ of deionized water in a hot-cell facility. The solution was then filtered to remove insoluble solids. Most of the radioactivity associated with the sample was removed by cation exchange, allowing the sample to percolate through a bed of AG50W-X8 resin (Biorad), 20 to 50 mesh, prepared in the sodium form. The resin must not be used in the usual $\mathrm{H}^{+}$form, since the chelator analytes tend to precipitate from solution as insoluble free acids when the matrix is exposed to the acid form of the resin. The sodium form of the cation exchange resin is conveniently prepared by stirring the resin with sufficient $6 \mathrm{~N} \mathrm{NaOH}$ until the solution tests and remains $(\mathrm{pH})$ basic. The resin is then washed with deionized water. After elution through the cation exchange resin, the net reduction of fission products (chiefly ${ }^{137} \mathrm{Cs}$ and $90 \mathrm{Sr}$ ) was sufficient (with total residual radioactivity in the microcurie-per-sample range) that the sample could be removed from the hot-cell environment and safely worked within a protected hood.

Measured aliquots of the sample, representing about 0.25 grams of the original waste sample, were taken to dryness in reactivials (VWR Scientific) at approximately $75^{\circ} \mathrm{C}$ using a gentle stream of dry nitrogen. Two milliliters of $12 \% \mathrm{BF}_{3}$ /methanol (Aldrich) was added, and the sample was heated to $100^{\circ} \mathrm{C}$ for 1 hour. The solution was cooled, and $2 \mathrm{~mL}$ of chloroform were added. The entire solution was then quenched in a vial containing $8 \mathrm{~mL}$ of $0.4 \mathrm{M} \mathrm{KH}_{2} \mathrm{PO}_{4}$ adjusted to $\mathrm{pH} 9.5$. To ensure that the resulting solution maintained a $\mathrm{pH}$ between 7 and $8, \mathrm{pH}$ paper was used. The vial was vortexed, and the aqueous and chloroform layers were allowed to separate. The chloroform layer, containing the derivatized organics, was retained, and the aqueous layer was discarded. At this point, essentially all of the radioactivity remained with the aqueous layer. The chloroform solution was monitored for radioactivity and then removed for subsequent GC/electron impact (EI) MS analysis. The derivatized waste sample was also analyzed using positive ion chemical ionization (CI) MS to confirm parent ion assignment. 
Figure 3.1 is a schematic illustrating the sample preparation and analysis scheme. Another step that has been recently added involves the neutralization of the sample prior to concentration. After the column was been eluted with base and the solution combined with the original sample, the resulting solution is very basic. As a result, much of the reagent, $\mathrm{BF}_{3} /$ methanol, may have been consumed. The neutralization step now allows the reagent/sample ratio to be higher; this may allow the derivatization recoveries to be higher.

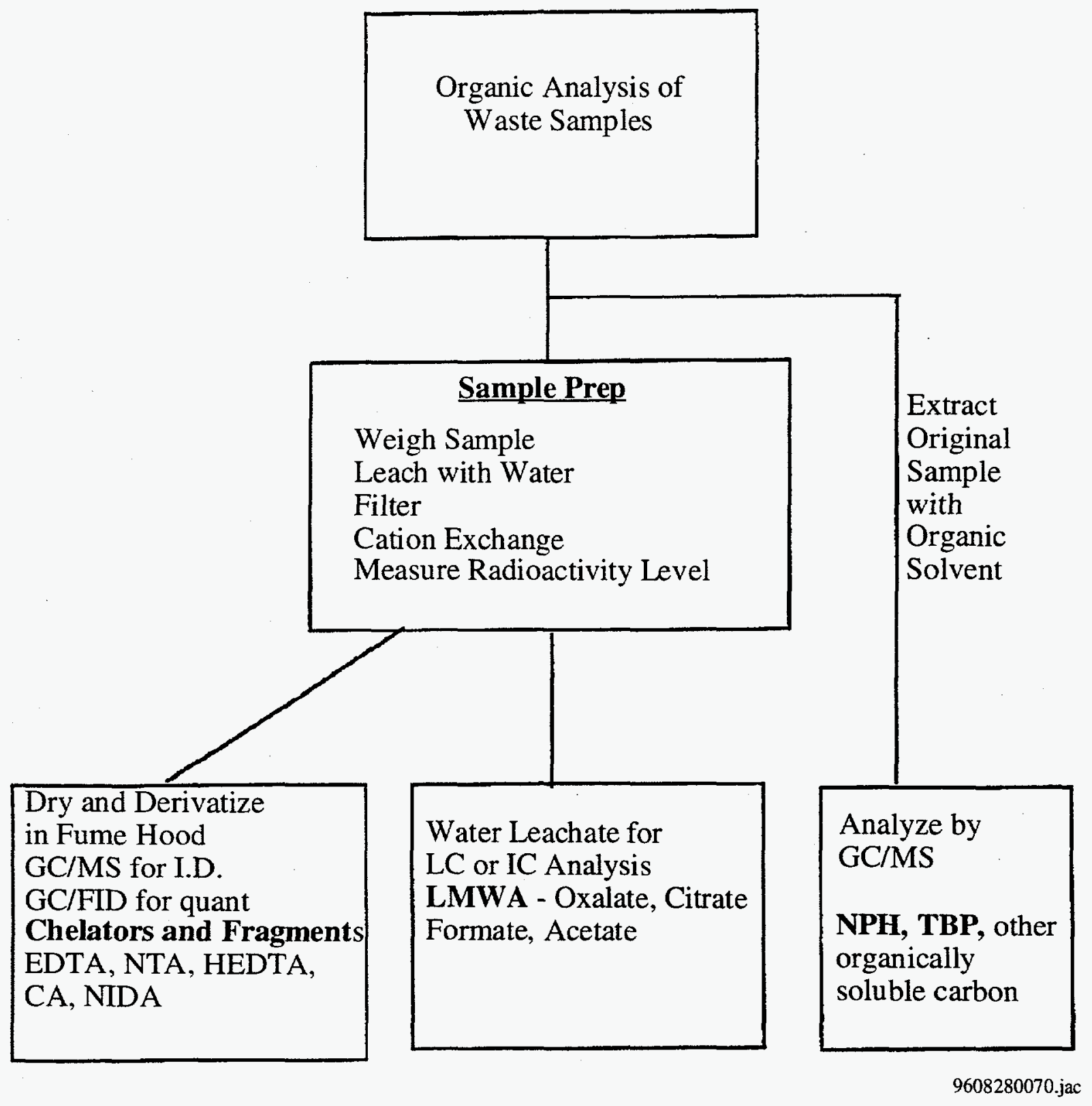

Figure 3.1. Schematic Illustrating Sample Tank Waste Sample Preparation and Analyses 


\subsubsection{Cation Exchange for Reduction of Radioactivity Levels}

In the early stages of sample preparation, the samples were all prepared in the hot-cell facilities and this includes derivatization for chelator analysis. Typically, a 5-g waste sample was stirred with $10 \mathrm{~mL}$ of doubly-distilled water overnight. The solution was filtered through a $0.45-\mu \mathrm{m}$ filter to remove any solid material. The aqueous solution was then dried using nitrogen-blow-down techniques, and the remaining residue was then heated with $2 \mathrm{~mL}$ of $\mathrm{BF}_{3} /$ methanol for 1 hour at $100^{\circ} \mathrm{C}$ to produce the methyl esters of chelators, chelator fragments, and carboxylic acids. After the solution cooled to room temperature, $1 \mathrm{~mL}$ of chloroform was added to the solution, and the entire mixture was added to $3-5 \mathrm{~mL}$ of $\mathrm{KH}_{2} \mathrm{PO}_{4}$ adjusted to $\mathrm{pH} 7.0$ with $\mathrm{NaOH}$. The organic layer containing the methyl esters was separated and subsequently analyzed using GC/MS. At that point, only 10 to $20 \%$ of the TOC could be accounted for.

Radioactivity removal through cation exchange was proven during a LC analysis of a tankwaste sample (Campbell et al. 1994a). A 1-mL aliquot of the water extract from a Tank SY-101 composite sample was diluted and analyzed using LC in a radioactive zone. After the analysis was complete, a counter was used to check for radioactive contamination. The LC column was scanned, and most of the radioactivity was located within the guard column consisting of cation exchange packing material. As a result, a step involving cation exchange to remove the radioactivity was added to the separation procedure. The use of cation exchange resin to remove the radioactivity allowed the samples to be removed from the hot cell to a fume hood; this was probably the single most important step in controlling the dryness of the sample prior to derivatization and heating during the derivatization procedure, which subsequently increased the TOC accounted for.

Initial tests were then performed to determine any losses of HEDTA and EDTA going through the $\mathrm{Na}^{+}$form of the cation exchange column. The results indicate the recoveries were approximately 90 and $95 \%$, respectively. However, if one uses the hydrogen form of the resin, losses of EDTA do occur, presumably because the acid form of EDTA is not soluble. Insoluble EDTA, oxalate, and citrate may cause some loss of TOC, but it appears they are minor contributors. Future work may entail recovery studies with citrate, oxalate, and EDTA in simulated matrices to verify the amount of TOC that may be lost with cation exchange. We converted cation exchange resin (AG $50 \mathrm{~W}-\mathrm{X} 8$, Biorad) from the hydrogen form to the sodium form with $6 \mathrm{~N} \mathrm{NaOH}$. The caustic was added in portions to a water slurry of the resin until the slurry remained basic $(\mathrm{pH} \mathrm{8-9).} \mathrm{The} \mathrm{resin}$ was allowed to equilibrate for an hour to ensure complete conversion to the sodium form; then it was filtered and rinsed with deionized water to remove excess sodium hydroxide.

The resin was loaded in plastic disposable columns (Econo-Pac, Biorad) using a bed volume of $18 \mathrm{~mL}$ of resin. The columns were used immediately upon loading, without allowing the resin an opportunity to dry. Blanks were run by passing $15 \mathrm{~mL}$ of $6 \mathrm{~N} \mathrm{NaOH}$ through the column, followed by washing with $15 \mathrm{~mL}$ of deionized water. The blank solution was submitted for TOC analysis.

We prepared radioactive storage tank waste samples by dissolving 3-5 grams of the waste in $20 \mathrm{~mL}$ of water and stirring overnight. The $\mathrm{pH}$ was checked and adjusted if necessary. Insoluble solids were removed by passing through a $0.45-\mu \mathrm{m}$ filter (Acrodisc, Gelman). A measured aliquot was removed for TOC and radiochemical analysis.

The samples were passed through two pre-loaded columns arranged in series. The columns were rinsed by passing a column volume of $1 \mathrm{~N} \mathrm{NaOH}(19 \mathrm{~mL})$ to collect sample hold-up, and the eluents were combined. Samples of the eluent were taken for TOC and radiochemical analysis. 
This allowed the aqueous sample to be removed from the hot cell and derivatized in the fume hood. The TOC was not changed by passing through the cation exchange column. The material was analyzed for radionuclides after passing through the cation exchange column, and the results indicate it is primarily Cs. However, with the techniques used (Gamma Energy Analysis), Sr would not have been detected. Transferring the derivatization procedure to the fume hood has improved our reproducibility and allows the parameters crucial to reproducible results (the temperature and dryness of the sample) to be controlled. Table 2.6 shows TOC accountability from Tank SY-101 core segment samples, incorporating cation exchange to remove radioactive constituents.

To determine if any TOC is lost through the cation exchange column, TOC values were determined before and after the cation exchange procedure with tank-waste samples. In addition, blanks were also analyzed to determine if any TOC was introduced from the column. The results are shown in Table 2.6 for samples from Tank SY-101. These results clearly indicate that the cation exchange column $\left(\mathrm{Na}^{+}\right.$form) does not remove or introduce any TOC. This is an extremely important aspect; the sample was not compromised by eluting through the cation exchange resin. Additional studies were undertaken with samples from Tank SY-103. The TOC value of sludge from Tank SY-103 was $9400 \mu \mathrm{g} \mathrm{C/g}$ before cation exchange and an average of $8500 \mu \mathrm{g} \mathrm{C} / \mathrm{g}$ after cation exchange.

The SY-103 matrix has been analyzed to determine the amount of ${ }^{137} \mathrm{Cs}$ and ${ }^{90} \mathrm{Sr}$ removed by treating the sample with AG-50W-X 8 cation resin. For the nonconvective-layer sample, $137 \mathrm{Cs}$ was reduced by a factor of approximately 900 . The $90 \mathrm{Sr}$ level was reduced by 150 , and gross alpha was reduced by a factor of approximately 1,400. For the convective-layer sample, the level of ${ }^{137} \mathrm{Cs}$ was reduced by a factor of approximately 200 . The $90 \mathrm{Sr}$ was reduced by a factor of 10 to 15 , and the gross alpha was reduced by a factor of approximately 1200 for the convective-layer sample. The apparent difference $90 \mathrm{Sr}$ removal between the convective and nonconvective-layer samples may reflect the degree of $\mathrm{Sr}$ complexation. In other words, the convective layer may contain a higher concentration of complexed Sr. As a result, less Sr would be removed with the use of cation exchange. The results are shown in Table 2.7.

Incorporating the cation exchange step to remove radioactivity was certainly successful in analyzing samples from Tanks SY-101 and SY-103. However, the assumption can not be made that it will work for every tank-waste sample. As an example, the results from Tank T-111 samples, analyzed for the Organic Tanks Program, indicate the loss of carbon going through the cation exchange column. The question at this point is whether it is indeed organic carbon that is lost. Published studies by Baldwin et al. (1994) point out the strengths and weaknesses of the various TOC techniques, which include persulfate, furnace oxidation, and a combination of the two methods. Persulfate determinations may not totally oxidize some types of organic hydrocarbons, and furnace techniques may give erroneously high values due to inorganic carbon. The pH of the T-111 sample, analyzed for the Organic Tanks Program, was 9; as a result, the $\mathrm{pH}$ of the sample may be an important variable in using the exchange column for reducing radioactivity. Further studies are underway to examine this phenomenon. It is recommended that the TOC measurements be made before and after the cation exchange column to ensure that no TOC has been removed or added to the sample. 


\section{Radiochemical Analysis}

The samples were assayed for fission products $\left({ }^{90} \mathrm{Sr},{ }^{137} \mathrm{Cs}\right)$ and for actinide content. Gamma energy analysis for ${ }^{137} \mathrm{Cs}$ was done on a high-purity $\mathrm{Ge}$ detector ( $80 \%$ efficiency) with efficiency calibrated geometries.

Alpha measurements were determined by pipetting aliquots onto stainless steel planchettes, drying over a flame, and counting using a standard alpha proportional counter.

We determined ${ }^{90} \mathrm{Sr}$ by separating $\mathrm{Sr}$ and using liquid scintillation counting (LSC), and we counted the ingrowth of ${ }^{90} \mathrm{Y}$ by Cherenkov counting. Samples and comparative standards were spiked with identical aliquots of ${ }^{85} \mathrm{Sr}$ and loaded onto $\mathrm{SrSpec}\left({ }^{\circledR}\right.$ columns (EICHROM Industries) with $8 \mathrm{M} \mathrm{HNO}_{3}$. They were rinsed free of ${ }^{90} \mathrm{Y}$ and other fission products with $8 \mathrm{M} \mathrm{HNO}_{3}$, and the purified ${ }^{90} \mathrm{Sr}$ was eluted with water. The chemical yield for $\mathrm{Sr}$ was calculated based on a gamma assay of the ${ }^{90} \mathrm{Sr}$ activity in each sample as compared to observed ${ }^{85} \mathrm{Sr}$ activity in identical geometries. The samples were then counted without delay by LSC (Quantalus, Wallac Oy). The samples were counted in water using the Cherenkov radiation emitted as an effect from ${ }^{90} \mathrm{Y}$ decay. The Cherenkov emission efficiency of ${ }^{85} \mathrm{Sr}$ was calculated from the comparator standards containing only ${ }^{85} \mathrm{Sr}$. The ${ }^{90} \mathrm{Sr}$ Cherenkov efficiency was determined from ${ }^{85} \mathrm{Sr}$ freshly purified from the ${ }^{90} \mathrm{Y}$ daughter, and ${ }^{90} \mathrm{Y}$ Cherenkov efficiency was determined by counting known activities of ${ }^{90} \mathrm{SrY}$ at equilibrium The ${ }^{90} \mathrm{Sr}$ activity was then calculated from several counts of the samples over a suitable ingrowth period. Activity at secular equilibrium was calculated by computational software.

In all radiochemical assays, background efficiency calibrations and system controls were done to ensure that the data were valid.

\section{Total Organic Carbon Determination}

Samples, blanks, standards, and spiked samples were prepared and analyzed using a UIC Coulometrics 5300 Carbon System with coulometry detector. Acidification with sulfuric acid (4N) allows determination of total inorganic carbon; introducing potassium persulfate and a silver nitrate catalyst followed by heating the sample to $600^{\circ} \mathrm{C}$ permits oxidation of most organic carbon species. The system is purged with purified oxygen to pass the $\mathrm{CO}_{2}$ to the coulometric cell. The entire analysis system is committed to the hot-cell environment with only the read-out being outside of the shielded facility.

Samples, blanks, and standards were done in duplicate. A spiked sample was prepared by adding a known amount of standard glucose to a random sample. Recoveries were generally $90-95 \%$ of the spiked material. The hot persulfate oxidation to determine TOC and total carbon has been shown to be valid for samples containing high concentrations of sodium nitrite, sodium nitrate, and sodium hydroxide typical of the radioactive waste matrices encountered.

\subsubsection{GC/MS and GC/FID for Chelators and Chelator Fragments}

Derivatization GC/MS is used to provide data on the speciation of organic components as well as functional groups (Grant et al. 1996b). 


\section{$G C / M S$}

The chelators and chelator fragments represent a class of compounds whose polarity and non-volatility precludes direct analysis by GC/MS; therefore, the carboxylic acid portion must be derivatized before analysis. The samples were analyzed using GC/MS to identify unknown components. The major components detected were EDTA, IDA, NTA, CA, succinic acid (SA), and ED3A. Chelators, chelator fragments, and several carboxylic acids have been quantitated in the convective and nonconvective-layer samples from Tank SY-103 using derivatization GC/FID. The chelator of highest concentration was EDTA in both layers. However, the concentration of CA was nearly the same as EDTA. Additional samples must be analyzed to 1) determine the accuracy and precision for GC/FID as a quantitation technique and 2) verify concentrations of EDTA and CA in both the convective and nonconvective-layer samples and compare with Barney's solubility results (Barney 1994). A total ion chromatogram from GC/MS analysis of a derivatized sample from Tank SY-103 is shown in Figure 3.2, and GC/FID chromatograms of the convective and nonconvectivelayer samples are shown in Figures 3.3 and 3.4, respectively.

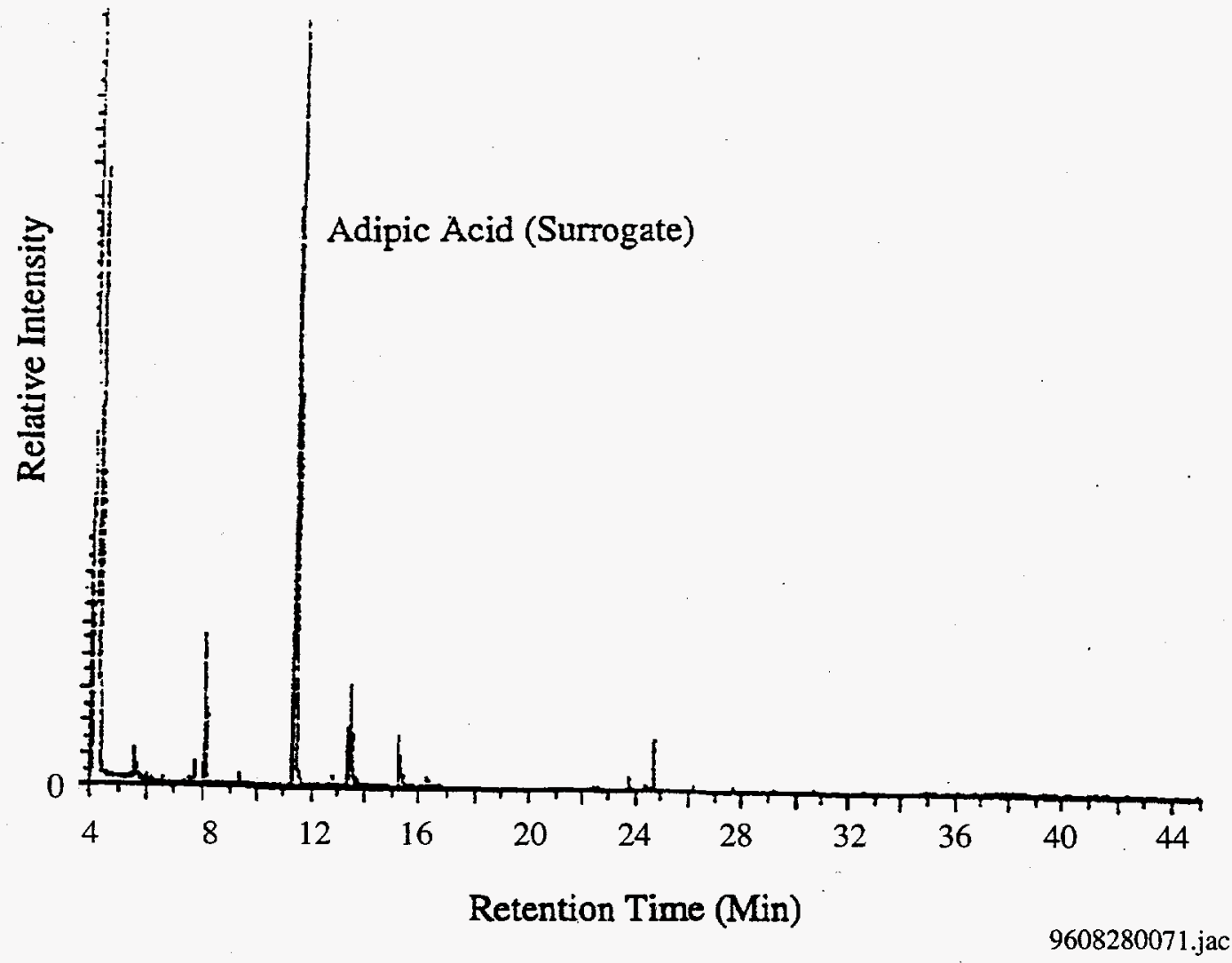

Figure 3.2 Total ion Chromatogram (GC/MS) of Derivatized Tank SY-103 Sample

Approximately $1 \mathrm{~mL}$ of a $10 \% \mathrm{w} / \mathrm{v}$ solution of $\mathrm{BF}_{3} /$ methanol (Aldrich) was added to about $5 \mathrm{mg}$ of the chelator in a reaction vial, and the mixture was vortexed and heated for 1 to 2 hours at $100^{\circ} \mathrm{C}$, depending on the chelator being derivatized. One $\mathrm{mL}$ of chloroform was added to the cooled reaction mixture and vortexed. A buffer solution $\left(0.4 \mathrm{M} \mathrm{KH}_{2} \mathrm{PO}_{4}\right)$ was made up, with the $\mathrm{pH}$ adjusted to 9.5 using sodium hydroxide. When this buffer solution was added to the contents of the vial, the solution separated into two layers, and an aliquot was removed from the chloroform layer for GC/MS analysis. Parent ion assignment was confirmed by using positive ion chemical ionization MS. 


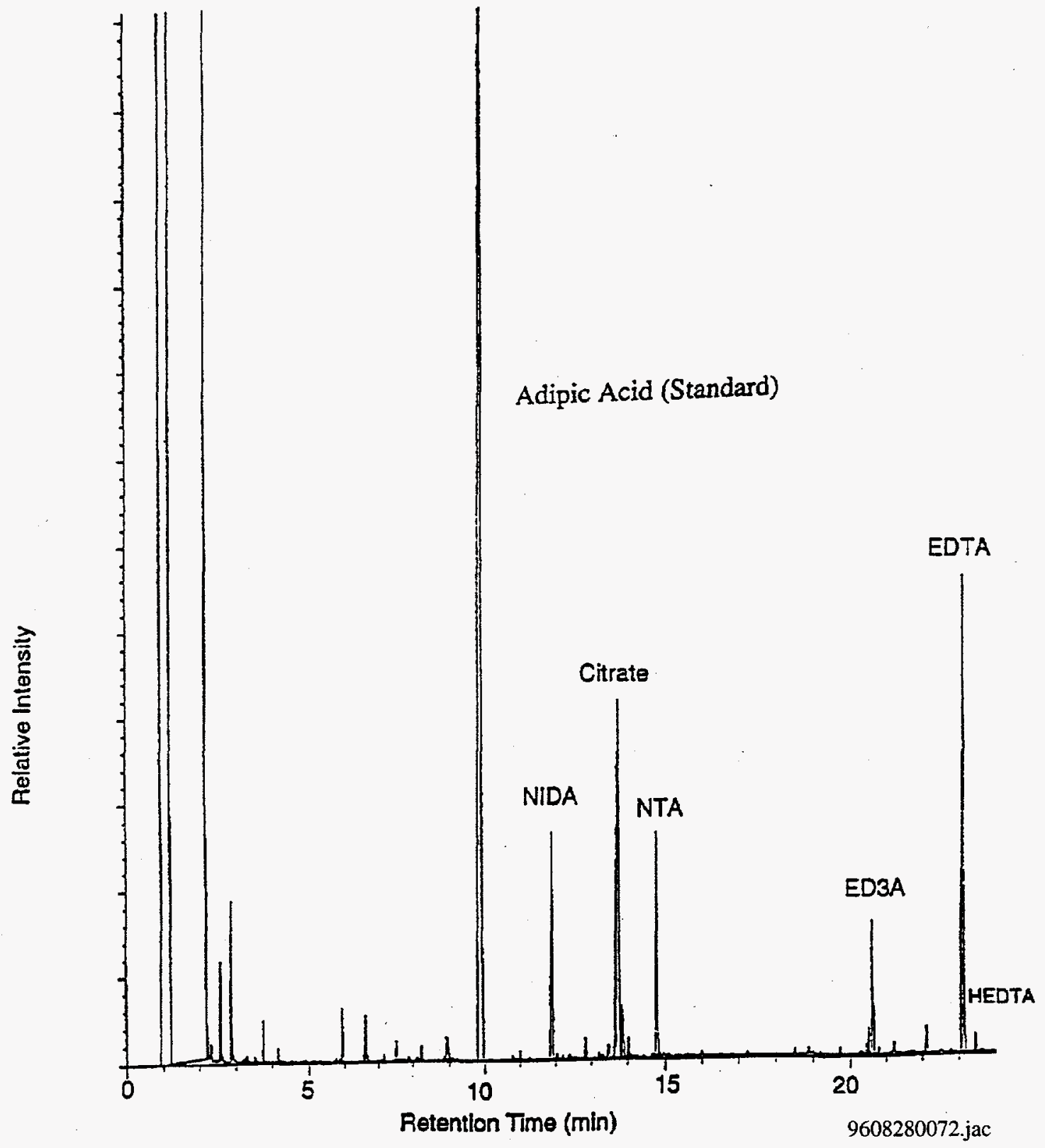

Figure 3.3. Gas Chromatography/Flame Ionization Chromatogram of Convective-Layer Sample from Tank SY-103

To determine the yield of the derivatization procedure, deuterated EDTA (for use as a yield tracer) was synthesized using the method of Vanyólòs (1955). To a solution containing $0.25 \mathrm{M}$ chloroacetic acid in cold water was added $0.5 \mathrm{M} \mathrm{NaOH}$. The solution was maintained at less than $5^{\circ} \mathrm{C}$ in ice during the addition, then added by drops with vigorous stirring to a cold aqueous solution of $0.06 \mathrm{M} \mathrm{d}_{4}$-ethylenediamine (Isotech). The solution was brought to $65^{\circ} \mathrm{C}$ and stirred for two hours, then acidified ( $\mathrm{pH} \mathrm{2}$ ) with concentrated $\mathrm{HCl}$. The resulting white solid $(60 \%$ yield) was washed and recrystallized from water. Derivatization using $\mathrm{BF}_{3} /$ methanol (above) yielded material that proved the product to be essentially pure. Dissolution of a sample in $\mathrm{D}_{2} \mathrm{O}$ and $200 \mathrm{MHz}$ proton nuclear magnetic resonance (NMR) revealed only signals attributable to entrained water and proton signals from the attached acetate groups. 


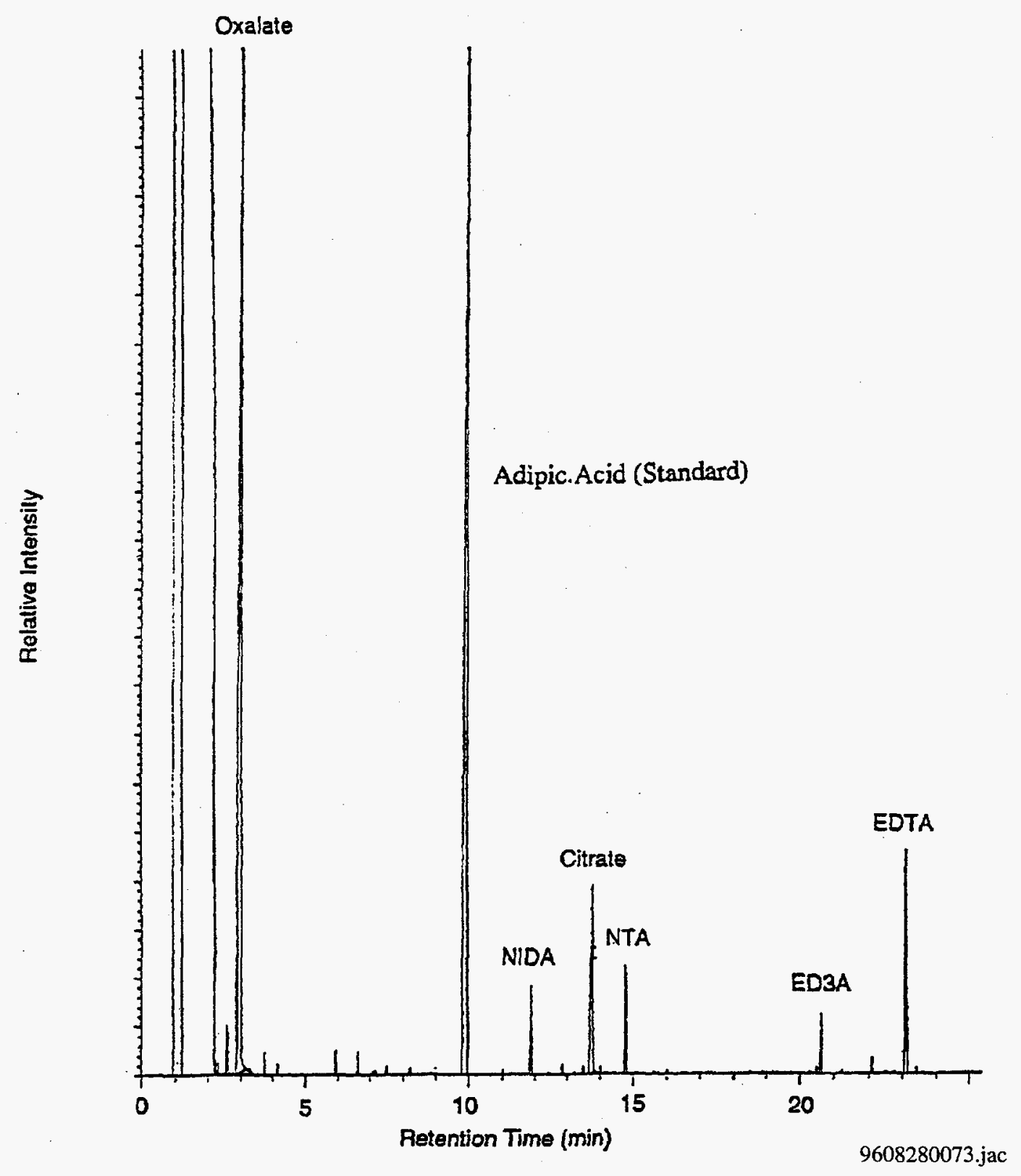

Figure 3.4. Gas Chromatography/Flame Ionization Detection Chromatogram of Nonconvective-Layer Sample from Tank SY-103

To probe the efficiency of the derivatization process in the waste matrix, a waste sample was spiked with concentrations of chelators (EDTA, NTA, HEDTA) and related organics (CA, SA) threeto five-fold above those found in the waste samples. An amount of $d_{4}$-EDTA similar to the total concentration of EDTA was added to the matrix; the sample was then derivatized as above, and the resulting data were analyzed in terms of net yield of the added chelators and acids.

To a 500-mL, four-necked flask, equipped with an overhead stirrer, an addition funnel, and a thermometer, were added $26.6 \mathrm{~g}$ (200 mmoles) of IDA (Aldrich) and $200 \mathrm{~mL}$ of $1 \mathrm{M}$ phosphoric acid. The contents of the flask were heated to $50^{\circ} \mathrm{C}$, and a solution of 27.6 grams ( $\left.400 \mathrm{mmoles}\right)$ of sodium nitrite in $60 \mathrm{~mL}$ of water was added by drops. The reaction was then stirred for 1 hour and 
extracted with five 100-mL portions of diethyl ether. The ethereal extract was dried (with $\mathrm{MgSO}_{4}$ ) and concentrated to produce a yellowish-white residue that, after recrystallization from ethyl acetatehexane yielded 13 grams of $\mathrm{N}$-nitrosoiminodiacetic acid (NIDA). $\mathrm{N}$-nitrosoiminodiacetic acid was methylated using $\mathrm{BF}_{3} /$ methanol, and the resulting methyl ester was analyzed using GC/MS. Accurate mass measurements of the methylated NIDA using a high-resolution MS (JEOL SX-102/SX-102) indicated the structure to be $\mathrm{C}_{6} \mathrm{H}_{10} \mathrm{O}_{5} \mathrm{~N}_{2}$, which is the elemental formula for methylated NIDA.

A fused silica column (DB-5, $30 \mathrm{~m} \times 0.25 \mathrm{~mm} \mathrm{ID,} \mathrm{0.25- \mu m} \mathrm{film} \mathrm{thickness,} \mathrm{J \& W} \mathrm{Scientific)}$ was used in the splitless mode. The oven temperature was typically programmed at $50^{\circ} \mathrm{C}$ for 1 minute, increased to $300^{\circ} \mathrm{C}$ at a rate of $8^{\circ} \mathrm{C} /$ minute, then held at $300^{\circ} \mathrm{C}$ for 5 minutes. The MS was tuned daily with perfluorotributylamine (PFTBA). In these studies, the MS was scanned from 50$500 \mathrm{amu}$ and operated in the electron impact mode $(70 \mathrm{eV})$. The source temperature was $200^{\circ} \mathrm{C}$, and the injector port and interfaces were $250^{\circ} \mathrm{C}$.

Chemical ionization was carried out with methane and isobutane in both positive and negative ion chemical ionization modes. The temperature of the source for positive ion chemical ionization MS was $200^{\circ} \mathrm{C}$ and $120^{\circ} \mathrm{C}$ for negative ion chemical ionization. The MS was scanned from 100-600 amu in the negative ion mode and $70-500$ amu in the positive ion mode.

Accurate mass measurements were performed on a JEOL SX-102/SX-102 double-focusing MS equipped with a Unix data system. The instrument was tuned to a resolution of 5000 (10\% valley definition). Data were acquired by scanning the mass range of 50-500 at a rate of 3 seconds per mass decade. Instrument tuning and real-time mass measurements were performed by leaking perfluorokerosene into the electron impact ion source from the septum inlet reservoir. Computerassisted accurate mass assignments and subsequent elemental compositions were made on data obtained from averaging four consecutive scans over the GC elution profile of the analyte. The instrument was equipped with an HP $5980 \mathrm{GC}$ fitted with $30-\mathrm{m} \times 0.25-\mathrm{mm}$ ID DB-5 capillary column (J\&W Scientific). The $\mathrm{GC}$ oven temperature was held at $50^{\circ} \mathrm{C}$ for 2 minutes, then programmed to increase $5^{\circ} \mathrm{C} /$ minute to $250^{\circ} \mathrm{C}$.

Results to quantify the relative amounts of chelators present in Hanford wastes versus the amount of carbon apparent in TOC analysis have been reported (Campbell et al. 1994b). However, the amount of conversion of these materials to methyl esters using Hanford tank matrix was quantified to determine species accountability. Initially, the direction taken to probe the overall yield from the $\mathrm{BF}_{3} /$ methanol esterification was to add a known quantity of aliphatic mono-carboxylic acid to the matrix and quantify the result obtained from this experiment for the aliphatic acid versus the result obtained from a separate derivatization using reagent acids as their respective sodium salts. For this probe to be useful, the aliphatic acid chosen must not interfere with the chromatography of the known chelators and chelator fragments found in the matrix. The first candidate tested for this application was myristic acid $\left(\mathrm{C}_{13} \mathrm{H}_{27} \mathrm{COOH}\right)$, the methyl ester of which eluted beyond that of NTA and before the methyl esters of ED3A and EDTA. A representative chromatogram is shown in Figure 3.5, with peak 5 being trimethyl NTA, peak 6 as methyl myristate, and peak 7 as tetramethyl EDTA.

Our results indicated that 80 to $95 \%$ of the myristic acid added to SY-101 matrix in an amount approximately that of the chelators present in the matrix was converted to the methyl ester using $\mathrm{BF}_{3} /$ methanol reagent. This number may not be an accurate reflection of the yield for chelators and chelator fragments in the matrix since these materials contain at least two, or as many as four, carboxylic acid sites per molecule and may not be methylated as readily as the singly 


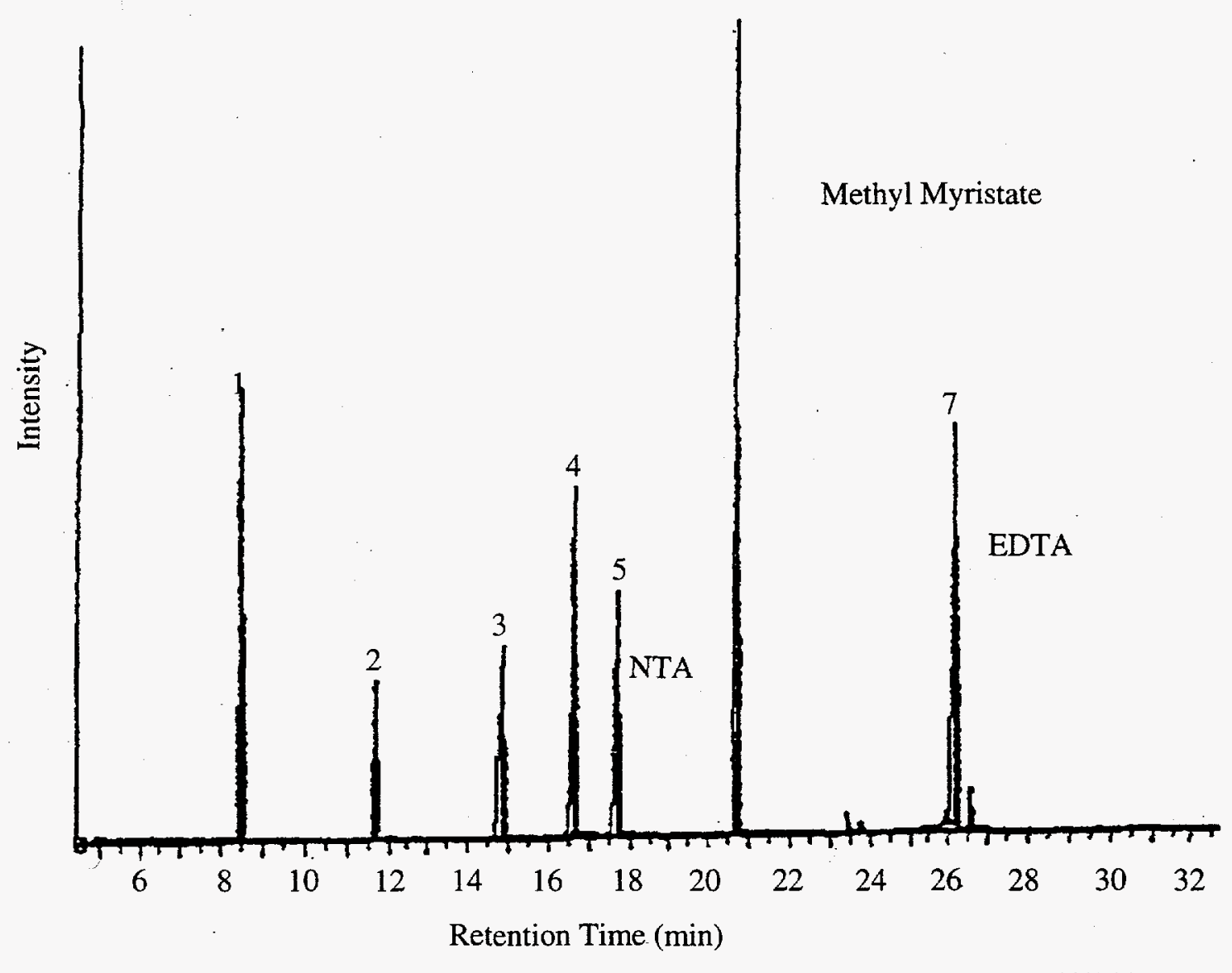

9608280074.jac

Figure 3.5. Total Ion Chromatogram (GC/MS) Indicating Myristic Acid as Tracer

carboxylated aliphatic acids. Further, steric influences in the case of NTA and EDTA may not allow these materials to methylate as readily as a straight-chain material. The limited solubility of aliphatic acid sodium salts in water may also contribute to loss of the acids in step-wise manipulations involved with the analysis of the matrix. Thus, this material may not possess overall utility in probing conversion yields of chelators in the Hanford tank wastes.

Currently, adipic acid (dibasic acid requiring 2 moles of $\mathrm{BF}_{3} /$ methanol) is being used as a yield tracer for GC/FID studies. Being a dibasic acid, this material is more representative of the carboxylates found in the waste mixture. Dimethyl adipate elutes in the GC region before NIDA and not near any of the primary analytes. Figures 3.6 and 3.7 are calibration curves for citric acid and EDTA as determined by GC/FID.

\subsubsection{LC and IC for Low-Molecular Weight Acids}

Liquid chromatography has been used to quantitate LMWAs (oxalic, formic, glycolic, and acetic acids, which are in the waste as acid salts) in samples from Tanks SY-101 and SY-103. The concentrations of acetate and formate in the convective-layer sample from Tank SY-103 were 1.6 and $4.4 \mathrm{mg} / \mathrm{g}$, respectively. These results are very similar to those obtained by the 222-S laboratory (Rice 1995). Acetic and formic acids amount to approximately $28.1 \%$ of the TOC in the convective-layer sample. For the nonconvective-layer sample, oxalic, acetic and formic acids constitute approximately 


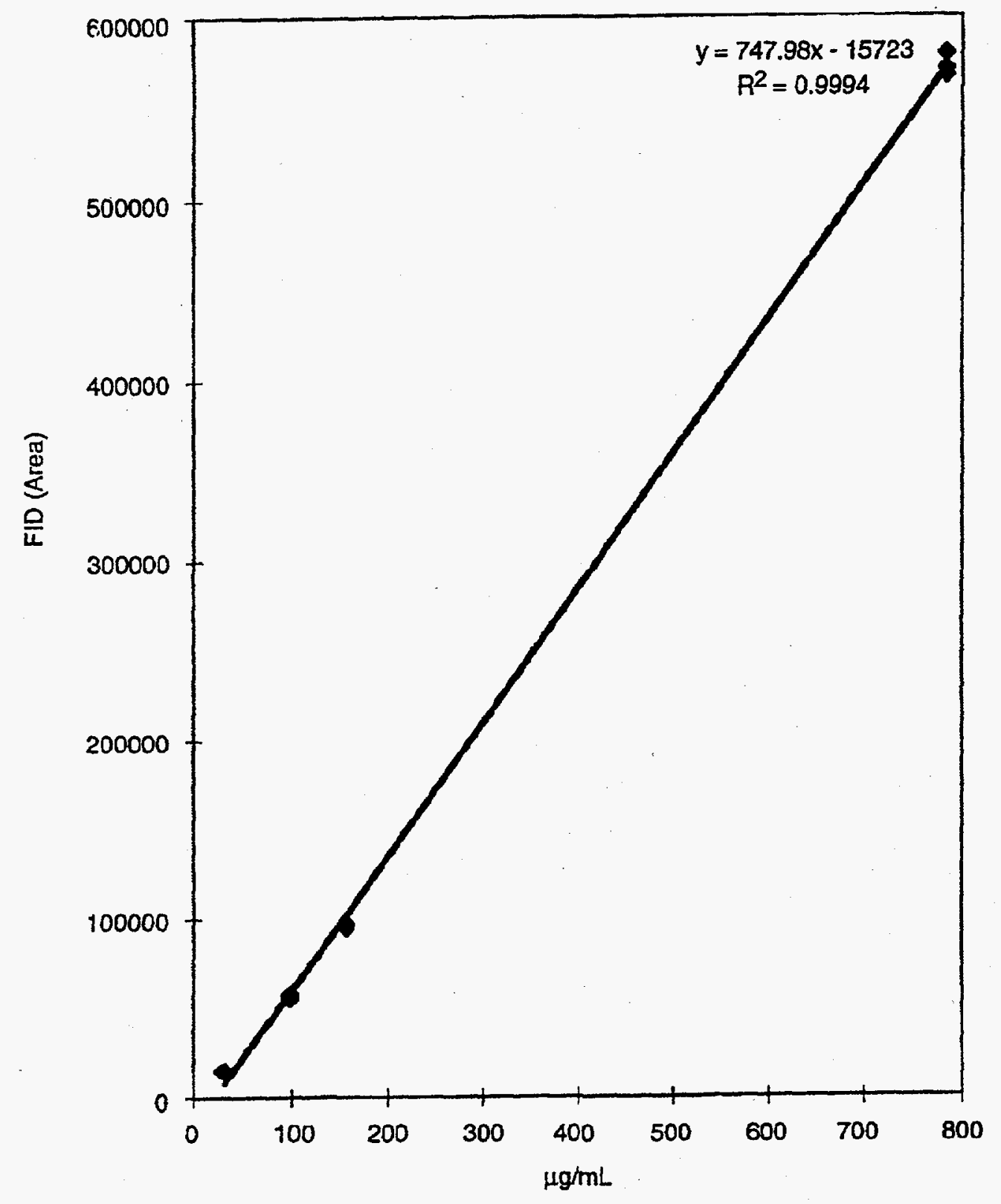

Figure 3.6. GC/FID Response Curve for Citric Acid

$81 \%$ of the TOC. Approximately 23 to $61 \%$ of the TOC is accounted for by these acids in samples from Tank SY-101. Oxalic acid constitutes approximately $40 \%$ of the TOC in the nonconvectivelayer samples from Tank SY-101. The concentration of oxalate in the nonconvective layer is approximately 3 to 4 times higher than the convective layer. The nonconvective layer sample from the lowest layer has the highest percentage of water-soluble organic carbon as LMWAs.

The IC analytical technique for separating and determining some solutes falls into the general classification of liquid-solid chromatographic methods, in which a liquid is passed through a solid stationary phase and then to a flow-through detector. The stationary phase is usually in the form of small-diameter, uniform particles packed into a cylindrical column. This column is constructed from 


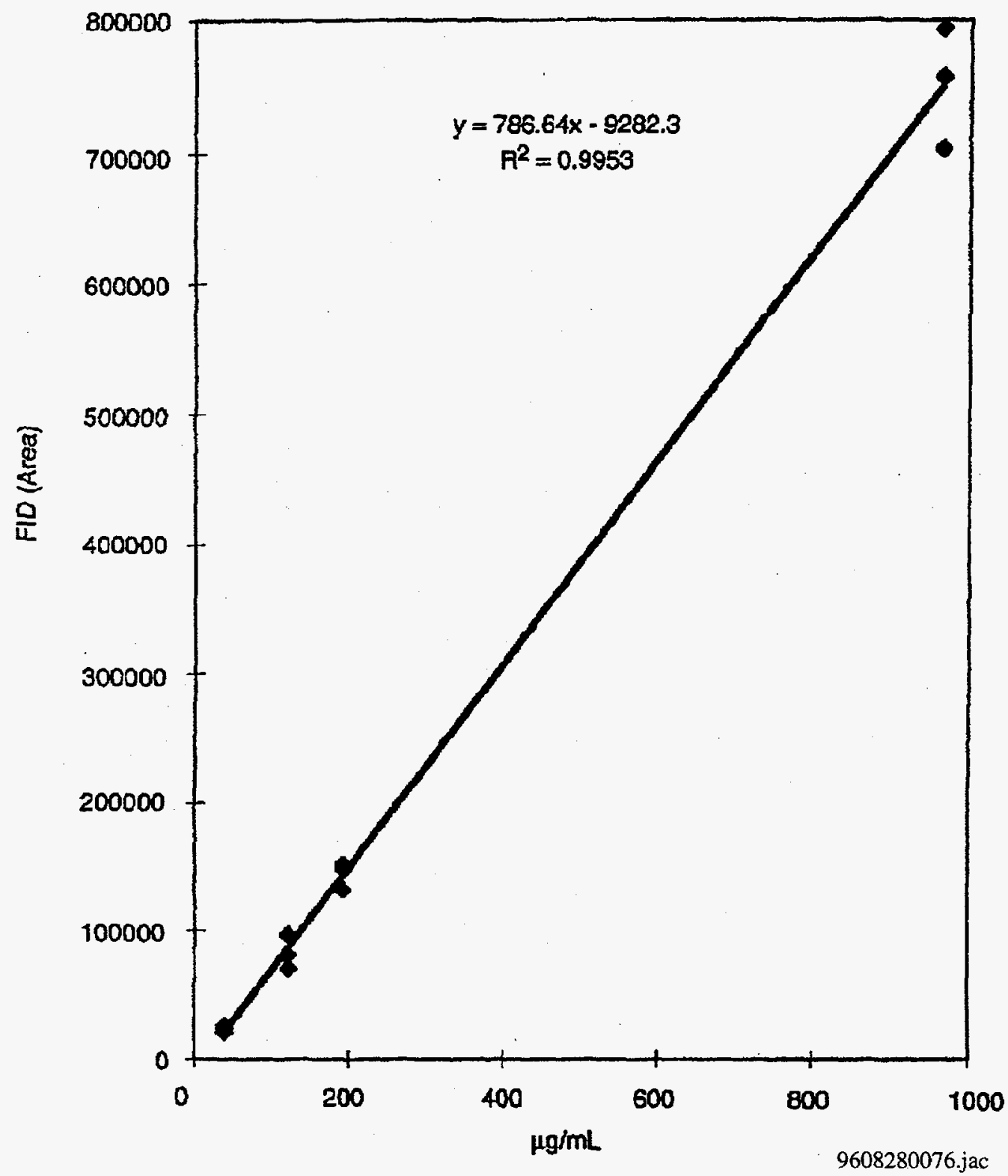

Figure 3.7. GC/FID Response Curve for EDTA

a rigid material and is generally $5-30 \mathrm{~cm}$ long, with an internal diameter in the range 4-9 $\mathrm{mm}$. The stationary phase particles are packed uniformly into the column and are retained by means of porous frits located at each end of the column. A high-pressure pump is required to force the eluent through the column at typical flow rates of $1-2 \mathrm{~mL} / \mathrm{min}$. The sample to be separated is introduced into the flowing eluent stream by means of an injection device inserted into the flow path before the column. The detector usually contains a low-volume cell through which the eluent flows.

The ion chromatograph is operated in the elution mode. An aliquot of the sample is applied to the top of the column via the injector, while the eluent is passed continuously through the column. The sample components progress through the column at different rates and therefore enter the detector at different times. The detector senses the sample components and produces the chromatograms. 
The foundations for modern IC were originally discovered by Small, Stevens, and Bauman in 1975 when they described a novel ion-exchange chromatographic method for the separation and conductimetric detection of anionic and cationic species (Small et al. 1975). Their method employed a low-capacity ion-exchange stationary phase for the separation step, together with a second column and conductivity detector that comprised the detection system for continuous monitoring of the eluted ions. The term "ion chromatography" was introduced only when the technology was licensed to the Dionex Corporation for commercial development. For this reason, IC was originally interpreted to mean the specific use of the same combination of separation and detection modes as reported in the original publication. chromatograms.

The technique of IC is very loosely defined, both in terms of the manner in which the solutes are separated and the types of solutes applicable to the technique. Ion chromatography typically encompasses those column LC techniques that can be used to determine 1) inorganic anions, 2) inorganic cations, 3) low-molecular-weight carboxylic acids, and 4) ionic organometallic compounds. Currently, we employ two IC modes for analysis, ion exchange and ion exclusion chromatography. Ion exchange relies on a differential affinity of ionic species for the stationary phase. Primarily, the affinity of analytes to the solid-phase resin of the column (a positively charged quaternary amine) are influenced by the $\mathrm{pH}$ of the eluent. Multiply-charged analytes (phosphate and citrate) elute late, after being fully ionized. Univalent species elute at lower $\mathrm{pH}$. Ion exclusion uses a separation that depends on Donnan exclusion and steric effects, as well as partitioning to effect the separation. The solid phase is fully sulfonated, and typically, since the eluting phase is acidic, the stronger acids elute first.

Liquid chromatography with UV detection was previously used to analyze LMWAs. To quantify organic acids, two procedures were required. For oxalic acid, a Dionex AG4A guard column and Dionex AS4A analytical column were used with $75 \%$ of $1.7 \mathrm{mM} \mathrm{NaHCO} 3$ and $1.8 \mathrm{mM}$ of $\mathrm{Na}_{2} \mathrm{CO}_{3}$ as the mobile phase and is shown in Figure 3.8. For acetic, formic, and glycolic acids, a Waters ion exclusion column was used with $0.01 \mathrm{~N} \mathrm{H}_{2} \mathrm{SO}_{4}$ as the mobile phase and is illustrated in Figure 3.9. Figure 3.10 is an LC chromatogram of a standard mixture of organic acids, including citrate, succinic, glycolic, and formic acids with UV detection using anion exclusion chromatography. Figure 3.11 is a chromatogram of a simulated waste sample under the same conditions. Because of high concentrations of nitrate and nitrite, it was difficult to quantitate citrate, succinate, and glycolate. It was not feasible to dilute the sample because UV cannot detect organic acids with adequate sensitivity. Alternatively, analysis for combined organic carboxylates in a tank-simulant matrix is possible using IC with a gradient elution profile and suppressed conductivity detection. Using an AS11 column to analyze for citrate and succinate (and separating the acids as carboxylates) has been shown to be repeatable and effective in analyzing several tank-waste simulants. Figure 3.12 is an IC chromatogram of an organic acids standard with conductivity detection. Figure 3.13 is an IC chromatogram of a simulated waste sample using conductivity detection. A Dionex AG11 guard column and Dionex AS-11 analytical column was used with conductivity detection. A step-wise gradient elution program was used with $\mathrm{NaOH}$ as the mobile phase: $0.5 \mathrm{mM} \mathrm{NaOH}$ for 1 min, $0.5-5.0$ $\mathrm{mM} \mathrm{NaOH}$ in $3.5 \mathrm{~min}$, and $5.0-38.25 \mathrm{mM} \mathrm{NaOH}$ in $12 \mathrm{~min}$. Ion chromatography has provided a single, faster, and cheaper method for analyzing LMWAs nearly free of matrix interferences. This method has been successfully applied to simulated wastes and will be used to analyze real wastes. 


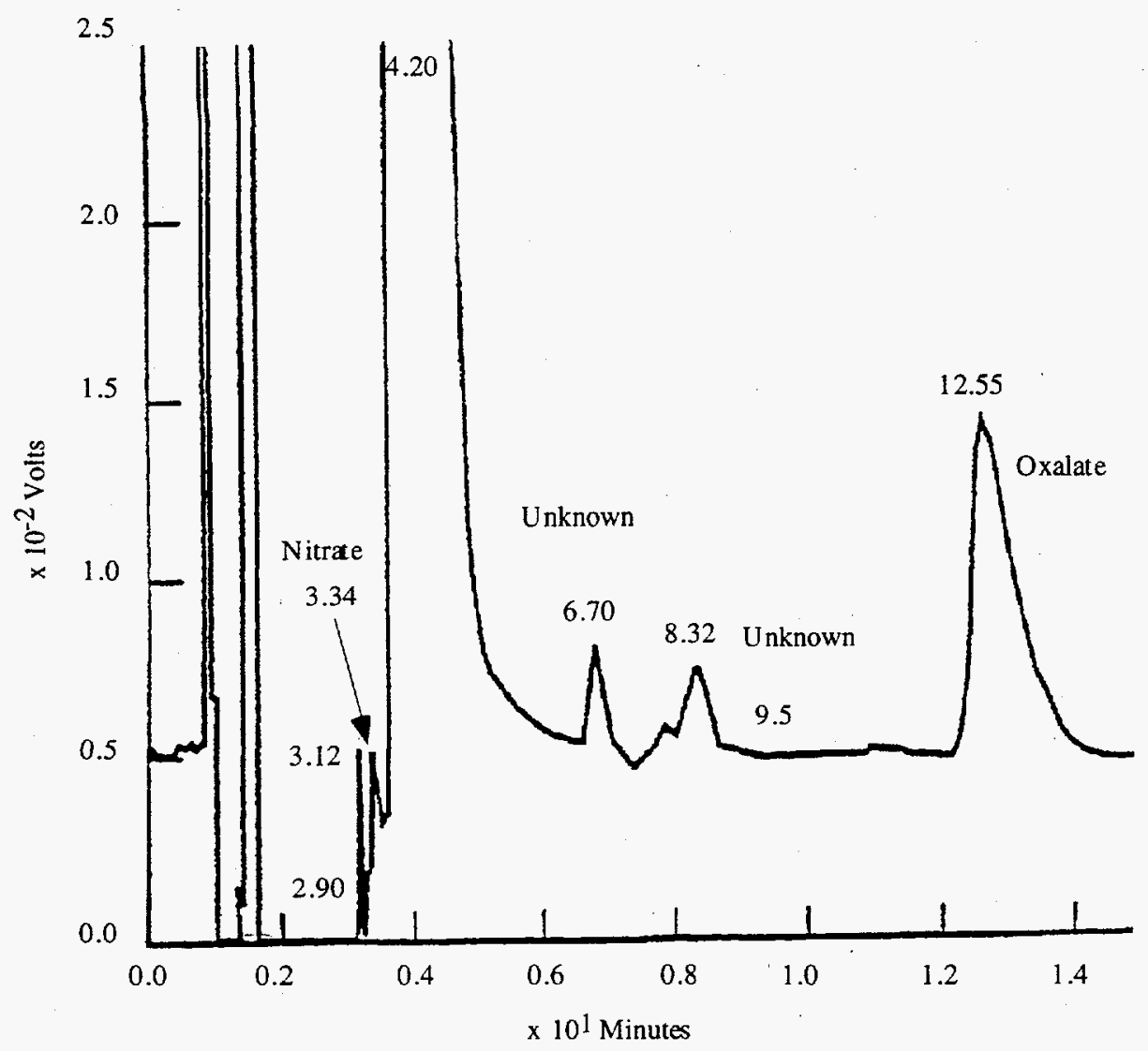

Figure 3.8. LC Chromatogram for Determination of Oxalate

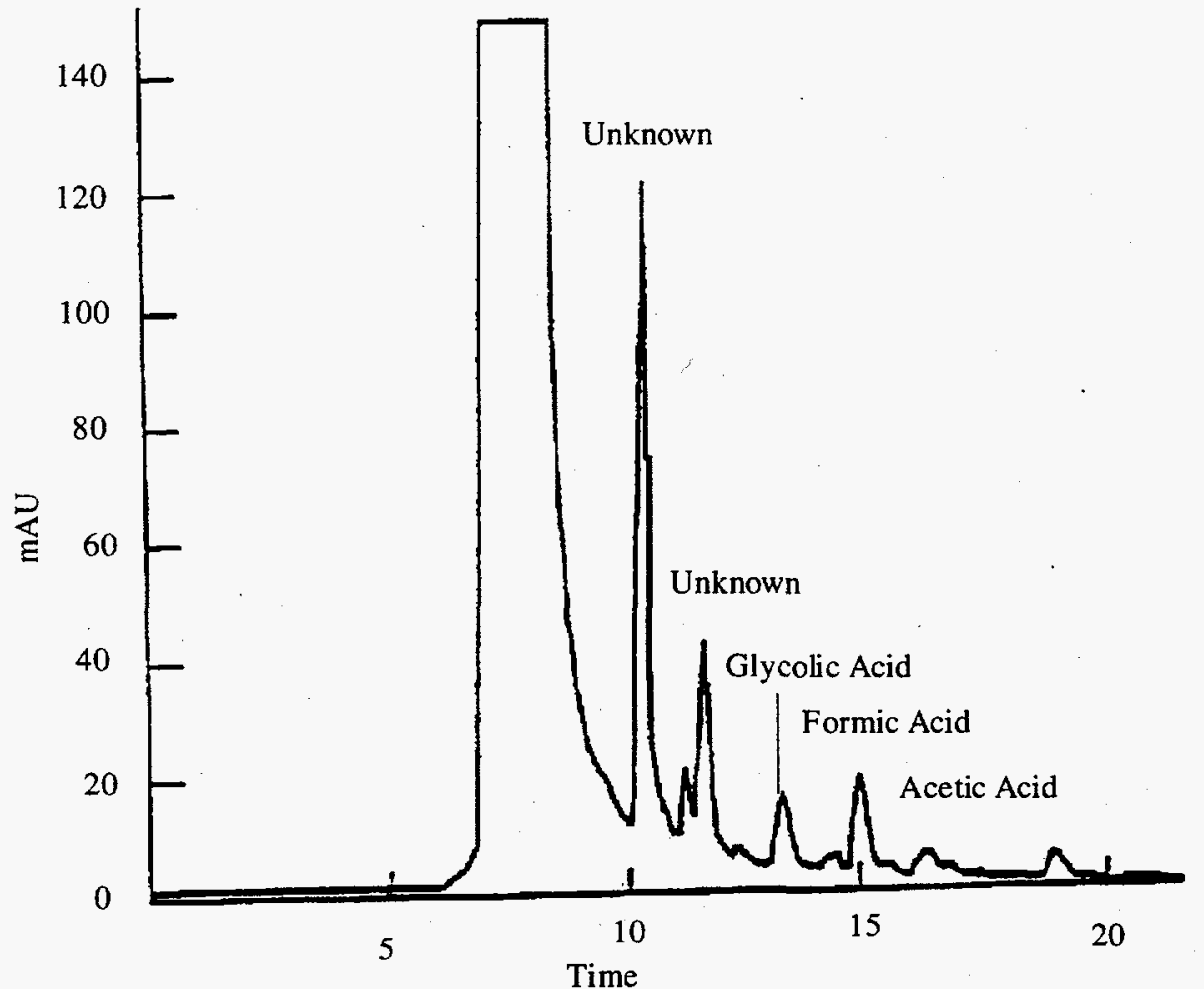

Figure 3.9. LC Chromatogram for Determination of Acetic, Glycolic, and Formic Acids 


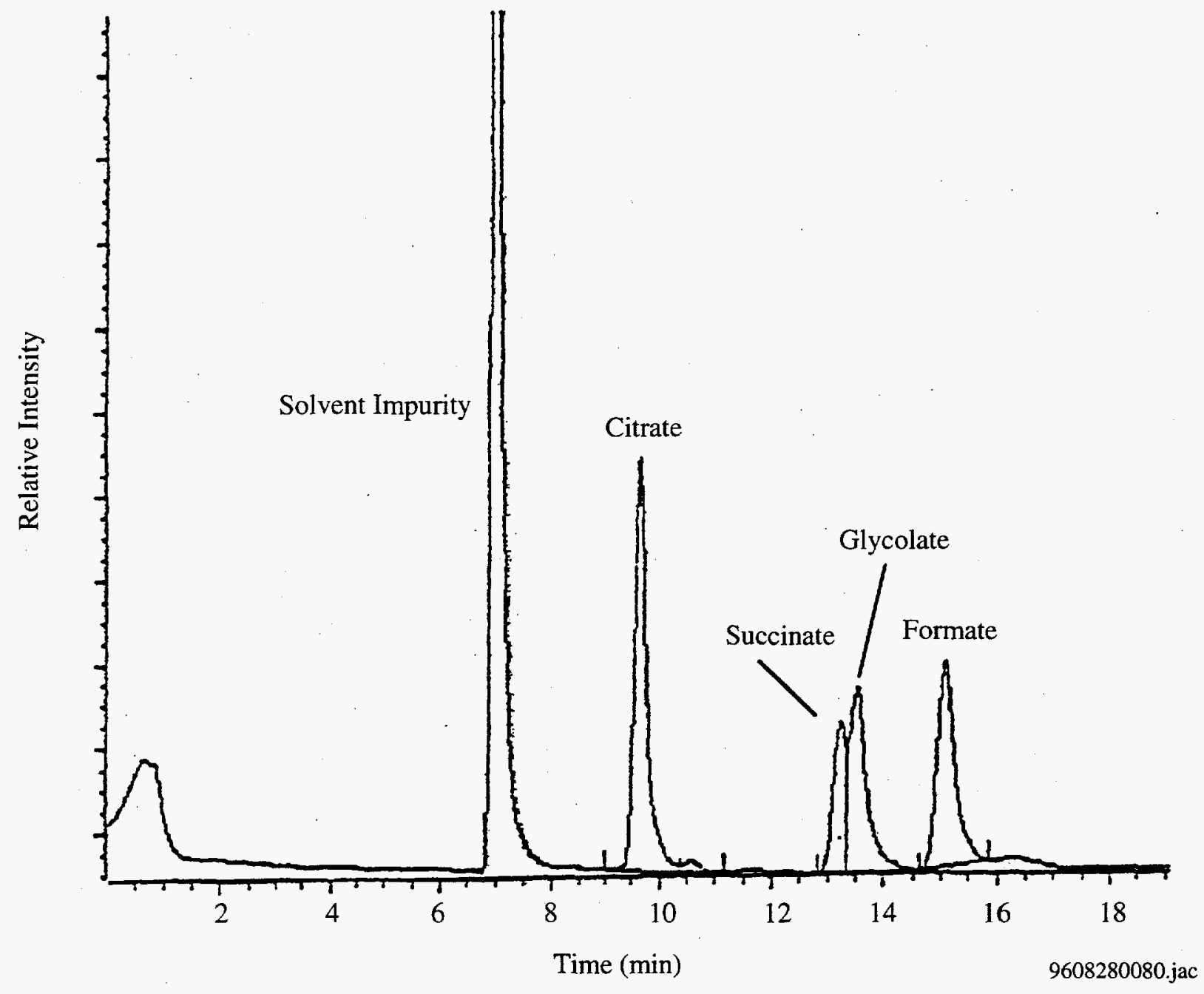

Figure 3.10.

LC Chromatogram of Low-Molecular Weight Acids Standards (Not in Presence of Simulant) with UV Detection 


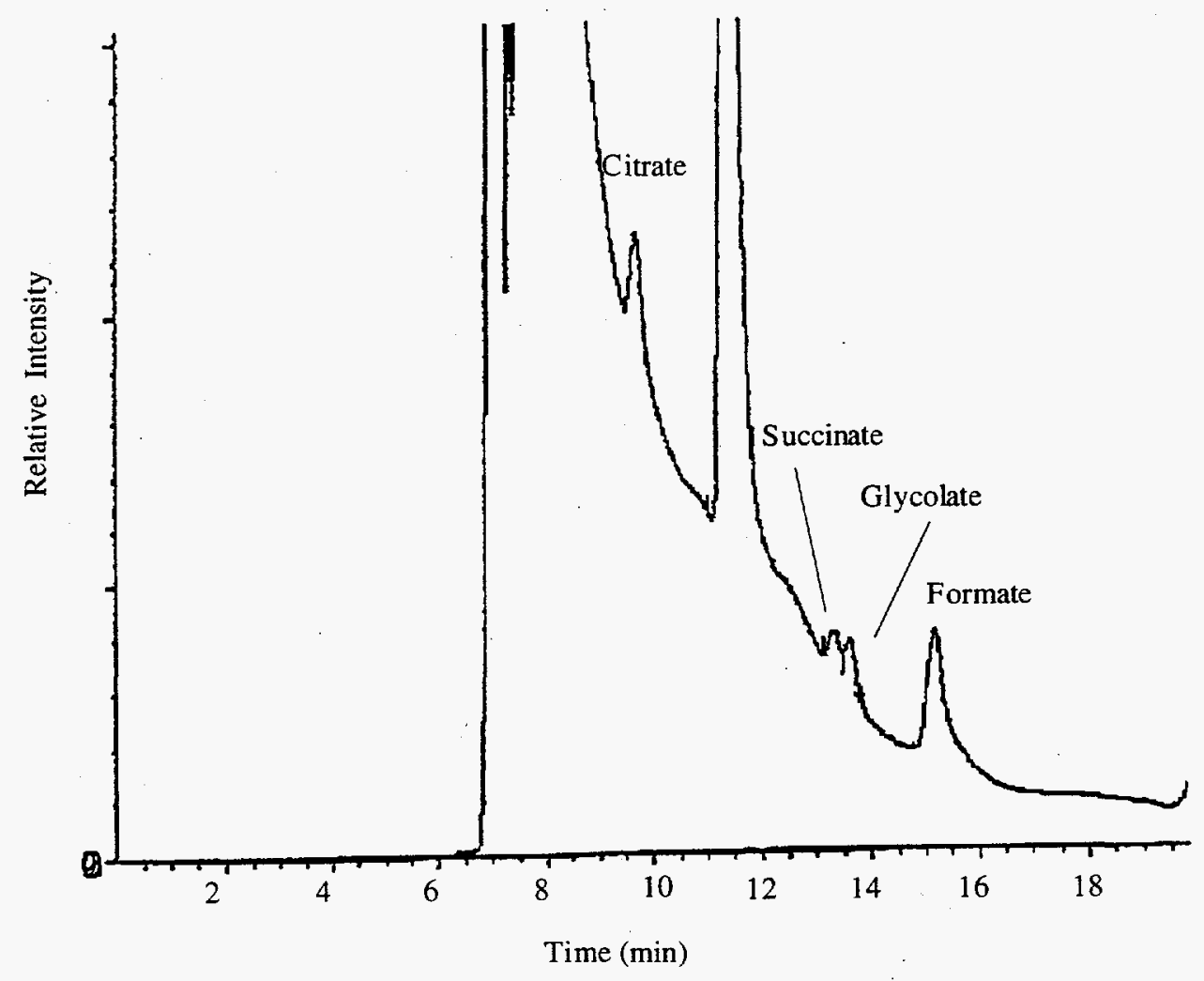

Figure 3.11. LC Chromatogram of Spiked Low-Molecular Weight Acids with UV Detection in Simulated Waste Sample

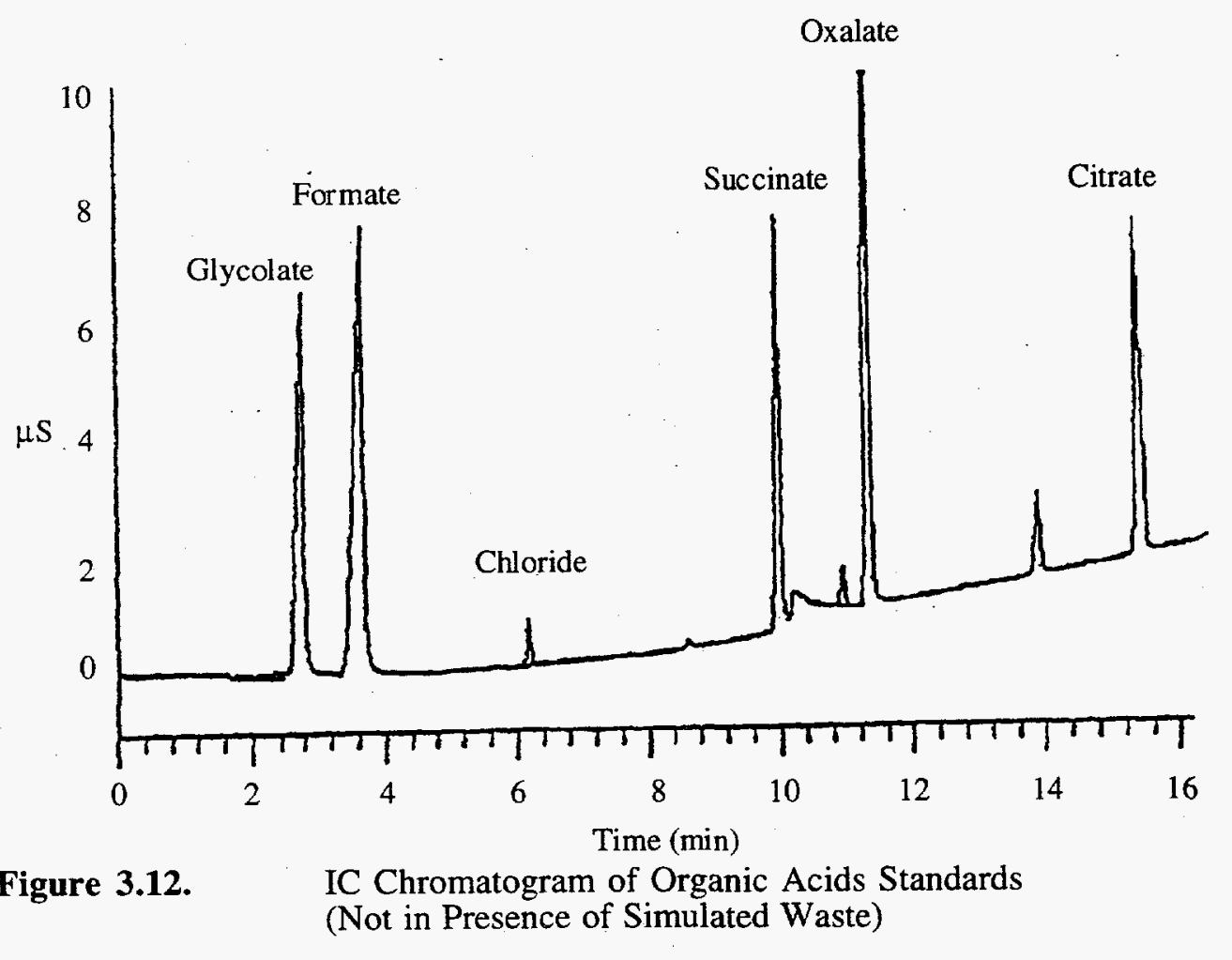




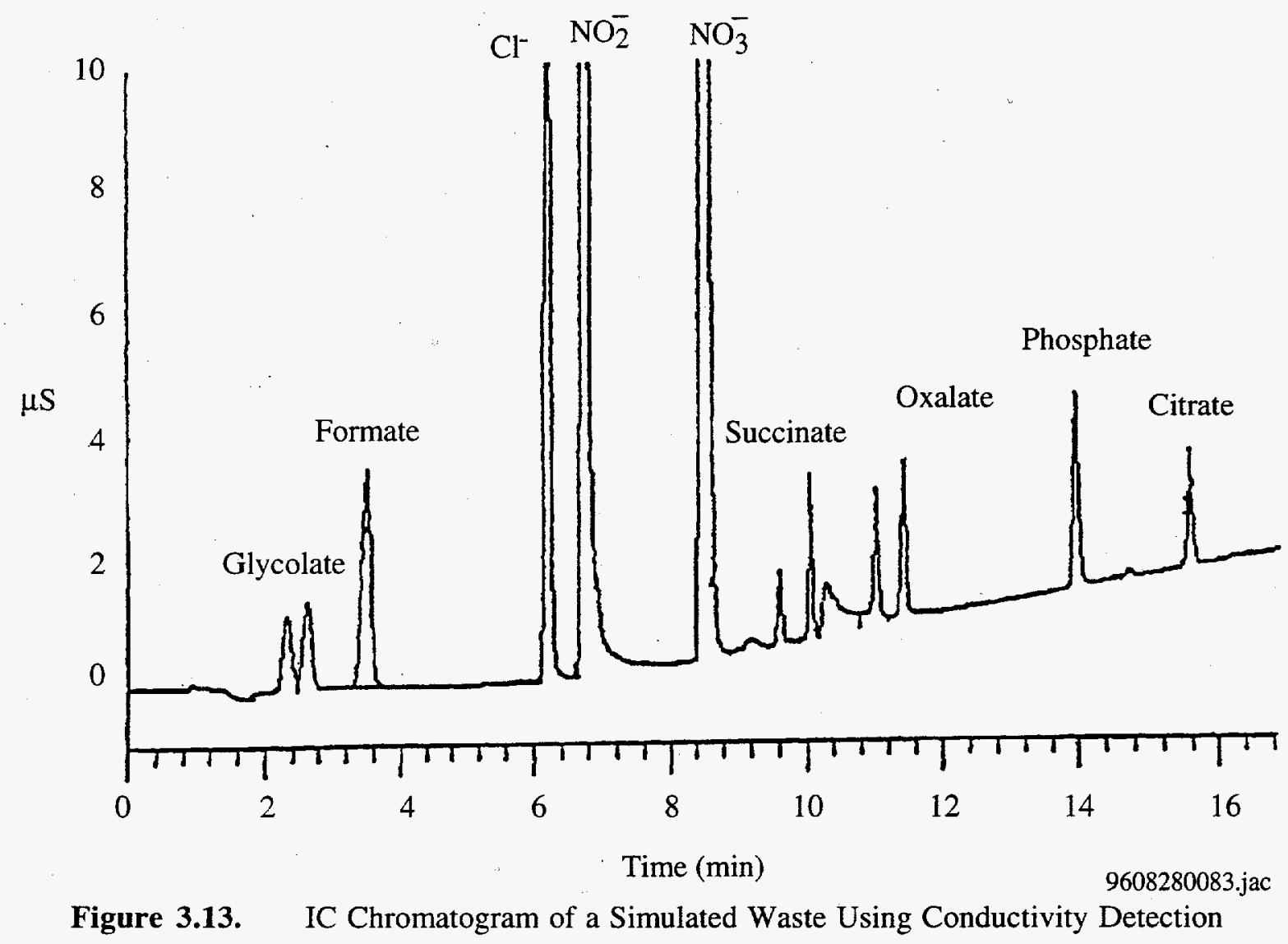

\subsubsection{Determination of NPH}

The procedure for extracting water-insoluble organic carbon was conducted in the hot cell. The sludge-like waste sample, at $\mathrm{pH} \approx 13$, was extracted with three equal volumes of chloroform, concentrated, and analyzed using GC/MS. The results from samples of Tank SY-101 are shown in Table $2.8 ; \mathrm{NPH}, \mathrm{C}_{12}-\mathrm{C}_{15}$, is the primary constituent of the water-insoluble carbon. Figure 3.14 is a total ion chromatogram of the chloroform extract of a sample from Tank SY-101. The peaks indicated are NPH $\left(\mathrm{C}_{12}\right.$ through $\left.\mathrm{C}_{15}\right)$. Because $73-93 \%$ of the TOC can be accounted for in samples from SY-101, very little, if any, water-soluble or water-insoluble carbon remains unidentified. Total ion chromatogram is a GC/MS term.

Sample R4258 has the highest concentration of NPH; the NPH concentration correlates strongly with the depth of the core sample, suggesting a density segregation of NPH. Table S.1 shows the TOC accounted for by chelators, chelator fragments, NPH, and low-molecular-weight carboxylic acids in samples from Tank SY-101. The same procedure was used to extract the organically-soluble carbon from samples of Tank SY-103. Figure 3.15 is a total ion chromatogram of the chloroform extract of the convective layer sample from Tank SY-103. The primary constituents are styrene-related components. Concentrations are shown in Table 2.8. In contrast to the results from Tank SY-101, the results of analyses from samples of Tank SY-103 indicated very little organically extractable carbon. The major components in the organically soluble fraction was styrene-related compounds. Figure 3.16 is a total ion chromatogram and mass spectra of the styrene- 


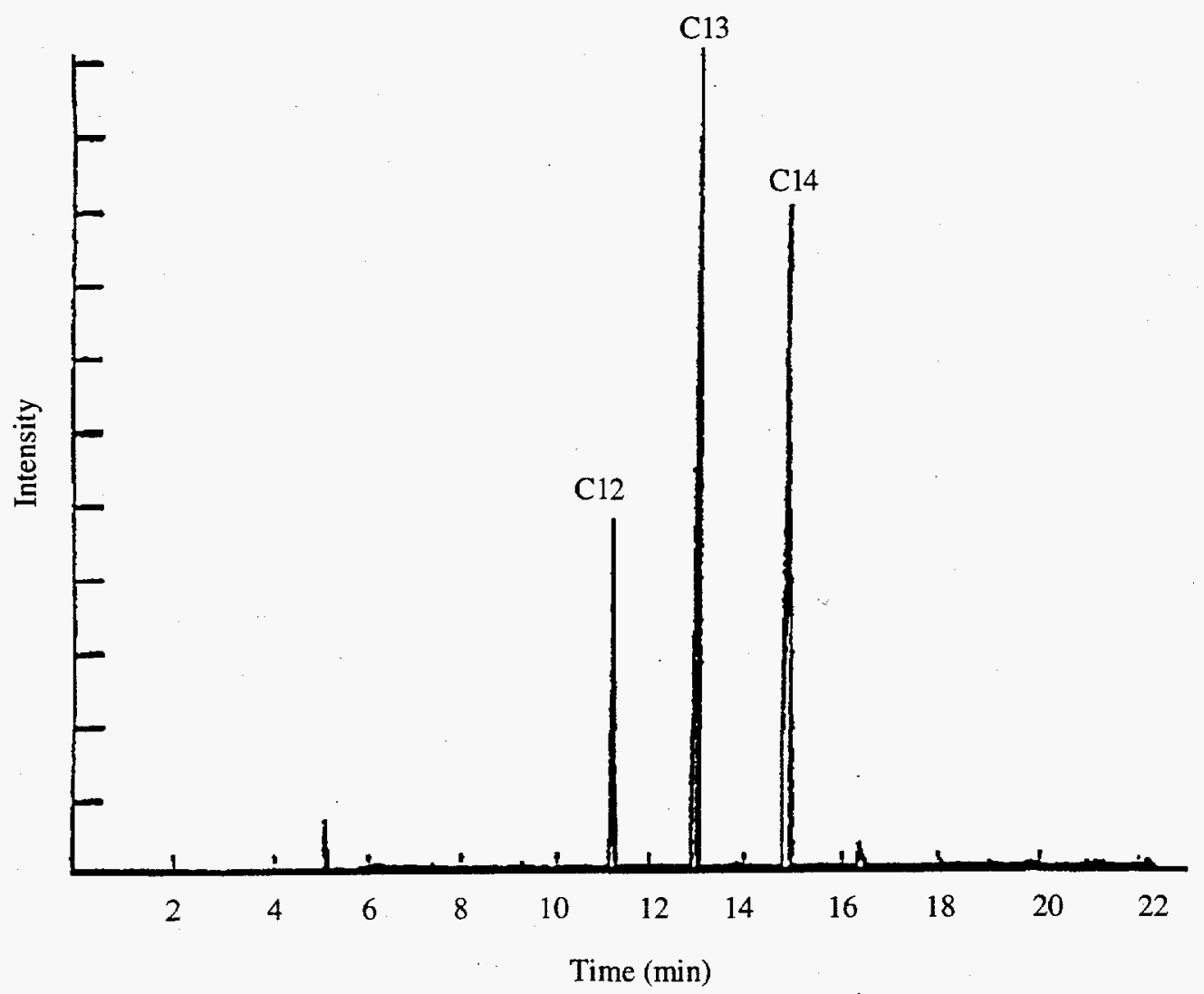

Figure 3.14. Total Ion Chromatogram (GC/MS) of the Chloroform Extract of Tank SY-101 Sample

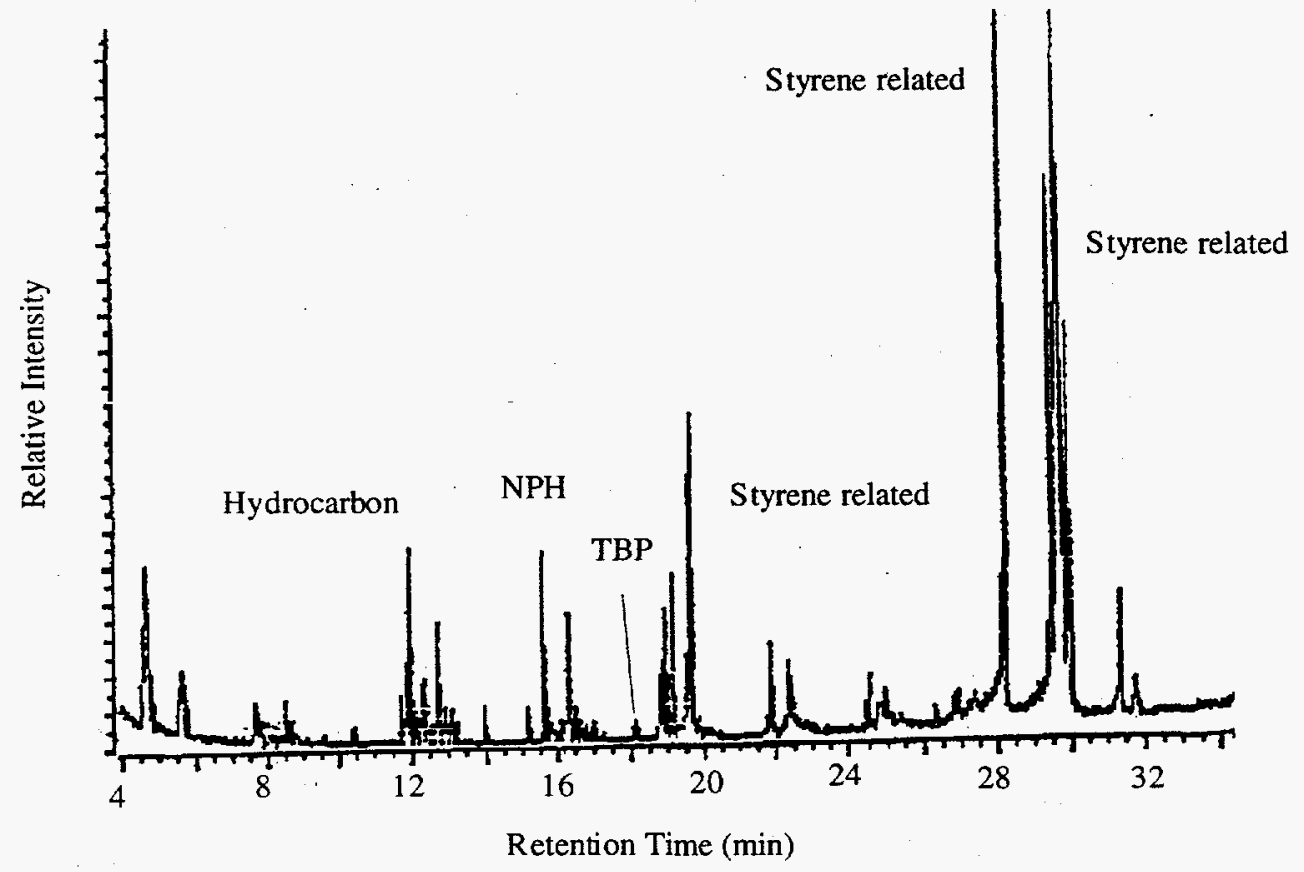

Figure 3.15. Total Ion Chromatogram (GC/MS) of Chloroform Extract of Tank SY-103 Sample 

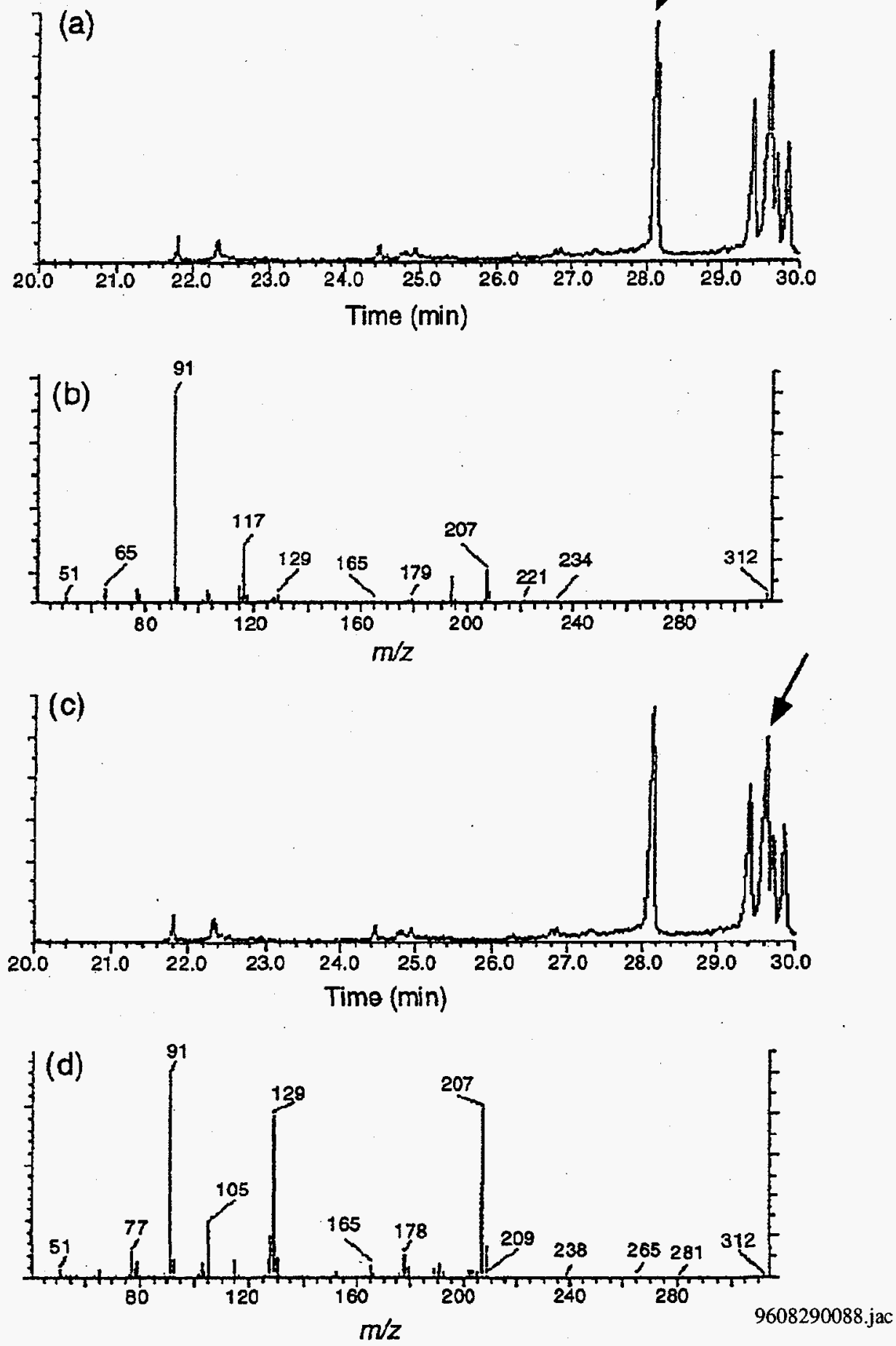

Figure 3.16. Total Ion Chromatogram (GC/MS) and Mass Spectra of Styrene-Related Compounds

related compounds. Figure 3.17 illustrates the data obtained from accurate mass measurements obtained on the JEOL mass spectrometer. 


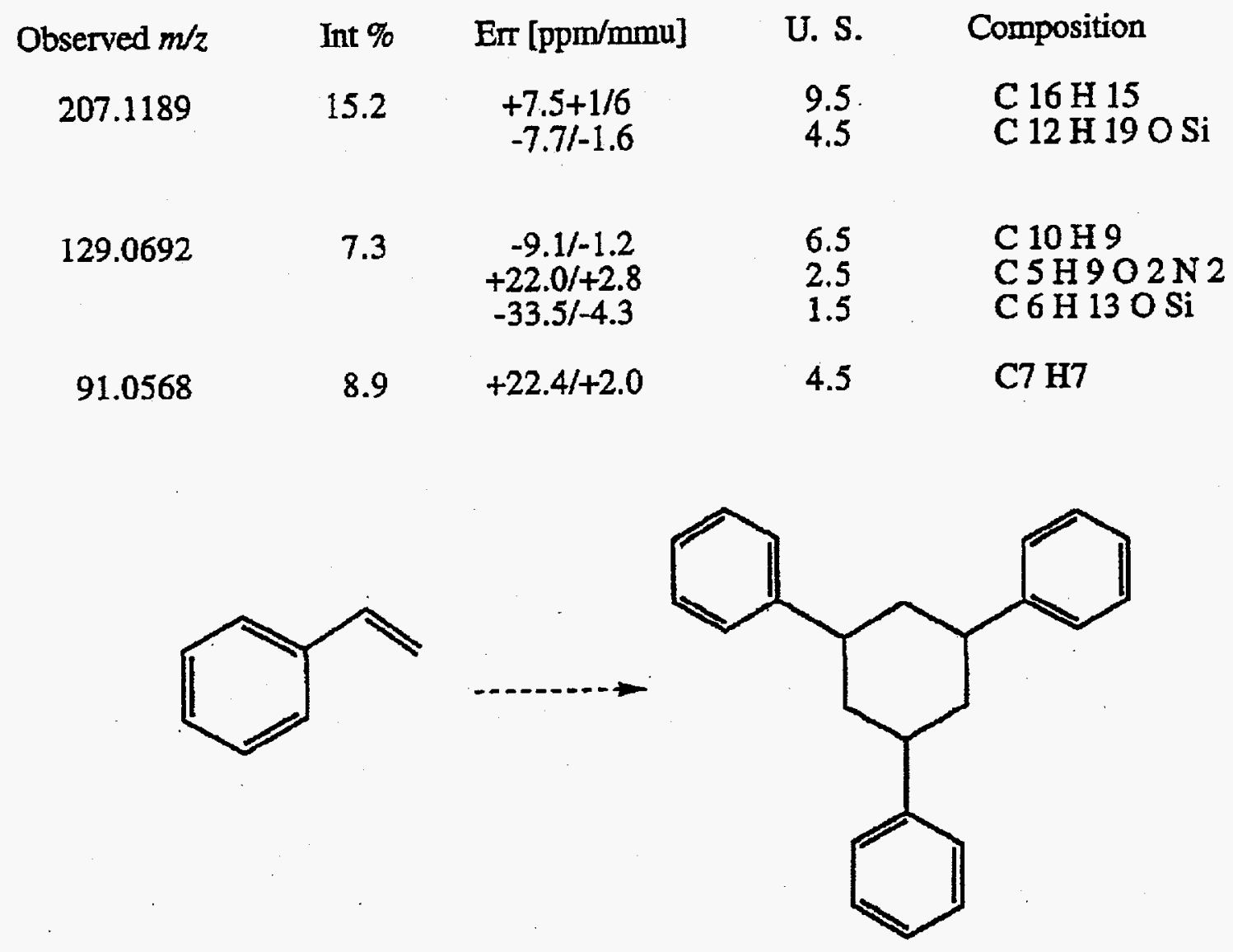

Styrene

Mol. Wt. 104

\section{Styrene Trimer}

Mol Wt. 312

MS Base Ion : 207

9608290089.jac

Figure 3.17. Accurate Mass Data

\subsection{Analysis of Heated Samples from Tank SY-103}

Samples from the convective layer of Tank SY-103 that were heated for 800 hours at 60,75 , 90,105 , and $120^{\circ} \mathrm{C}$ were obtained from the Gas Generation Task (Sam Bryan, Task Leader). The samples have been analyzed, and the results show the interesting fact that major differences exist between samples heated at 60 and $120^{\circ} \mathrm{C}$.

Table 2.11 lists the concentration of analytes in the original sample ( $\mathrm{mg} \mathrm{C} / \mathrm{g}$ ), the sample heated at $60^{\circ} \mathrm{C}$, and the sample heated at $120^{\circ} \mathrm{C}$. The results represent the average of four separate analyses. The estimated experimental deviation is approximately $15-20 \%$. Even at $60^{\circ} \mathrm{C}$, the chelators have degraded, and the concentration of EDTA has decreased, but NIDA, NTA, and ED3A 
have increased in concentration. The differences in concentration between the original and sample heated at $60^{\circ} \mathrm{C}$ are significant. These observations are consistent with Toste (1989), who found that even at room temperature, the chelators in the waste simulants degraded considerably.

The differences between the concentrations of EDTA, NTA, ED3A, and NIDA in the original sample and the sample heated at $120^{\circ} \mathrm{C}$ are significant. At $120^{\circ} \mathrm{C}$, essentially all of the EDTA has disappeared, and the difference in concentration of $\mathrm{CA}$ is within experimental uncertainty. However, the NIDA, NTA, ED3A-related components have apparently increased in concentration. In a comparison of the concentrations of the heated samples at 60 and $120^{\circ} \mathrm{C}$, the differences for ED3A and EDTA are significant. This is shown schematically in Figure 3.18. Precision/accuracy determination will require a level of effort beyond current funding levels. However, this task must be completed to determine whether the differences we are observing are experimentally significant.

The total organic carbon appears to be increasing as a function of temperature, which could possibly be explained in several ways:

- The response factor for NIDA (IDA) may have been underestimated because of decomposition. If this were the case, the concentrations of IDA may be too large.

- Some sample may have been lost during heating, which is highly unlikely.

- The EDTA concentration may be underestimated.

We are in the process of investigating these items.

The analytical results of the samples heated at 75,90 , and $105^{\circ} \mathrm{C}$ are somewhat suspect. In some cases, the concentrations vary considerably, and the differences are within experimental uncertainty. Derivatization GC/FID may not be capable of detecting small changes in concentration. We believe that the derivatization procedure may not be capable of derivatizing the sample fully because of its hardness and cement-like nature. For this reason, we are evaluating other techniques (funded separately from either Flammable Gas or Organic Tanks Safety Programs) for analyzing chelators and chelator fragments. An example is LC with UV detection and copper complexation; preliminary results using this technique will be discussed in a following section.

Part of the sample preparation procedure (See Figure 3.1) is to elute the water leachate or liquid sample through the cation exchange resin, rinse the column with $\mathrm{NaOH}$ to elute any organics off the resin, and then combine the solutions before removing them from the hot cell. As a result, the samples have an excess of $\mathrm{NaOH}$. The excess hydroxide might be causing the apparent variability of chelator concentrations in the 75,90 and $105^{\circ} \mathrm{C}$ heated samples. When the derivatization reagent, $\mathrm{BF}_{3} /$ methanol in this case, is added to the dried sample, a portion of the reagent will react with the base. If insufficient reagent remains, incomplete derivatization may occur. Therefore, the concentrations may vary considerably. This may point out the fact that the temperature increments (i.e., $60,75,90^{\circ}$, etc.) may produce smaller concentration changes than can be distinguished by the analytical technique. We are exploring the possibility of partially neutralizing the sample solution before drying, the premise being that more reagent will be available for the derivatization process. Preliminary results look very promising.

The heated and irradiated samples from the Gas Generation Task will be analyzed using IC or LC for low-molecular weight organic acids. 


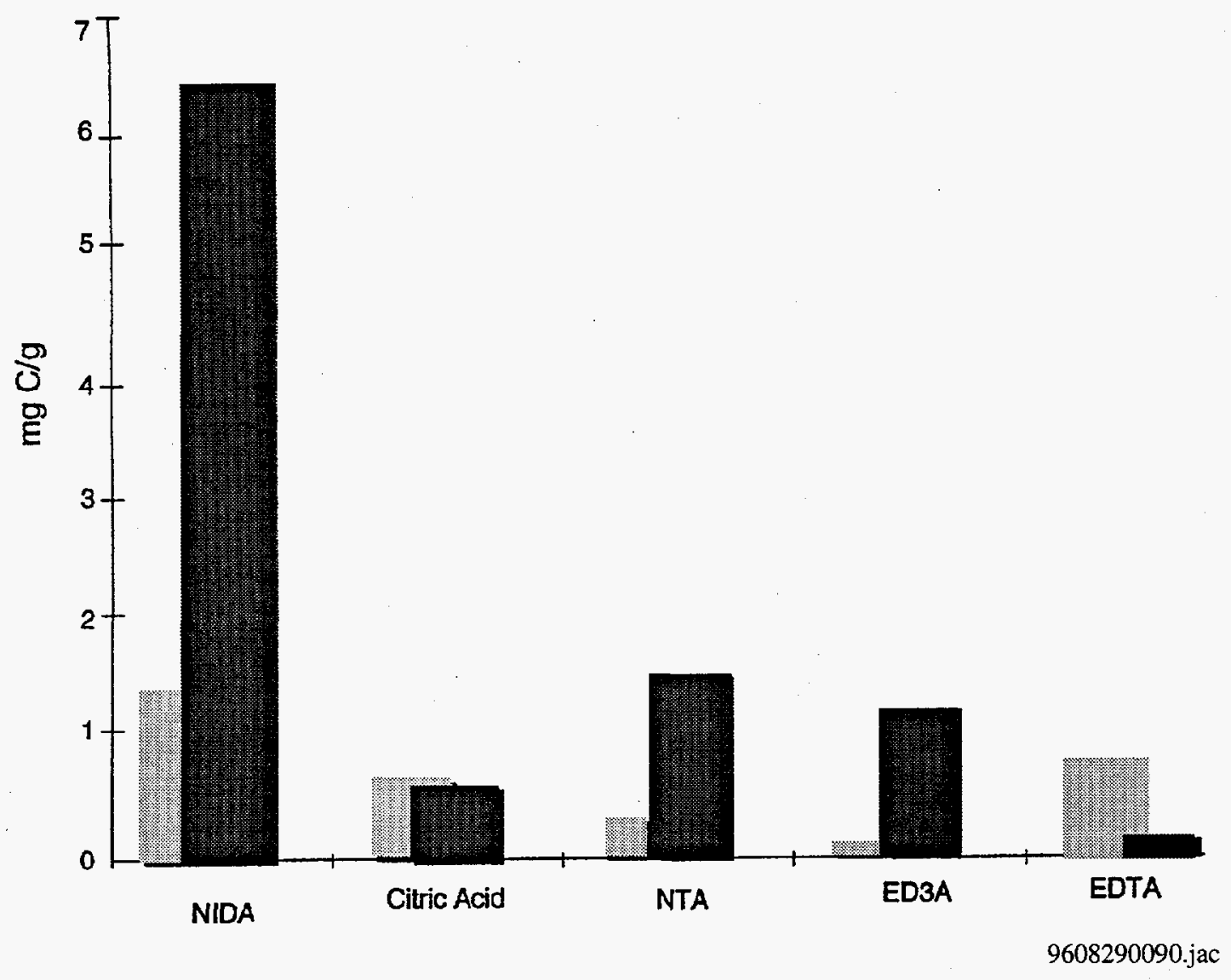

Figure 3.18. Results from Analysis of the Original Sample and $120^{\circ} \mathrm{C}$-Heated Sample from Tank SY-103. Initial (left) and heated (right).

\subsection{Alternative Methods Being Developed}

\subsubsection{Organic Functional Group Screening Development}

Another potentially useful technique for obtaining organic information cost effectively is Fourier Transform (FT) Raman and infrared (IR) spectroscopy for screening organic functional groups. While these techniques will not provide complete quantitative organic content information, they do indicate relative amounts of specific organic functional groups, such as $\mathrm{C}-\mathrm{H}$ and $\mathrm{COO}^{-}$, which may be enough as a quick screening tool to determine if complete organic speciation is required. This capability was developed under the Organic Tanks Safety Program and is described in more detail elsewhere (Wahl et al. 1996). This capability has not been tested on actual tank waste samples to date; however, results with simulant analyses were encouraging.

The theoretical basis for relating specific organic functional groups such as $\mathrm{C}-\mathrm{H}$ and $\mathrm{COO}^{-}$to sample reaction enthalpy has been described. Simultaneous to development of the spectroscopy techniques for functional group determination, studies with conventional energetics determinations \{e.g., differential scanning calorimetry (DSC)\} were employed to determine if experimentally functional groups could relate to energetics and to tie the spectroscopic results to more traditional methods. 
Preliminary results from the FT-IR and Raman spectroscopy studies suggested that spectroscopic determination of functional groups would be a good indicator of enthalpy content as a preliminary screening technique. For example, FT-IR analysis of liquid simulant samples showed that $\mathrm{COO}^{-}$content could be quantitated within $20 \%$ relative error for different organics and $\mathrm{C}-\mathrm{H}$ content within $30 \%$ relative error. Since the goal of this analytical method is to provide a screening tool to determine relative enthalpy content of tank waste samples in a hot cell and not complete quantitation, these preliminary results are well within the range of a useful screening tool. Additional work on testing mixtures of organics and testing actual tank waste samples that have been speciated for comparison should be completed for final testing of this method. A summary of the key findings of these two spectroscopic techniques is provided.

\section{FT-Raman Spectroscopy}

- Non-linear but predictable trend of $\mathrm{C}-\mathrm{H}$ response over the range of $2-8$ moles $\mathrm{C}-\mathrm{H}$ bond $/ \mathrm{kg}$ sample. Little variation due to water content of the solid samples was observed.

- Linear C-H response for liquid samples down to a level of $0.5 \% \mathrm{w} / \mathrm{w}$ was obtained. However, different organic compounds responded a little differently.

- Initially may need more development than FT-IR for liquid samples and hot-cell applications, but is more amenable in the long term for solid samples and in-tank analysis with fiber optic probes.

\section{FT-IR Spectroscopy}

- Solution response for mole carboxylate/kg solution was linear for all organics tested. The maximum $\mathrm{COO}^{-}$error was $20 \%$.

- Solution response for $\mathrm{C}-\mathrm{H}$ was linear for all organics tested. The quantitation of $\mathrm{C}-\mathrm{H}$ was broken into three distinct wavelength regions in the spectrum. Quantitation errors using these three regions resulted in a maximum error of $27 \%$.

- Solid response for carboxylate and $\mathrm{C}-\mathrm{H}$ was non-linear, but quantifiable. Quantitation errors are possible for TOC levels greater than $4 \% \mathrm{COO}^{-}$because almost all of the light is absorbed by the sample.

- Moisture content did not affect quantitation of $\mathrm{COO}^{-}$or $\mathrm{C}-\mathrm{H}$ of solids unless the samples contained less than $10 \%$ total water. This is because the sample had poor contact with the crystal. This can likely be resolved by adding a slight amount of liquid to the sample to ensure good contact during analysis.

- Quantitation of $\mathrm{COO}^{-}$and $\mathrm{C}-\mathrm{H}$ is excellent for solution work; however, solution work requires sample preparation. Quantitation of $\mathrm{COO}^{-}$and $\mathrm{C}-\mathrm{H}$ for solids works well; however, solids analysis may require minimal treatment of the sample if the moisture level is too low (i.e., adding small quantity of water to facilitate crystal contact).

- Remote analysis systems are in use currently by industry; however, sensitivity and other problems may be encountered with deployment to remote tank analysis. 
- For solids analysis, attenuated total reflectance may not be the best method. It was chosen because of its ease for implementation into the hot-cell working environment.

The complementary nature of IR and Raman spectroscopy was apparent for the solid and liquid simulant waste samples studied. Some possible ways may exist to correct for the changes in tank matrix that would otherwise interfere with results. For Raman, the Rayleigh line (elastically scattered radiation) could, in theory, be used to partially correct for the matrix effects. Similarly for FT-IR, the $2200-\mathrm{cm}^{-1}$ region of the spectrum, where no distinct features are present, could be used to correct for scattering due to the tank matrix. Additional work on testing mixtures of organics and testing actual tank waste samples that have been speciated for comparison should be completed for final testing of this method.

\subsubsection{Matrix-Assisted Laser Desorption/ionization Time-of Flight MS}

Some difficulty and uncertainty still exists in using derivatization GC for chelator analysis. While this is currently the best method available for analyzing these components in the complex tank waste samples, the derivatization procedure is time-consuming and often difficult with the consistency of the actual tank waste matrix. Although not explicitly in the FY 1996 scope of work and not funded directly through the Tanks Safety Program, techniques have been evaluated for analyzing chelators and chelator fragments directly using liquid chromatography with copper complexation and UV detection and MALDI/TOF MS. Both techniques show considerable promise for analyzing chelators and organic acids directly: If successful with actual wastes, these techniques could save an appreciable amount of money currently invested in analyzing for organics.

The MALDI/TOF MS technique is used to obtain molecular-weight information of nonvolatile, thermally labile compounds. The MALDI technique desorbs and ionizes these thermally labile compounds followed by TOF MS analysis to determine molecular weights of the analyte ions based on their mass-to-charge $(\mathrm{m} / \mathrm{z})$ ratios. The samples analyzed by MALDI are mixed uniformly with a matrix substance and applied to a metal slide in microliter amounts. The matrix and analyte solutions are allowed to dry and form uniform crystals. The sample slide is inserted in the vacuum system of the MS, and a laser beam is directed at the sample spot to volatilize the sample. A brief pulse ( $3 \mathrm{~ns}$ ) of nitrogen laser light $(\lambda=337 \mathrm{~nm})$ is directed onto a small target area (about $100 \mu \mathrm{m}$ in diameter) of the sample/matrix deposited on the sample slide. The matrix rapidly absorbs heat energy from irradiation, inducing vaporization and ionization of itself and the analyte. Common matrices are sinapinic acid (3,5-dimethoxy-4-hydroxycinnamic acid) and 2,5-dihydroxybenzoic acid. When the laser light contacts the matrix and sample, there is localized and rapid (nanoseconds) heating of the matrix and sample. Under rapid heating conditions, organic compounds favor vaporization reactions over decomposition reactions (Buehler et al. 1974). Matrix-assisted laser desorption/ionization has been shown to be a very useful MS ionization technique for biomolecules (Hillenkamp et al. 1991), polymers (Bahr et al. 1992), and other organic molecules (Ligard and Duncan 1995).

The MALDI technique has many potential advantages for analyzing tank waste. It is a very rapid analysis technique (minutes) and thus would be an ideal rapid screening tool for determining non-volatile organics in tank waste if high salt content does not interfere with the analyses. In addition, this technique works best at relatively low analyte concentrations (micromolar), and samples can therefore be diluted to reduce radioactivity levels before sample handling. This technique would be very simple to implement for radioactive sample analysis. A small drop of sample is deposited on a stainless steel probe, the solvent is dried, and then the probe is inserted onto a probe tip holder for 
insertion into the vacuum system by remote operation (computer controlled). This is shown schematically in Figure 3.19. If sample contamination levels are too high, the benchtop instrument design would be compatible with glovebox or fume hood operations.

Preliminary examples of the capability of MALDI for a variety of organic compounds are shown in Figures 3.20, 3.21, 3.22, and 3.23. The MALDI technique characteristically provides molecular-weight information for both small and large molecules. While matrix ions are always. observed, the $(\mathrm{M}+\mathrm{H})^{+}$or $(\mathrm{M}+\mathrm{Na})^{+}$ions dominate the analyte signal in the positive ion mode, and the $(\mathrm{M}-\mathrm{H})^{-}$ion dominates in the negative ion mode, where $\mathrm{M}$ is the intact analyte molecule. Figure 3.20 shows the $(\mathrm{M}+\mathrm{H})^{+}$ion of HEDTA (molecular weight $=278$ ) at $\mathrm{m} / \mathrm{z} 279$. The matrix ions at $\mathrm{m} / \mathrm{z} 138$ and 155 are from the gentisic acid matrix. The spectrum of EDTA is shown in Figure 3.21. The $(\mathrm{M}+\mathrm{H})^{+}$ion is at $\mathrm{m} / \mathrm{z} 294,(\mathrm{M}+\mathrm{H}+\mathrm{Na})^{+}$ion at $\mathrm{m} / \mathrm{z} 316$, and the di-, tri-, and tetra Na adducts. The positive ion spectrum of NTA is shown in Figure 3.22. The $(\mathrm{M}+\mathrm{Na})^{+}$ion is at $\mathrm{m} / \mathrm{z} 215$ and the di-Na ion at $\mathrm{m} / \mathrm{z}$ 237. The negative ion spectrum of citric acid is illustrated in Figure 3.23. Table 3.1 lists the ions observed for the analytes in the positive and negative ion mode. Further studies are being conducted to determine the effects from other sample components, such as salts and sample $\mathrm{pH}$, on these analyses.

Table 3.1. $\quad$ Ions Observed for the Analytes by MALDI-TOF MS in the Positive or Negative Ion Mode. No positive ions were observed for sodium nitrate, sodium nitrite, oxalic acid, fumaric acid, maleic acid, succinic acid, ammonium sulfate, and citric acid. There were no negative ions for IDA, HEDTA, EDDA, NTA, and EDTA.

Analyte

Sodium Nitrate

Sodium Nitrite

Oxalic Acid

Fumaric Acid

Maleic Acid

Succinic Acid

Ammonium Sulfate

Citric Acid

IDA

HEDTA

EDDA

NTA

EDTA $\underline{\text { Molecular Weight }}$

85

69

90

116

116

118

132

192

134

278

191

292

\section{Ions Observed $(\mathrm{m} / \mathrm{z})$}

$(-)$

$$
\begin{array}{r}
62\left(\mathrm{NO}_{3}^{-}\right) \\
46\left(\mathrm{NO}_{2}^{-}\right) \\
89(\mathrm{M}-\mathrm{H})^{-} \\
115(\mathrm{M}-\mathrm{H})^{-} \\
115(\mathrm{M}-\mathrm{H})^{-} \\
117(\mathrm{M}-\mathrm{H})^{-} \\
97\left(\mathrm{HSO}_{4}^{-}\right) \\
191(\mathrm{M}-\mathrm{H})^{-}
\end{array}
$$


Deposit $1 \mu \mathrm{L}$ Sample and

Matrix Solution

$\forall$

000000

Sampling Plate

Membrane
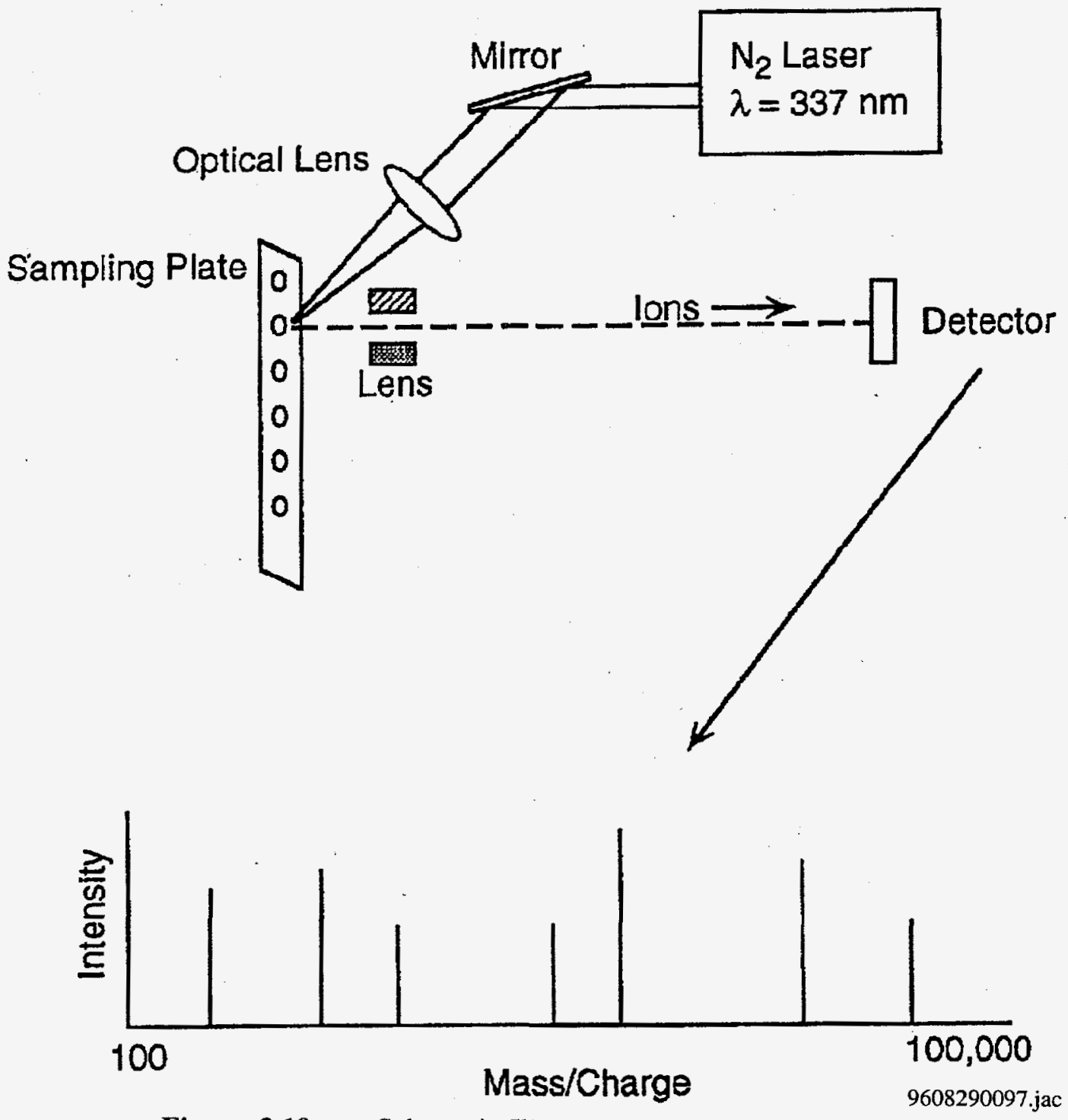

Figure 3.19. Schematic Illustrating MALDI Operation 


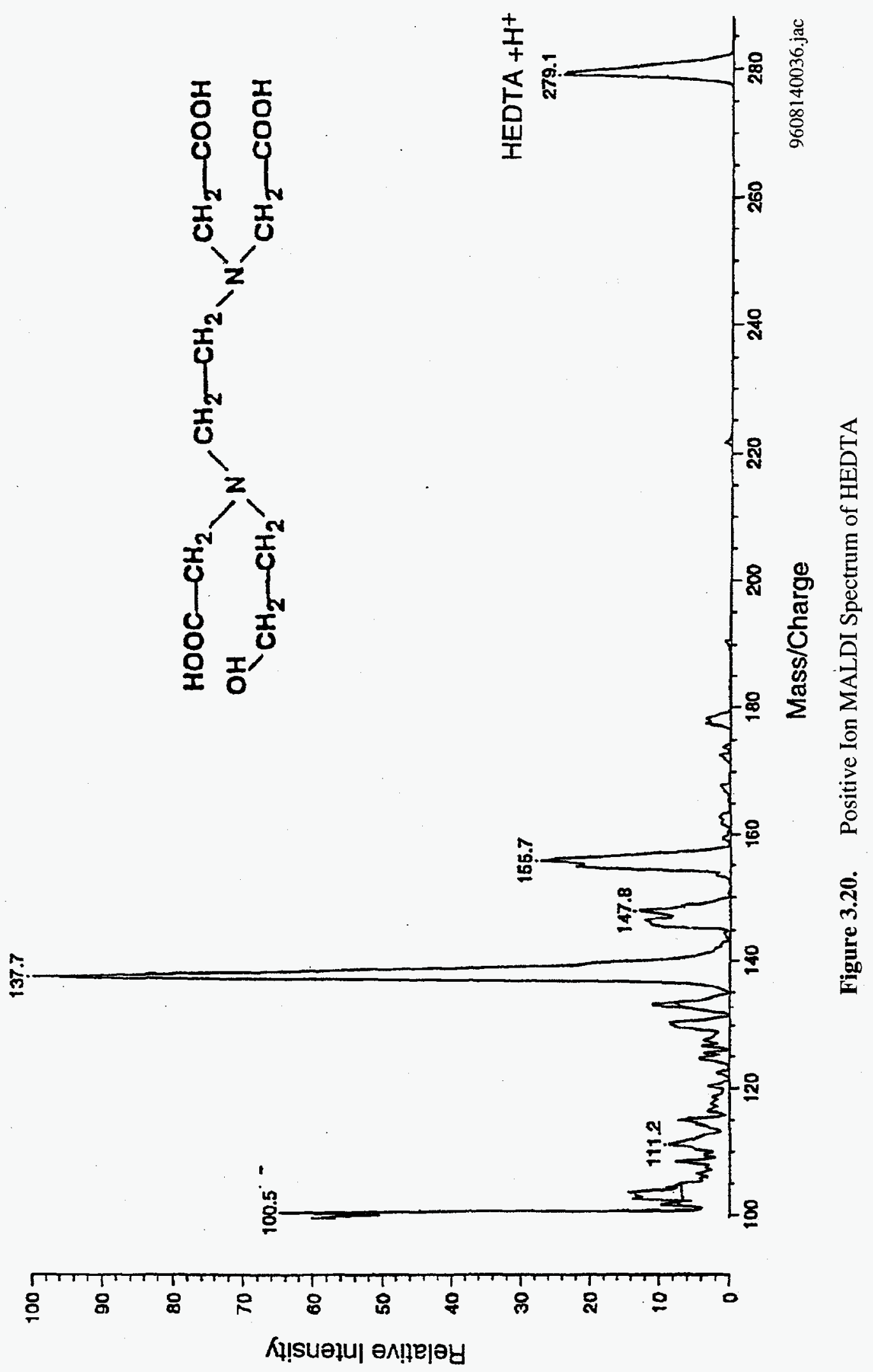




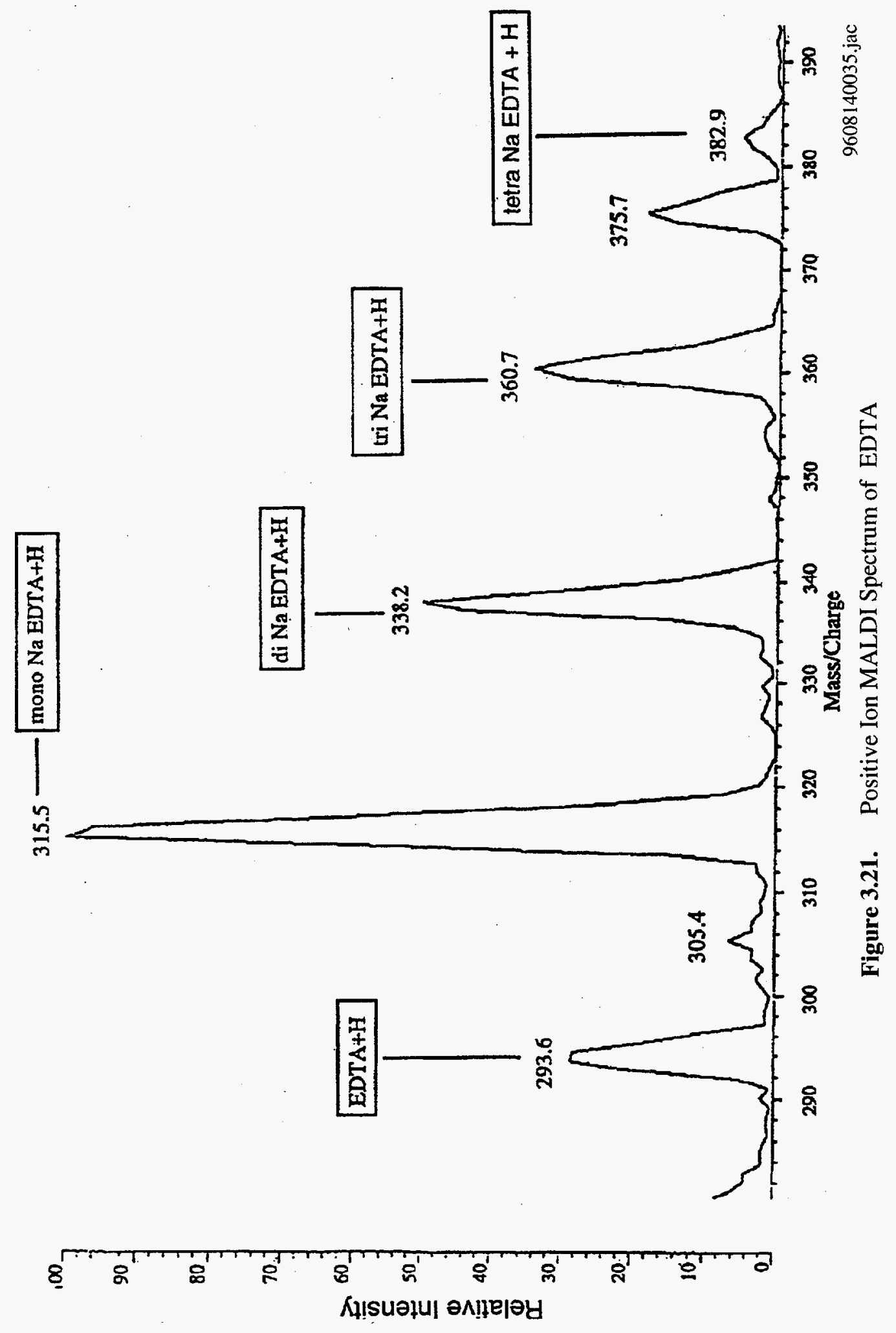




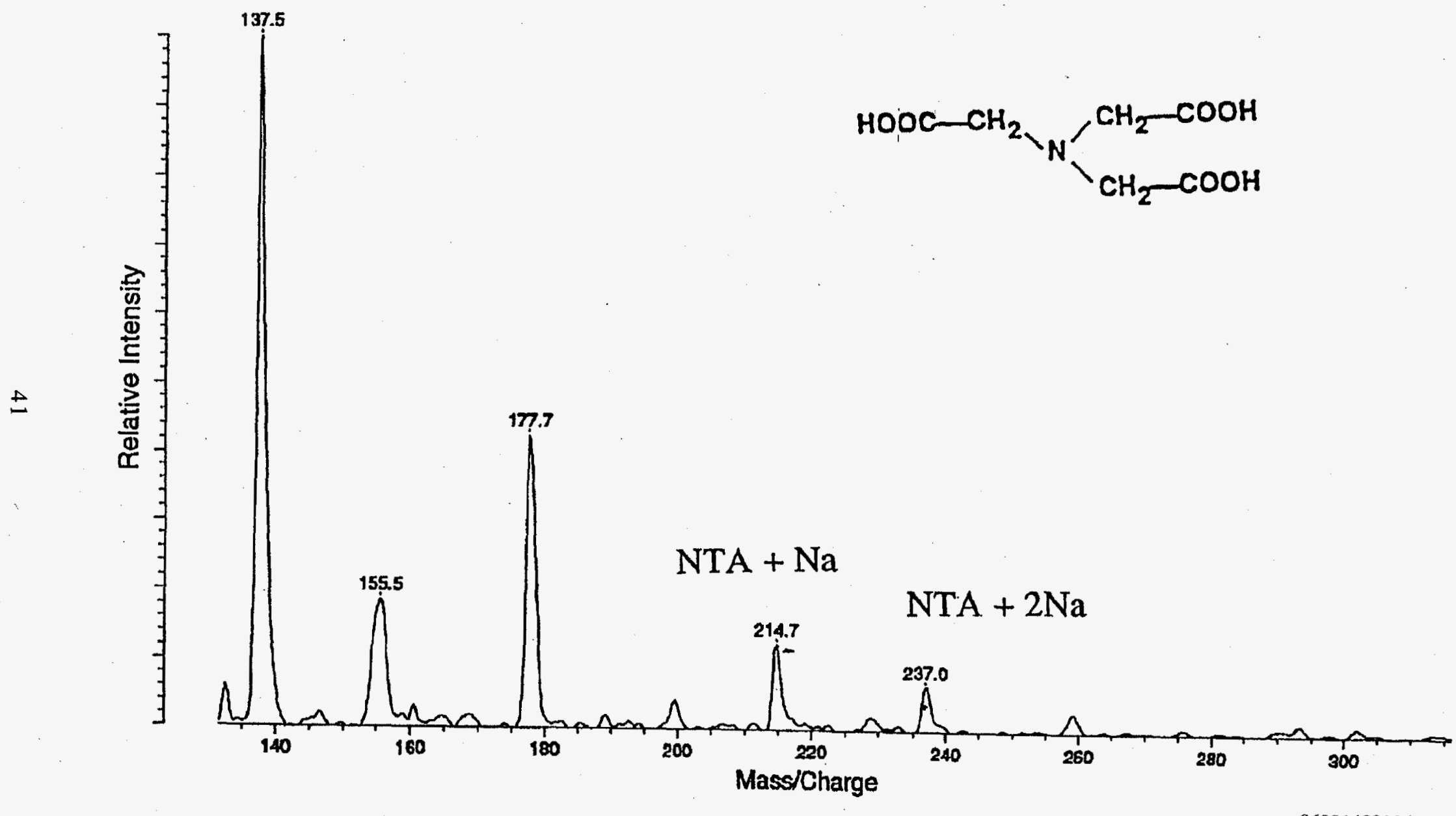

Figure 3.22. Positive Ion MALDI Spectrum of NTA 

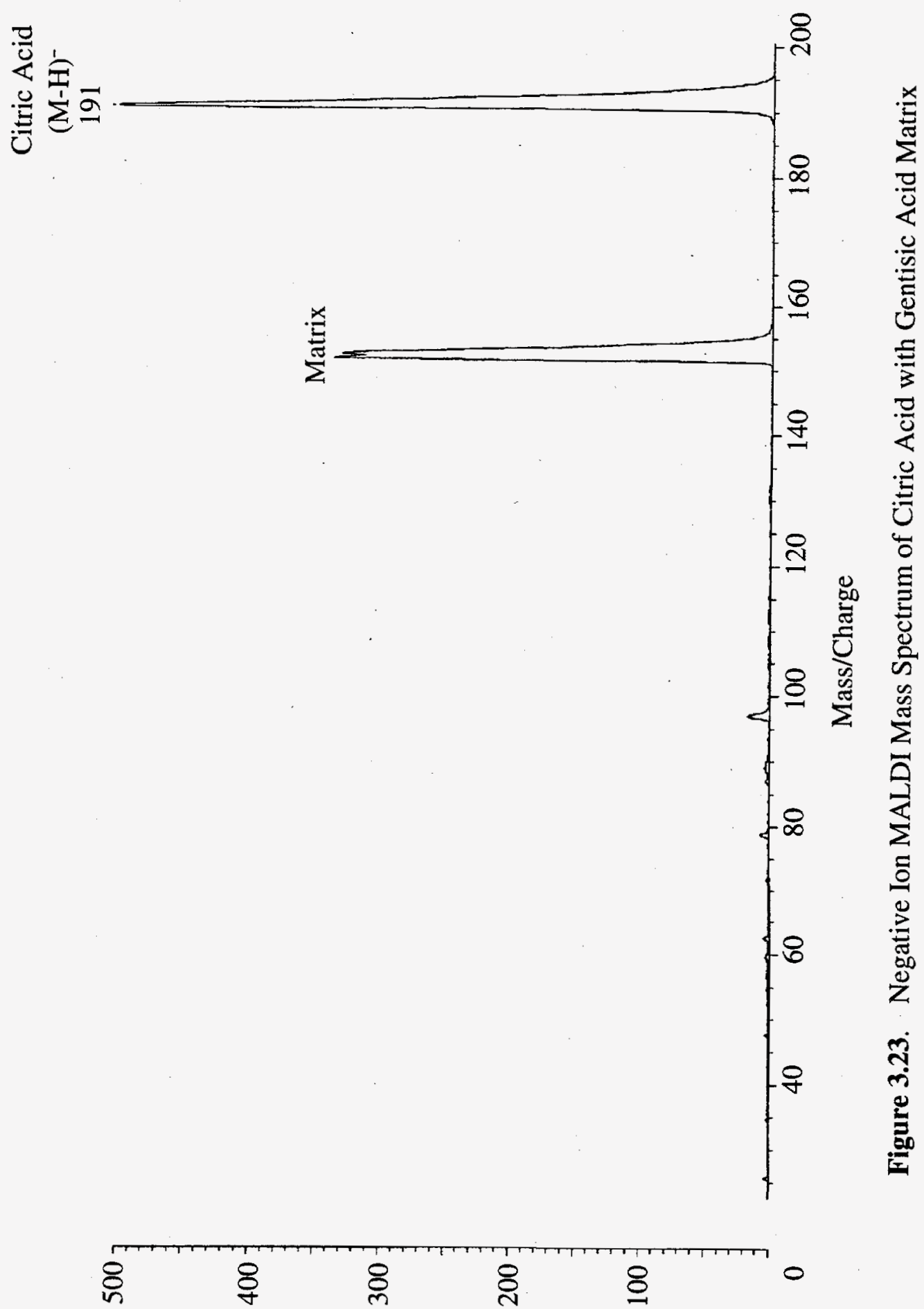

( 
this $\mathrm{pH}$. We studied $\mathrm{pH}$ values and found that all peaks in a standard mixture were efficiently separated by adjusting the $\mathrm{pH}$ to 5.5 . The retention times of the standards were then used to successfully identify the chelator fragments in $\gamma$-aged SYM-PAS-95-1a simulants supplied by William Samuels (Camaioni et al. 1996).

The instrumentation included a Hewlett Packard Series 1050 Isocratic high-performance liquid chromatography (HPLC) pump, a Unicam 4225 UV detector, and a Hewlett-Packard (HP) 3396 Series II integrator for collecting data. The analytical column was a Brownlee RP18, $25 \mathrm{~cm} x$ $4.6 \mathrm{~mm}$, spheri-5 monofunctional $5 \mu \mathrm{C} 18$ with equivalent guard column. The mobile phase consisted of $0.002 \mathrm{M}$ dodecyltrimethylammonium bromide as the ion-pairing agent and $0.05 \mathrm{M}$ potassium dihydrogen phosphate to buffer the system. The $\mathrm{pH}$ was brought up to $5.5 \mathrm{using} 6 \mathrm{~N}$ $\mathrm{NaOH}$. Samples were prepared by weighing $50 \mathrm{mg}$ in a $25-\mathrm{mL}$ solution and pipetting $1 \mathrm{~mL}$ of the latter into a $10-\mathrm{mL}$ volumetric; $50 \mu \mathrm{L}$ of $0.5 \mathrm{M} \mathrm{CuSO}_{4}$ was added to complex with the analytes, thus making them visible to the detector. The solution was then diluted to the mark, and $20 \mu \mathrm{L}$ was injected into the HPLC for ion-pair chromatographic analysis. Simulants were filtered before analysis if necessary.

Figure 3.24 is an ion-pair chromatogram of the chelator standards. The peak identification was determined from retention times of standards injected individually or spiked into simulant mixtures. The order of elution at a flow rate of $1.5 \mathrm{~mL} / \mathrm{min}$ under these buffer conditions was ED3A with HEDTA, symmetrical ethylenediaminediacetic acid (S-EDDA), IDA, unsymmetrical ethylenediaminediacetic acid (U-EDDA), NTA, and EDTA. Complete separation of all the chelator fragments is being pursued by careful control of the mobile phase $\mathrm{pH}$. To confirm these preliminary peak identifications, efforts to couple this separation to mass spectrometry is also being pursued.

Figure 3.25 is a chromatogram of a simulated waste. All of these fragments were identified in simulant samples exposed to $150 \mathrm{Mrads}, 100 \mathrm{Mrads}, 50 \mathrm{Mrads}$, and $30 \mathrm{Mrads}$. The S-EDDA, which does not derivatize with $\mathrm{BF}_{3}$ /methanol, IDA, and to some extent, U- EDDA, has proved difficult to detect by methods used to date. This procedure offers the advantage of determining all of the common chelators directly in the waste sample without the need for prior derivatization. Studies are ongoing to determine detection limits and the feasibility of quantitating the fragments.

Figure 3.26 is an ion-pair chromatogram of a convective-layer sample from Tank SY-103. The major components tentatively identified include s-EDDA, u-EDDA, EDTA, IDA, and HEDTA. Figure 3.27 is an ion-pair chromatogram of a heated convective-layer sample.

\subsection{Degradation of Organics in Flammable Gas Tanks}

Although not explicitly in the FY 1996 scope of work, it was deemed appropriate to discuss the preliminary results of estimating degradation for chelators and chelator fragments. We are estimating the extent that organics have degraded in flammable Gas Tanks by comparing the fill history with the composition as determined by organic speciation. As an example, we have obtained the fill history of Tank SY-101 and compared this with the results obtained from organic analysis. For oxalic acid, the fill history estimates the concentration to be approximately $0.008 \mathrm{mg} / \mathrm{g}$ of sample (Agnew 1996), but the results from actual analysis indicate a concentration of approximately 15 $\mathrm{mg} / \mathrm{g}$. Another example is citric acid with an initial concentration of $3.5 \mathrm{mg} / \mathrm{g}$ from fill history compared to $0.8 \mathrm{mg} / \mathrm{g}$ from speciation. For EDTA, the initial concentration was estimated to be 12 $\mathrm{mg} / \mathrm{g}$, and the measured concentration was determined to be $4.2 \mathrm{mg} / \mathrm{g}$. These results are consistent 


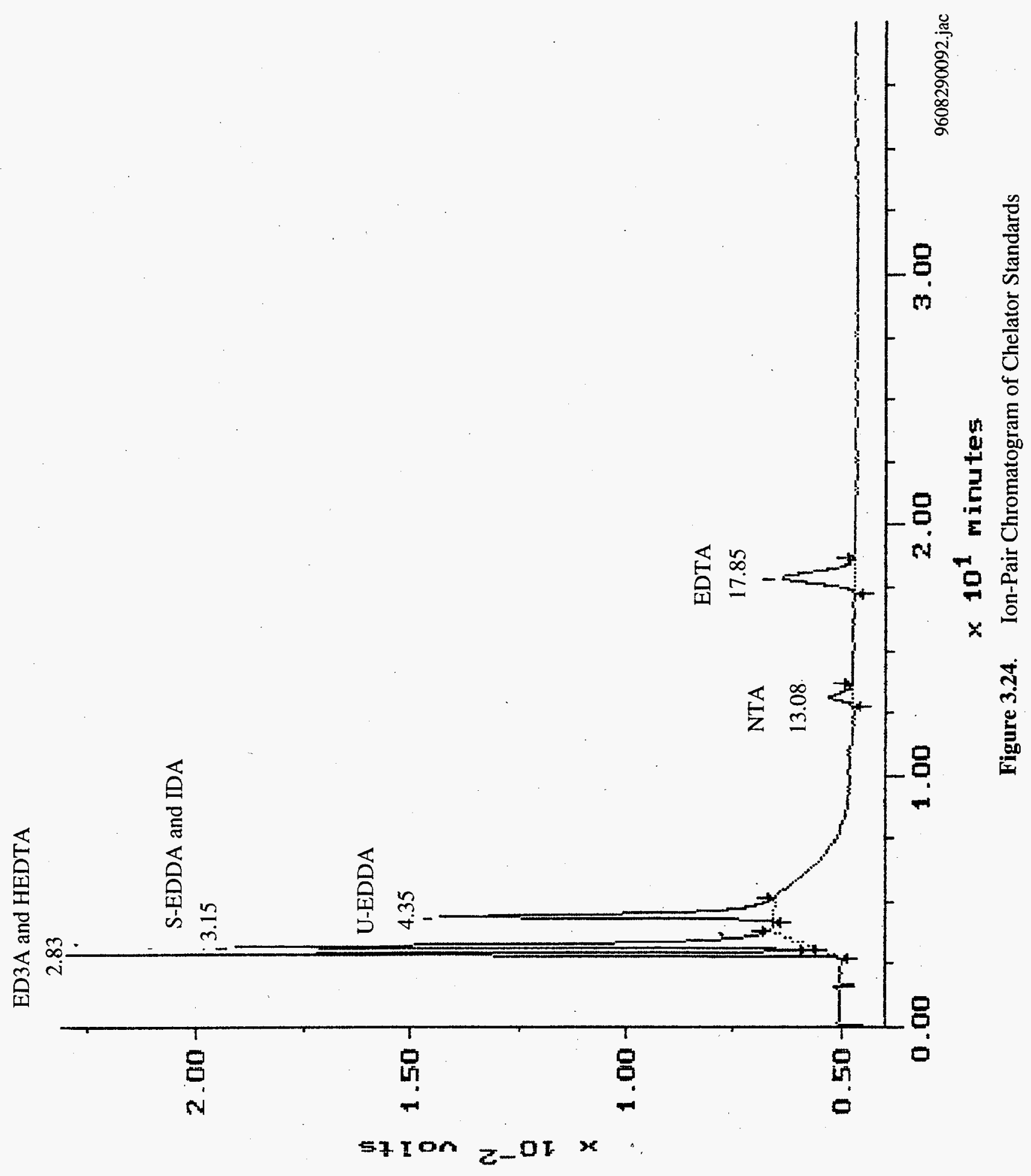




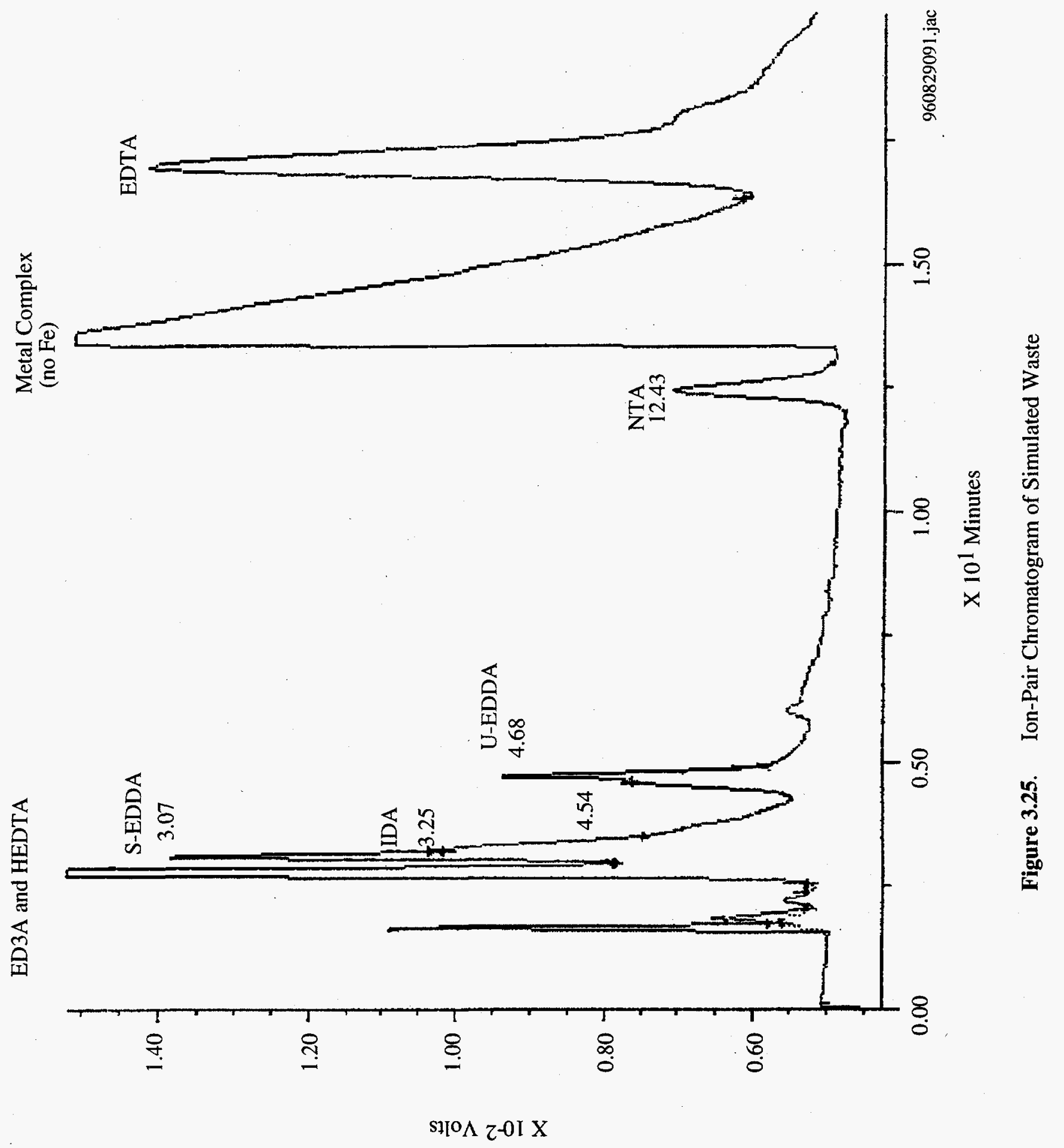




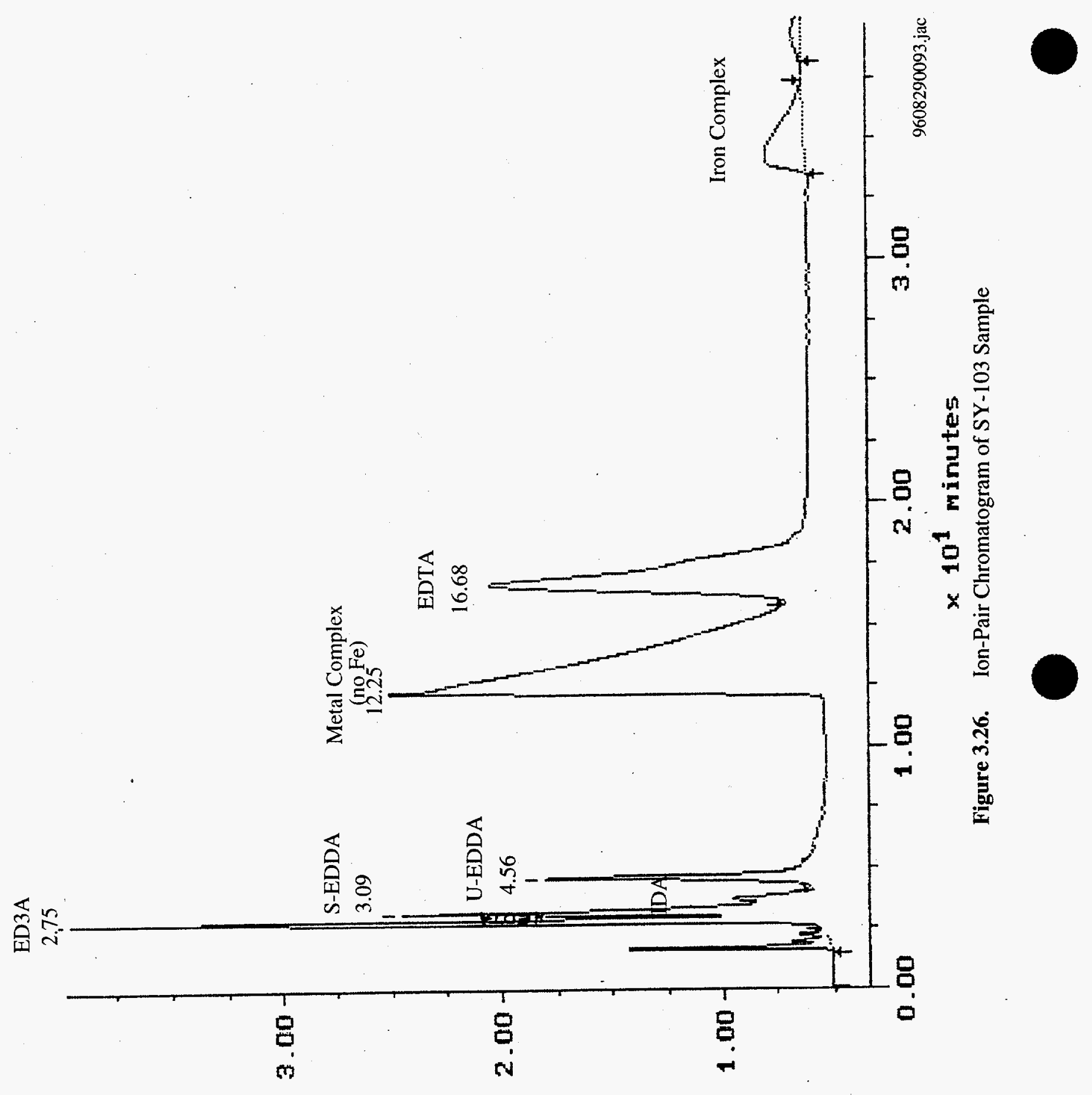




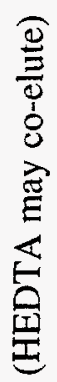

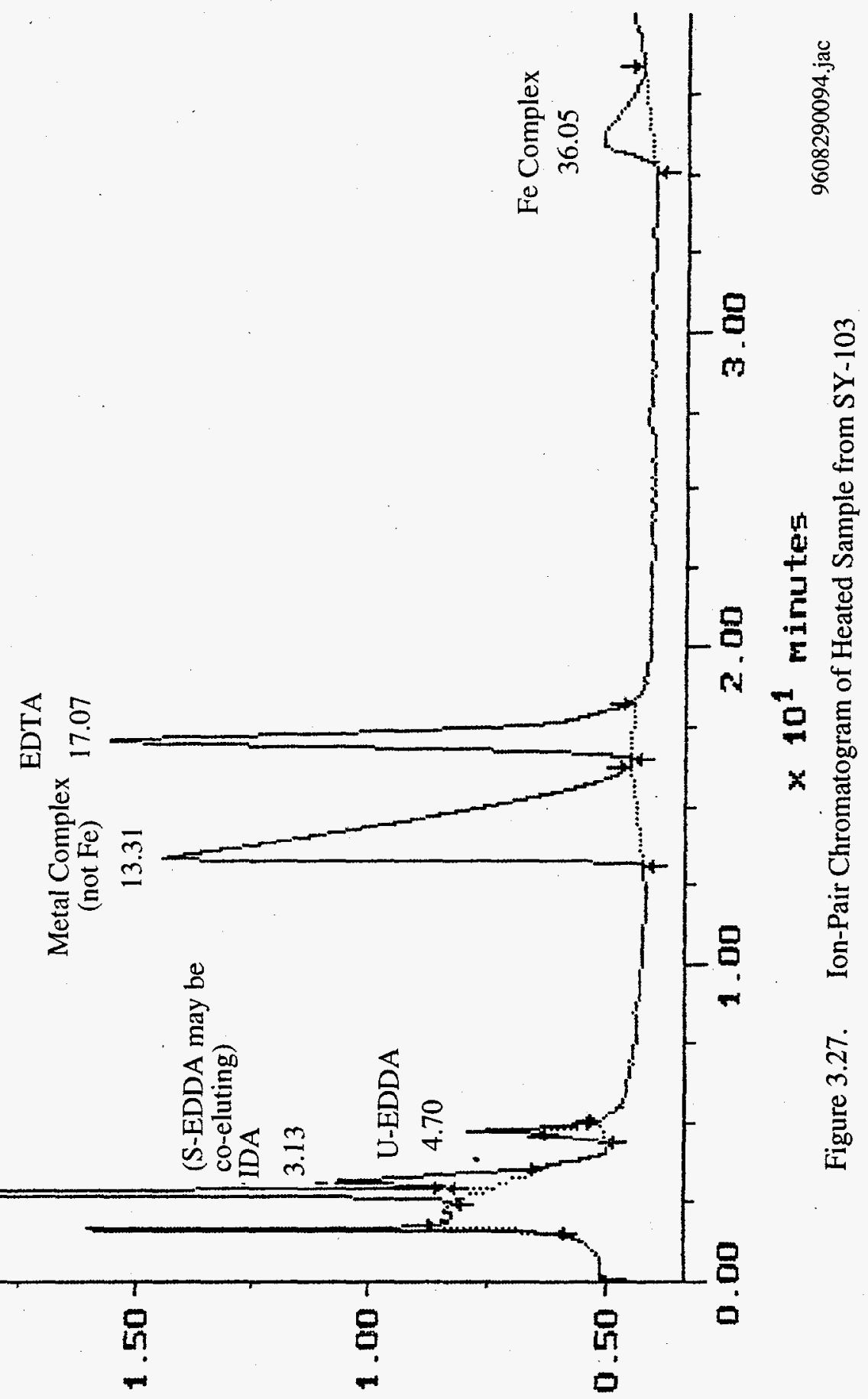


with degradation studies of waste simulants where EDTA and citric acid degrade to smaller organic compounds, whereas oxalic acid is a degradation product (Camaioni et al. 1994).

We have made several assumptions: 1) the fill history is reasonably accurate, 2) the analysis of small samples really represents the tank composition, and 3) the tank waste is relatively homogeneous. With these caveats, the preliminary results may be used to estimate the degree the organics have degraded. Further statements regarding the extent that organics have degraded will depend on comparing the fill history of other tanks with actual analysis of samples. The results of comparing fill history and actual analysis may provide information concerning when a tank may be deemed safe and also simplify speciation. In other words, if degradation of the organics can be linked to the determination of several components, the number of analyses will be greatly reduced. 


\subsection{Future Work}

The objective of the Actual Waste Organic Analysis Task is to apply organic analytical methods to Flammable Gas Tank waste samples to identify and/or quantify the amount of specific organic species. As analytical problems, such as different waste types, interferences, etc., arise, methods will be modified to produce needed results. In addition, because the present methods, particularly derivatization GC/MS, are time-consuming and costly, alternative methods for direct analysis will be evaluated.

Present plans for funding during FY 1997 include combining the Actual Waste Organic Analysis Task (Flammable Gas Task) with the Advanced Waste Analysis (Organic Tanks Safety Program) under the auspices of the Organic Tanks Safety Program. Analytical capabilities will be used to support other Pacific Northwest National Laboratory Flammable Gas Tanks tasks such as Gas Generation Studies (Sam Bryan, Task Leader) and Gas Bubble Retention Studies (Phil Gauglitz, Task Leader) as needed. In addition, analytical support will be provided for the Organic Tanks Waste Aging Studies (Don Camaioni, Task Leader).

Organic constituents, the source material for some of the flammable gases, and quantities play a key role in gas composition and generation. To address flammable gas safety issues, a sufficient understanding of the organics in tanks other than SY-101 and SY-103 is needed. It is critical to understand the role of organics in how gas is generated, what types of gases are expected to be generated, and the quantities of potential or actual gas generation. 
-

-

\section{0}




\subsection{References}

Bahr, U, A Deppe, M Karas, F Hillenkamp, and U Giessman. 1992. "Mass Spectrometry of Synthetic Polymers by UV-Matrix Assisted Laser Desorption/Ionization," Anal. Chem. 64:2866.

Baldwin, DL, RW Stromatt, and WI Winters. 1994. Comparative Study of Total Organic Carbon (TOC) Methods for High-Level Mixed Waste, PNL-SA-2374, Pacific Northwest Laboratory, Richland, Washington.

Barney, GS. 1994. The Sólubilities of Significant Organic Compounds in HLW Tank Supernate Solutions. WHC-SA-24565-FP, Westinghouse Hanford Company, Richland, Washington.

Bryan, SA, CM King, LR Pederson, SV Forbes, and RL Sell. 1996. Gas Generation from Tank 241: SY-103 Waste. PNNL-10978, Pacific Northwest National Laboratory, Richland, Washington.

Buehler, RJ, E Flanigan, LJ Greene, and L Friedman. 1974. "Proton Transfer Mass Spectrometry of Peptides. A Rapid Heating Technique for Underivatized Peptides Containing Arginine." J. Am. Chem. Soc., 96:3990-3999.

Camaioni, DM, WD Samuels, SA Clauss, AK Sharma, KL Wahl, and JA Campbell. 1996. Organic Tanks Safety Program: FY96 Waste Aging Studies. PNNL-11312. Pacific Northwest National Laboratory, Richland, Washington.

Campbell, JA, SA Clauss, KE Grant, FV Hoopes, BD Lerner, RB Lucke, GM Mong, JK Rau, and RT Steele. 1994a. Flammable Gas Safety Program. Analytical Methods Development: FY 1993 Progress Report. PNL-9062. Pacific Northwest Laboratory, Richland, Washington.

Campbell, JA, SA Clauss, KE Grant, FV Hoopes, BD Lerner, RB Lucke, GM Mong, JK Rau, KL Wahl, and RT Steele. 1994b. Flammable Gas Safety Program. Analytical Methods Development: FY 1994 Progress Report. PNL-10127. Pacific Northwest Laboratory, Richland, Washington.

Grant, KE, RB Lucke, SA Clauss, GM Mong, BD Lerner, and JA Campbell. 1996a. Qualitative Determination of Low-Molecular Weight Organic Acids in Mixed Hazardous Wastes Using Thermospray Liquid Chromatography/Mass Spectrometry. Accepted for publication in Journal of Radioanalytical and Nuclear Chemistry.

Grant, KE, GM Mong, RB Lucke, and JA Campbell. 1996b. Qualitative Determination of Chelators and Their Degradation Products in Waste from Tank 241-SY-101 Using Derivatization Gas Chromatography/Mass Spectrometry. Submitted for publication Journal of Radioanalytical and Nuclear Chemistry.

Hillenkamp, F, M Karas, RC Beavis, and BT Chait. 1991. "Matrix-Assisted Laser Desorption/Ionization Mass Spectrometry of Biopolymers," Anal. Chem. 63:1193A.

Ligard, R and MW Duncan. 1995. "Utility of Matrix-Assisted Laser Desorption/Ionization Time-ofFlight Mass Spectrometry for the Analysis of Low Molecular Weight Compounds," Anal. Chem. 9:128. 
Mong, GM, JA Campbell, RD Orr, SA Clauss, KL Wahl, and FV Hoopes. 1996. "Activity Reduction. of Radioactive Mixed Wastes for Subsequent Carboxylate Determinations." Submitted for publication in Journal of Radioanalytical and Nuclear Chemsitry.

Rice, AD. 1995. 216-Day Final Report for Tank 241-SY-103, Push Mode-Core 62. WHC-SD--WMDP-074, Rev. 0, Westinghouse Hanford Company, Richland, Washington.

Small, H, TS Stevens, and WC Bauman. 1975. "Novel Ion Exchange Chromatographic Method Using Conductimetric Detection," Anal. Chem., 47, 1801-1809.

Toste, AP. 1989. J. Radioanaly. Nuc. Chem. 161:549-559.

Vanyolos, A. 1955. Rev. Chim. (Bucharest), 6:378-379.

Wahl, KL, JA Campbell, IE Burgeson, SA Bryan, DM Camaioni, RT Hallen, BD Lerner, and RD Scheele. 1996. Use of Organic Functional Group Concentrations as a Means of Screening for Energetics. PNNL-10883. Pacific Northwest National Laboratory, Richland, Washington. 


\title{
Appendix A
}

\author{
Preprint
}

Qualitative Determination of Low-Molecular-Weight Organic Acids in Mixed Hazardous Wastes Using Thermospray Liquid Chromatography/Mass Spectrometry 
Qualitative Determination of Low-Molecular-Weight Organic Acids in Mixed Hazardous Wastes Using Thermospray Liquid Chromatography/Mass Spectrometry

K.E. Grant, R.B. Lucke, S.A. Clauss, G. M. Mong, B. D. Lerner, and J.A. Campbell

Advanced Organic Analytical Methods Group,

Pacific Northwest Laboratory**

Richland, WA 99352

Submitted To Journal of Radioanalytical and Nuclear Chemistry

Accepted for publication 
Qualitative Determination of Low-Molecular-Weight Organic Acids in Mixed Hazardous Wastes Using Thermospray Liquid Chromatography/Mass Spectrometry

K.E. Grant(a), R.B. Lucke, S.A. Clauss, G. M. Mong, B. D. Lerner, and

J.A. Campbell(b)

Advanced Organic Analytical Methods Group,

Pacific Northwest Laboratory**

Richland, WA 99352

(a) Associated Western Universities Faculty Member from Columbia Basin College, Pasco, Washington

(b) Author to whom correspondence should be addressed. 


\begin{abstract}
A technique has been developed for the qualitative determination of low-molecular-weight organic acids in radioactive, mixed hazardous wastes using thermospray liquid chromatography/mass spectrometry. A tank waste was analyzed, and the results indicated the presence of citric, glycolic, acetic, and nitrosoiminodiacetic acid (NIDA). Further investigation revealed NIDA was formed under acidic conditions with the reaction of iminodiacetic acid and the high nitrate/nitrite concentration present in the waste.
\end{abstract}


Qualitative Determination of Low-Molecular Weight Organic Acids in Mixed Hazardous Wastes Using Thermospray Liquid Chromatography/Mass Spectrometry

\author{
K.E. Grant ${ }^{1}$, R.B. Lucke, S.A. Clauss, G. M. Mong, B. D. Lerner, and \\ J.A. Campbell* \\ Advanced Organic Analytical Methods Group, \\ Pacific Northwest Laboratory** \\ Richland, WA 99352 \\ INTRODUCTION
}

Approximately 240 and 150 tons of ethylenediaminetetraacetic acid (EDTA) and N-(2hydroxyethyl)ethylenediaminetriacetic acid (HEDTA), respectively, were used in defense-related activities at the U.S. Department of Energy's Hanford site in southeastern Washington state (1). These chelators are now part of the complex mixed wastes, defined as waste containing both hazardous chemicals and radionuclides, found in large storage tanks at Hanford. The chelators form water-soluble complexes with most heavy metals, thereby enhancing the migration of heavy metals in soils. For example, studies at Oak Ridge National Laboratory demonstrated that EDTA caused the low-level migration of ${ }^{60} \mathrm{Co}$ from pits and trenches containing intermediate-level liquid wastes (2). Another study at the Maxey Flats commercial low-level-waste disposal site revealed migration of Pu-EDTA and ${ }^{60}$ Co-EDTA complexes (3). In addition, after approximately 40 years of storage under radiolysis and favorable conditions for chemical degradation, chelator fragments may have formed with equivalent or additional complexing capability. Recent studies with simulated wastes indicate chelator degradation is, in fact, quite vigorous $(4,5)$. As a result, the presence of chelators and their degradation products is an important consideration when handling and storing mixed wastes.

The Hanford site has 177 high-level waste storage tanks. Of these, 23 tanks are being watched closely because of the possibility that flammable-gas mixtures may be produced from the mixed waste contained in the storage tanks. One tank in particular, Tank 241-SY-101 (Tank SY101), has exhibited episodic releases of flammable gas mixtures since its final filling in the early 1980s. Studies of simulated waste mixtures (SWM) have indicated that chelator concentration influences gas generation and retention. It was postulated that the chelators form hydrophobic surfaces on solids in the SWM. These hydrophobic surfaces are more conducive to bubble attachment, leading to flotation of the solids and eventually crust formation (6). The presence of chelators becomes very important for understanding crust formation and gas release. In addition, among the degradation products of the chelators are a number of smaller organic acids, some of which may be linked to the production of flammable gases such as hydrogen. 
The usual method of analysis for organic acids is by capillary gas chromatography (GC) with or without mass spectrometry (MS) after solvent extraction and derivatization. Derivatization techniques that have been used include reaction with diazomethane to form methyl esters, reaction with boron trifluoride $\left(\mathrm{BF}_{3}\right)$ /methanol to form methyl esters, and reaction with trimethylsilyl reagents to produce trimethylsilyl esters $(7,8)$. High performance liquid chromatography (HPLC) is a routine method for the rapid analysis of short-chain organic acids. Organic acids have been analyzed using normal phase silica separation $(9,10)$, but more frequently they have been separated underivatized $(11,12)$, or as their phenacyl derivatives (13). High performance liquid chromatography using cation-exchange columns eluted with dilute acid and ultraviolet (UV) detection at $210 \mathrm{~nm}$ has been used (14). However, this method lacks specificity because any UVabsorbing interference may also be detected at the same time. Urinary organic acids have been analyzed by plasmaspray liquid chromatography (LC)/MS (15). Mixtures of organic acids have also been analyzed by ion-exclusion partition chromatography/MS (16).

In this study, a method for the qualitative analysis of low-molecular-weight organic acids in mixed hazardous wastes was developed using thermospray LC/MS. Analysis using LC/MS shows some advantages over GC analysis since derivatization is not required, and the non-volatile inorganic species do not have to be removed as long as they are soluble in the mobile phase. The acids investigated were oxalic acid, $\mathrm{N}$-nitrosoiminodiacetic acid (NIDA), citric acid, tartaric acid, gluconic acid, glyoxylic acid, glycolic acid, formic acid, and acetic acid. The acid standards were analyzed after passing through the analytical column using thermospray LC/MS. The ions observed in some cases were either $(\mathrm{M}+\mathrm{H})^{+}$or $(\mathrm{M}+\mathrm{H}+18)^{+}$for the organic acids. A standard mixture of these acids was used to determine conditions suitable for maximum separation. Calibration curves were prepared to check for linearity of response.

A synthetic waste sample containing nitrate, nitrite, $\mathrm{NaOH}, \mathrm{EDTA}, \mathrm{HEDTA}$, and citrate was spiked with standard acids to determine the detection limits of the analytes. A waste sample from Tank SY-101 was analyzed using thermospray LC/MS and an acidic mobile phase. The results indicated the presence of citric, glycolic, NIDA, and acetic acids.

Nitroso compounds are well-known carcinogens (17) and may often be formed under acidic conditions by the reaction of amines and nitrites, particularly in foods such as beer (18) and cured meats (19). The presence of nitroso compounds in tank waste would present additional health hazards and disposal problems. To confirm the presense of nitroso compounds, the tank waste was analyzed using thermospray LC/MS and a basic mobile phase. Results of the analysis 
of the tank waste under basic conditions indicated NIDA was an artifact from exposure of the sample to acidic conditions in our preparation and separation procedures to identify chelator fragments. Thus, thermospray LC/MS has helped determine that nitroso compounds are not native to the wastes in large concentrations and has proven to be invaluable in characterizing these complex materials.

\section{EXPERIMENTAL SECTION}

\section{$\underline{\text { Reagents }}$}

Gluconic, sulfuric, formic, acetic, phosphoric, and hydrochloric acids were obtained from Aldrich (Milwaukee, WI). Gluconic acid was in the form of the potassium salt. Formic acid and acetic acid were diluted from the concentrated acid reagents. Tartaric acid and hexanoic acid were obtained from Chemical Services (West Chester, PA). The sulfuric, acetic, phosphoric, and hydrochloric acids used in preparing the mobile phases were diluted from the concentrated acid reagents. Milli-Q (Millipore Corp., Bedford, MA) water was used for all dilutions. NNitrosoiminodiacetic acid was synthesized in the following manner.

\section{Synthesis of N-Nitrosoiminodiacetic Acid}

To a 500-mL, 4-necked flask, equipped with an overhead stirrer, an addition funnel, and a thermometer, were added $26.6 \mathrm{~g}$ ( 200 mmoles) of iminodiacetic acid (Aldrich) and $200 \mathrm{~mL}$ of $1 \mathrm{M}$ phosphoric acid. The contents of the flask were heated to $50^{\circ} \mathrm{C}$, and a solution of $27.6 \mathrm{~g} \mathrm{(} 400$ mmoles) of sodium nitrite in $60 \mathrm{~mL}$ of water was added dropwise. The reaction was then stirred for $1 \mathrm{~h}$ and extracted with five 100-mL portions of diethyl ether. The ethereal extract was dried $\left(\mathrm{MgSO}_{4}\right)$ and concentrated to yield a yellowish-white residue, which after recrystallization from ethyl acetate-hexane afforded $13 \mathrm{~g}$ of NIDA. N-nitrosoiminodiacetic acid was methylated using $\mathrm{BF}_{3} /$ methanol, and the resulting methyl ester was analyzed using GC/MS (7,8). Accurate mass measurements of the methylated NIDA using a high resolution mass spectrometer (JEOL SX-102/ $\mathrm{SX}-102$ ) indicated the structure to be $\mathrm{C}_{6} \mathrm{H}_{10} \mathrm{O}_{5} \mathrm{~N}_{2}$, which is the elemental formula for methylated NIDA. The structure for NIDA is shown below: 


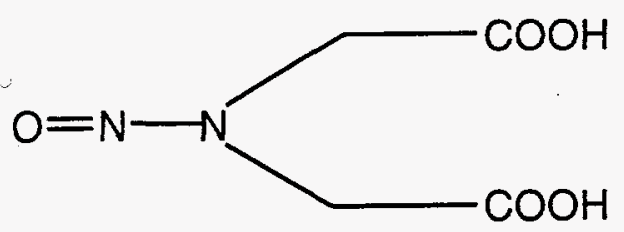

NIDA

\section{Instrument Conditions}

\section{LC/MS}

A Bio-Rad HPLC organic acids column, Aminex Ion Exclusion, HPX-87H, 300 X 7.8 $\mathrm{mm}$, with compatible guard column was used. The mobile phase for this part of the work was $0.001 \mathrm{~N} \mathrm{HCI}$ (isocratic). The LC oven temperature was $40^{\circ} \mathrm{C}$, and the flow rate was $0.6 \mathrm{~mL} / \mathrm{min}$. A typical run time was approximately $25 \mathrm{~min}$. Standards of organic acids were analyzed after introduction onto the analytical column. A mixture of organic acids was also analyzed after separation by the analytical column.

The thermospray analyses were performed using the HP 5988A LC/MS in the isocratic mode. The ion source was $275^{\circ} \mathrm{C}$, and the stem initial temperature was $100^{\circ} \mathrm{C}$. Typical values for the tip and the vapor were $230^{\circ} \mathrm{C}$ and $272^{\circ} \mathrm{C}$, respectively. Filament operation was in both the onand-off modes. The multiplier voltage was $2500 \mathrm{~V}$, and the scan range was either 80 to 500 or 90 to $300 \mathrm{amu}$, depending on the mixtures being analyzed. The injection volume was either $10 \mu \mathrm{L}$ or $20 \mu \mathrm{L}$, depending on the concentration of the sample.

The instrument was tuned with polyethylene glycol (PEG) tuning solution to give maximum abundance of ions. It should be noted that the thermospray ion source should be cleaned approximately once a week to remove nonvolatile chloride salts resulting from the use of $\mathrm{HCl}$ as the mobile phase. Also, since $\mathrm{HCl}$ possesses corrosive effects on metal surfaces, water was flushed through both the HPLC and thermospray system at the end of the day. As long as these cleaning and flushing procedures were followed, no detrimental effects of the thermospray or chromatographic equipment were observed. 
Waste Sample Analysis

The waste sample represented a composite of several segments of actual waste obtained by core drilling the waste in Tank SY-101. This material was radioactive, contained a high concentration of nitrate and nitrite, and the $\mathrm{OH}^{-}$concentration was $2 \mathrm{M}$. The total organic carbon (TOC) was 1.1 to $1.5 \%$.

An aqueous extract of the waste sample was passed through a Bio-Rad Analytical Grade Cation Exchange column (AG 50W-X8, 50-100 mesh, sodium form) in a remote handling hot cell, which removed almost all of the radioactivity due to primary fission products in the waste, before being transferred to the instruments for analysis. The cation exchange process reduces the radioactivity levels by as much as 1000 -fold without removal or introduction of any organic carbon (20). The hot cell facilities are used to prepare (e.g. sample dissolution, dilution, and solvent extraction), and occasionally, to analyze nuclear wastes. For highly radioactive wastes (e.g. 3-11 $\mathrm{R} / \mathrm{h}$ ), the hot cell must be used. This room is composed of thick walls $(\approx 1.3 \mathrm{~m}$ ) equipped with a sample entry port, viewing windows (leaded glass and oil-filled), and remote manipulators, which are operated by a highly-trained specialist. When a radioactive sample is processed in the hot cell, the procedure is both time consuming and difficult. Sample turnaround is much lower when using the hot cell facilities. Wastes with low-to-moderate specific or total radioactivity, $\leq 1 \mathrm{R} / \mathrm{h}$, may be prepared and analyzed outside the hot cell in a radiation hood or glove box. The actual cutoff levels that differentiate lab bench work, glove box work, and hot cell work are usually site specific based upon local practice or the judgment of the resident health physicist.

After removal from the hot cell, a 1-g aliquot of the waste sample was weighed and placed in a $25.0-\mathrm{mL}$ volumetric flask. The sample was then neutralized with $6 \mathrm{~N} \mathrm{HCl}$ to the $\mathrm{pH}$ of the mobile phase using an Orion extended-scale $\mathrm{pH}$ meter. The solution was then diluted to volume using Milli-Q water. An aliquot of the solution was filtered into a $\mathrm{LC}$ vial using a Gelman Acrodisc LC13, $0.45-\mu \mathrm{m}$ syringe-tip filter. Approximately $20 \mu \mathrm{L}$ was used for HPLC or thermospray LC/MS analysis.

\section{$\underline{\text { Basic Conditions }}$}

An aliquot of the aqueous fraction removed from the hot cell was analyzed directly without the addition of acid. The waste sample was analyzed using thermospray LC/MS under basic conditions using ammonium carbonate as the mobile phase at $\mathrm{pH} 10$. The thermospray 
conditions were the same as indicated above. A Dionex AS4A anion exchange column was used with a flow rate of $0.7 \mathrm{~mL} / \mathrm{min}$.

\section{RESULTS AND DISCUSSION}

$\underline{\text { HPLC }}$

Several different mobile phases were investigated to see which would give the best separation of the acids. Among these were $0.01 \mathrm{~N} \mathrm{H}_{2} \mathrm{SO}_{4}, 0.1 \mathrm{~N} \mathrm{HC}_{2} \mathrm{H}_{3} \mathrm{O}_{2}, 0.01 \mathrm{M}$ and 0.001 $\mathrm{N} \mathrm{HCI}$, and $0.1 \mathrm{~N} \mathrm{H}_{3} \mathrm{PO}_{4}$. All showed substantial separation of the organic acids, but the last three mobile phases listed above tended to show tartaric acid as a shoulder on the citric acid peak and/or glyoxylic acid as a shoulder on the gluconic acid peak. This may not present much of a problem since neither tartaric acid nor gluconic acid are likely to be constituents of real waste. As shown in Figure 1, $0.01 \mathrm{~N} \mathrm{H}_{2} \mathrm{SO}_{4}$ gave a good separation of all of the acids under the instrument conditions stated earlier. All of the acids can be detected except for hexanoic, a straight-chain monocarboxylic acid that is not very soluble in water. The aldehyde function on glyoxylic acid is labile, oxidizing readily to produce oxalic acid. If quantitation is desired, this standard should be made up daily. The very large peaks at the beginning of the chromatogram may be due to nitrates, etc. Bicarbonate is also present in the sample, which could give rise to a carbonic acid peak.

\section{Thermospray LC/MS}

The mobile phase selected for thermospray LC/MS was $0.001 \mathrm{~N} \mathrm{HCI} \mathrm{because} \mathrm{it} \mathrm{is}$ considerably more volatile than $0.01 \mathrm{~N} \mathrm{H}_{2} \mathrm{SO}_{4}$. A mobile phase of $0.001 \mathrm{~N} \mathrm{HCI}$ has been used with some success by Pacholic et al. in characterizing mixtures of organic acids by ion-exclusion partition chromatography-mass spectrometry (16). Water is flushed through the entire system at the end of each day to prevent damage to instrument components from the HCI.

Figure 2 shows the mass spectrum of citric acid after passing through the column and into the thermospray system. The base ion is at $\mathrm{m} / \mathrm{z} 131$; the $(\mathrm{M}+\mathrm{H})^{+}$at $\mathrm{m} / \mathrm{z} 193$ is also observed. Other organic acids show ions at various combinations of $\left(\mathrm{M}+\mathrm{H}+\mathrm{nH}_{2} \mathrm{O}\right)^{+}$. Figure 3 is a mass spectrum of gluceruc acid. For example, acetic acid is readily detectable due to $\mathrm{m} / \mathrm{z} 97$ which appears to be due to $\left(\mathrm{M}+\mathrm{H}+2 \mathrm{H}_{2} \mathrm{O}\right)^{+}$. Table 1 is a list of the ions and relative intensities observed for the organic acids. Large background effects, which may be the result of hydrated chloride species, are a persistent problem if scanning was done at mass values much less than 80 . An ion-suppression column for removing chloride ions would make the detection easier for lowermolecular-weight acids, such as formic acid. 
All of the acids except oxalic acid gave results in positive ion thermospray with the filament either on or off. Oxalic acid has the lowest $\mathrm{pK}_{\mathrm{a}}$ value of all the acids studied and cannot be determined by this method. Table 2 shows the organic acids together with their molecular weights, pka's at room temperature, and the ion used for identification. However, oxalic acid is readily detectable by several other methods, including HPLC, plasmaspray MS (which is similar to thermospray except a plasma discharge is present to assist ionization), and GC/MS after derivatization with butanol/HCI ( 8 ).

\section{Waste Sample}

A total ion thermospray LC/MS chromatogram of an actual waste sample is shown in Figure 4. Figures $5 \mathrm{a}-\mathrm{d}$ are the total ion chromatogram, extracted ion plots of $\mathrm{m} / \mathrm{z} 193$ for citric acid, $\mathrm{m} / \mathrm{z} 95$ for glycolic acid, and m/z 97 for acetic acid, respectively.

Figure $6 \mathrm{a}$ is a mass spectrum of the peak at retention time $8.0 \mathrm{~min}$ in the total ion chromatogram. The thermospray mass spectrum of synthesized NIDA is shown in Figure $6 \mathrm{~b}$. The mass spectra are sufficiently similar to provide supporting evidence for the presence of nitroso compounds in tank waste. However, further research was required to determine whether NIDA was an artifact of the sample preparation and analysis under acidic conditions or whether it exists as a component in the actual waste.

\section{Nitroso Compounds}

Nitroso compounds such as NIDA have been previously identified in the waste samples using derivatization ( $\mathrm{BF}_{3}$ /methanol) $\mathrm{GC} / \mathrm{MS}$, $\mathrm{LC} / \mathrm{MS}$ with an acidic mobile phase, and $\mathrm{LC}$ under acidic conditions. The mass spectrum of the derivatized, synthesized standard was identical to that observed in the GC/MS total ion chromatogram, and the thermospray mass spectrum was identical to that of the major component in the total ion chromatogram. However, in both of these instances, the separation or derivatization involved acidic conditions or reaction with a Lewis acid. Another procedure involved derivatization under basic conditions with a methylating reagent, dimethyl sulfate. Under those conditions, results of the analysis of the derivatized simulated waste spiked with iminodiacetic acid (IDA) indicated the presence of NIDA. Other studies indicated that NIDA was stable under derivatization. Studies by researchers at Georgia Institute of Technology showed that NIDA was a reactive intermediate and could not exist in appreciable quantities under 
basic conditions present in the waste tanks (21). However, our investigations have indicated that this material is generated in acidic media and appears to be stable in extracts from Lewis acids.

To verify the presence of nitroso compounds in the tank waste, a procedure was developed to utilize thermospray LC/MS with ammonium carbonate as the mobile phase $(\mathrm{pH} \approx 10.0)$. Results of analyzing IDA through the analytical column showed a base peak at $\mathrm{m} / \mathrm{z} 134(\mathrm{M}+\mathrm{H})^{+}$ with minor ions at $\mathrm{m} / \mathrm{z} 151\left(\mathrm{M}+\mathrm{NH}_{4}{ }^{+}\right)^{+}$and $152\left(\mathrm{M}+\mathrm{H}+\mathrm{NH}_{4}{ }^{+}\right)^{+}$. This is illustrated in Figure 7a. A thermospray mass spectrum of NIDA under basic conditions is shown in Figure $7 \mathrm{~b}$. A waste sample from Tank SY-101 was analyzed under basic conditions using single ion monitoring at $\mathrm{m} / \mathrm{z} 134,151$, and 152 for IDA and $\mathrm{m} / \mathrm{z} 180$ for NIDA. The total ion chromatogram is shown in Figure $8 \mathrm{a}$. The mass spectrum of the peak at retention time 5.0 is shown in Figure $8 \mathrm{~b}$. The results indicated the presence of IDA; a minor component at $\mathrm{m} / \mathrm{z} 180$, possibly indicative of NIDA, was present at approximately $5 \%$.

The thermospray LC/MS results clearly indicate that the nitroso compounds identified in the derivatization GC/MS total ion chromatograms and LC chromatograms under acidic conditions are artifacts of the derivatization and separation processes. The nitroso compounds are formed under acidic conditions by the reaction of an analyte with a free active amine hydrogen, as in the case of IDA and ethylenediaminetriacetic acid, with available nitrite present in the waste samples.

\section{CONCLUSIONS}

High performance liquid chromagraphy and thermospray LC/MS procedures developed for analyzing low-molecular-weight organic acids in mixed hazardous wastes have proved successful in detecting the presence of acids in both synthetic and actual waste samples. The acids were separated and the response was very good, even at low concentrations, except for hexanoic acid, which is not very soluble in water, and oxalic acid, which responds well in HPLC but gives no response in positive-ion thermospray. Since a number of these acids, especially glycolic acid, have been difficult or impossible to separate by GC procedures, these methods show considerable promise.

\section{ACKNOWLEDGMENT}

This work was supported by the Department of Energy under contract DE-AC06-76RLO 1830. Pacific Northwest Laboratory is operated by Battelle Memorial Institute. The authors would like to thank Karen Wahl and Roger Bean for helpful suggestions. The authors would also 
like to acknowledge Westinghouse Hanford Company for support of this work. In addition, the authors would like to thank Rick Steele, John Rau, and Vaughn Hoopes of the hot cell facilities. 


\section{REFERENCES}

1. Metcalf, S.G. Determination of EDTA and HEDTA in Hanford Defense Waste by High Performance Liquid Chromatography, RHO-SA-218, 1991, Rockwell Hanford Operations, Richland, Washington, pp. 1-32.

2. Means, J.L.; Crerar, D.A.; Duguid, J.O. Science. 1978, 200, 1477-1482.

3. Toste, A.P.; Myers, R.B. "The Relation Contributions of Natural and Waste-Derived Organics to the Subsurface Transport of Radionuclide." In: The Effects of Natural Organic Compounds and of Micororganisms on Radionuclide Transport, 1986, pp. 57-76, RWM-6, Radioactive Waste Management Committee, OECD Nuclear Energy Agency, Paris, France.

4. Toste, A.P. J. Radioanaly. Nuc. Chem. 1992, 161, 549-559.

5. Strachan, D.M. Minutes of the Tank Waste Science Panel, PNL-8278, March 25-27, Denver, Colorado, pp. K.1-K.75.

6. Bryan, S.A.; Pederson, L.R.; Scheele, R.D. Synthetic Waste Studies Final Report $\mathbf{2}$ 1992, PNL-8169, Pacific Northwest Laboratory, Richland, Washington, pp. 1-103.

7. Lucke, R. B.; Campbell, J.A.; McKeeta, K.L.; Clauss, S.A. "Analysis of Chelator and Chelator Fragments in Mixed Hazardous Wastes by Derivatization GC/MS." In: Proceedings of the 39th ASMS Conference on Mass Spectrometry and Allied Topics, May 19-24, 1991, Nashville, Tennessee.

8. Campbell, J.A.; Clauss, S.A.; Grant, K.E.; Hoopes, V.; Lerner, B.D.; Lucke, R.B.; Mong, G.M.; Rau, J.; Steele, R. Flammable Gas Safety Program, Analytical Methods Development: FY 1993 Progress Report ${ }_{2}$ PNL-9062, Pacific Northwest Laboratory, Richland, Washington.

9. Schwarzenbach, R. J. Chromatogr. 1980, 202, 397-401.

10. Hara, S.; Dobashi, Y.; Oka, K. J. Chromatogr. 1982, 239, 677-682.

11. Distler, W. J. Chromatogr. 1978, 152, 250-253. 
12. Libert, B. J. Chromatogr. 1981, 210,540-542.

13. Engfelhardt, H.; Elgass, H. J. Chromatogr. 1982, 249, 183-188.

14. Bennett, M.J.; Bradley, C.E. Clin. Chem. 1984, $\underline{30}$, 542-545.

15. Mills, G.A.; Walker, V.; Clench, M.R.; Parr, V.C. Biomedical and Environmental Mass Spectrometry. 1988, 16, 259-261.

16. Pacholec, F.; Eaton, D.R.; Rossi, D.T. Anal. Chem. 1986, 58, 2581-2583.

17. Magee, P.N.; Barnes, J.M. Adv. Cancer Res. 1967, 10, 163.

18. Sen, N.P.; Seaman, S. J. Assoc. Off. Anal. Chem. 1981, 64, 933-8.

19. Harvey, D.C.; Fazio, T.; Howard, J.W. J. Assoc. Off. Anal. Chem. 1978, 61, 1374-8.

20. Campbell, J.A.; Stromatt, R.W.; Smith, M.R.; Koppenaal, D.W.; Bean, R.M.; Jones, T.E.; Strachan, D.M.; Babad, H. Anal. Chem. 1994, 66, 1208A-1215A.

21. Ashby, E.C.; Barefield, E.K.; Liotta, C.L.; Neumann, H.M.; Boatright, D.; Doctorvich, F.; Deshpande, A.; Yao, C.F. "Mechanisms of the Chemical Decomposition of Complexants in Hanford HLW Simulants." Presented at the 208th American Chemcial Society National Meeting, Washington, D.C., August 21-25, 1994. 
Table 1. Ions Observed in Thermospray LC/MS and Relative Intensities

Acid

Acetic Acid

Citric Acid

Gluconic Acid

Glycolic Acid

Glyoxylic Acid

Hexanoic Acid

Tartaric Acid $\mathrm{m} / \mathrm{z}$ and Assignment

$97\left(\mathrm{M}+\mathrm{H}+2 \mathrm{H}_{2} \mathrm{O}\right)$

131

149

147

$193(\mathrm{M}+\mathrm{H})$

$125\left(\mathrm{M}+\mathrm{H}-4 \mathrm{H}_{2} \mathrm{O}\right)$

$179\left(\mathrm{M}+\mathrm{H}-\mathrm{H}_{2} \mathrm{O}\right)$

$99\left(\mathrm{M}+\mathrm{H}-3 \mathrm{H}_{2} \mathrm{O}\right)$

$143\left(\mathrm{M}+1-3 \mathrm{H}_{2} \mathrm{O}\right)$

$197(\mathrm{M}+\mathrm{H})$

$95\left(\mathrm{M}+\mathrm{H}+\mathrm{H}_{2} \mathrm{O}\right)$

113

$77(\mathrm{M}+\mathrm{H})$

153

95

113

$92\left(\mathrm{M}+\mathrm{H}_{2} \mathrm{O}\right)$

$135\left(\mathrm{M}+\mathrm{H}+\mathrm{H}_{2} \mathrm{O}\right)$

$99\left(\mathrm{M}+\mathrm{H}-\mathrm{H}_{2} \mathrm{O}\right)$

$117(\mathrm{M}+\mathrm{H})$

$153\left(\mathrm{M}+\mathrm{H}+2 \mathrm{H}_{2} \mathrm{O}\right)$

$151(\mathrm{M}+\mathrm{H})$

91

97
Relative Intensity

$100 \%$

$100 \%$ $33 \%$ $17 \%$ $2 \%$

$100 \%$ $98 \%$ $24 \%$ $22 \%$ $12 \%$

$100 \%$

$12 \%$

$4 \%$

$2 \%$

$100 \%$

$8 \%$

$2 \%$

$100 \%$ $32 \%$ $22 \%$ $6 \%$

$100 \%$ $38 \%$ 
Table 2. Acid Standards Analyzed, Molecular Weights, $\mathrm{K}_{\mathrm{S}}$, and Ion Used for Qualitative Determination

\begin{tabular}{|l|l|l|l|l|}
\hline Acetic Acid & MW & $\underline{\mathrm{T}}$ & $\underline{\mathrm{K}}$ & $\underline{\text { Ion }}$ \\
Citric Acid & 192.13 & $20^{\circ} \mathrm{C}$ & $1.76 \times 10^{-5}$ & 97 \\
& & $1) 7.10 \times 10^{-4}$ & 193 \\
Glycolic Acid & 76.05 & $25^{\circ} \mathrm{C}$ & $1.48 \times 10^{-4}$ & 95 \\
Oxalic Acid & 90.04 & $25^{\circ} \mathrm{C}$ & $1) 5.90 \times 10^{-2}$ & \\
Hexanoic Acid & 116.16 & $25^{\circ}$ & $1.31 \times 10^{-5}$ & 135 \\
$\alpha$ - Tartaric Acid & 150.09 & $25^{\circ} \mathrm{C}$ & $1) 1.04 \times 10^{-3}$ & 151 \\
Formic Acid & 46.03 & $20^{\circ} \mathrm{C}$ & $1.77 \times 10^{-4}$ & \\
Glyoxylic Acid & 74.04 & $25^{\circ} \mathrm{C}$ & $4.6 \times 10^{-4}$ & 95 \\
Gluconic Acid & 196.16 & $25^{\circ} \mathrm{C}$ & $2.5 \times 10^{-4}$ & 125
\end{tabular}




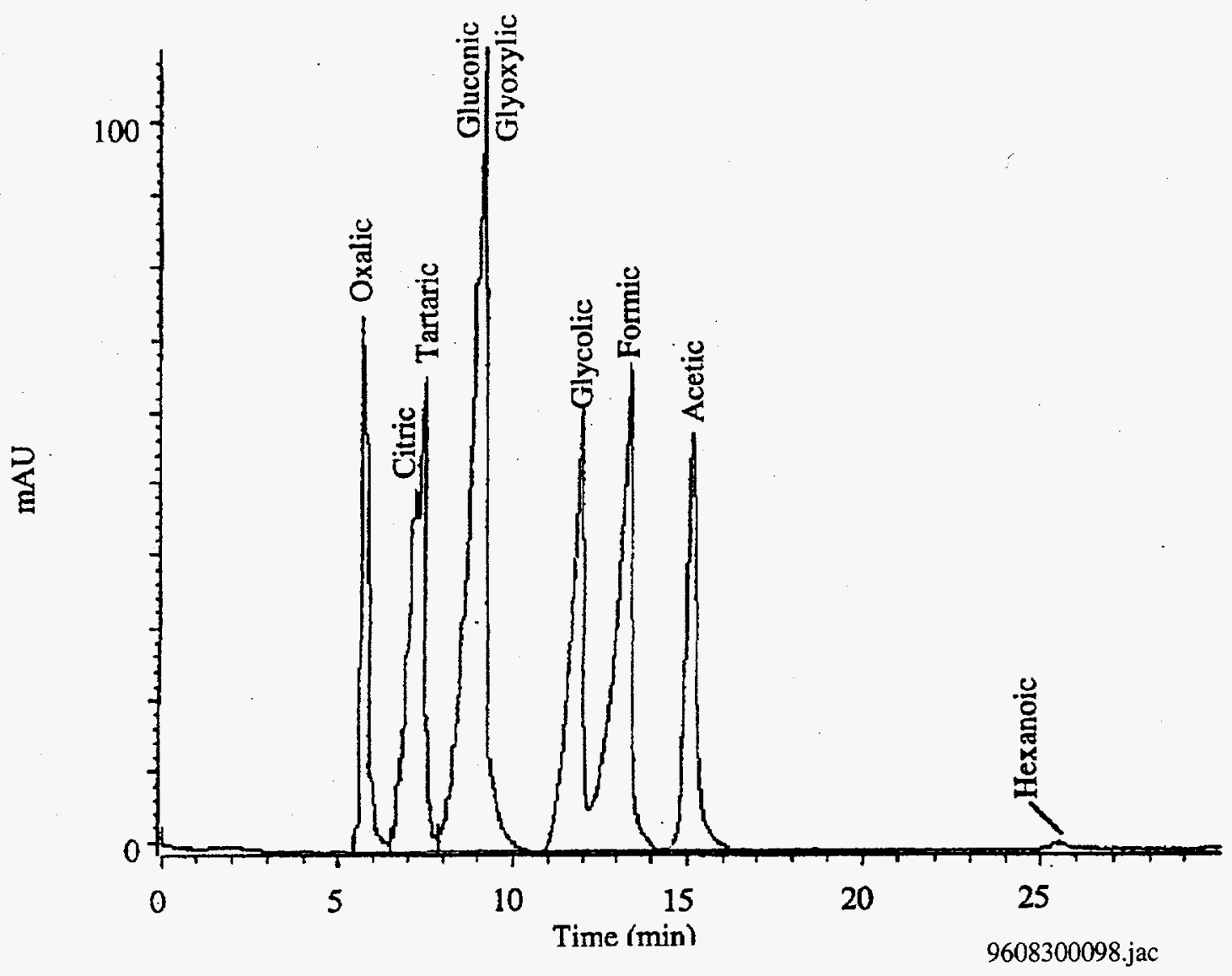

Figure 1. LC Chromatogram of Simulated Waste Spiked with Organic Acids 


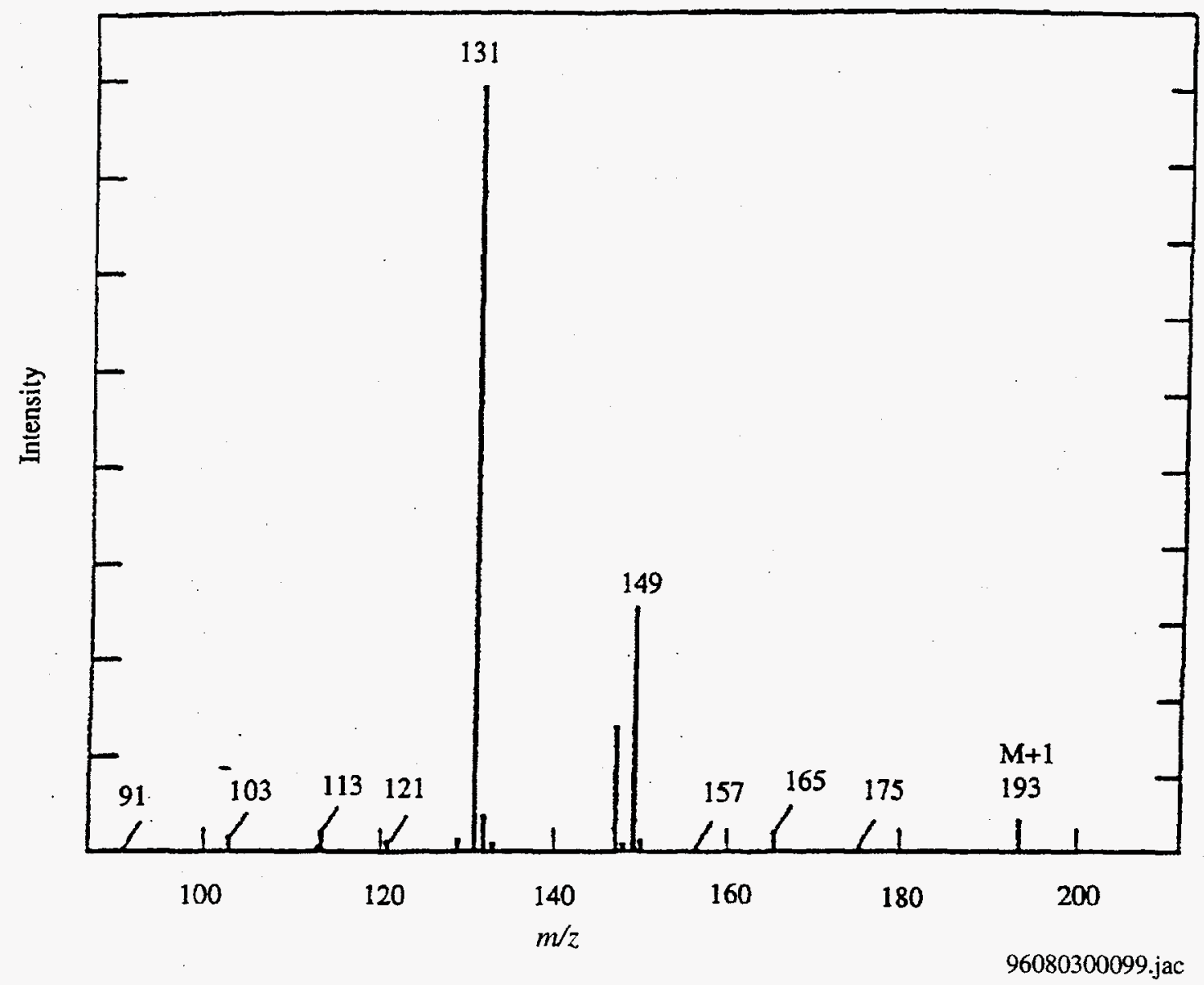

Figure 2. Thermospray Mass Spectrum of Citric Acid 


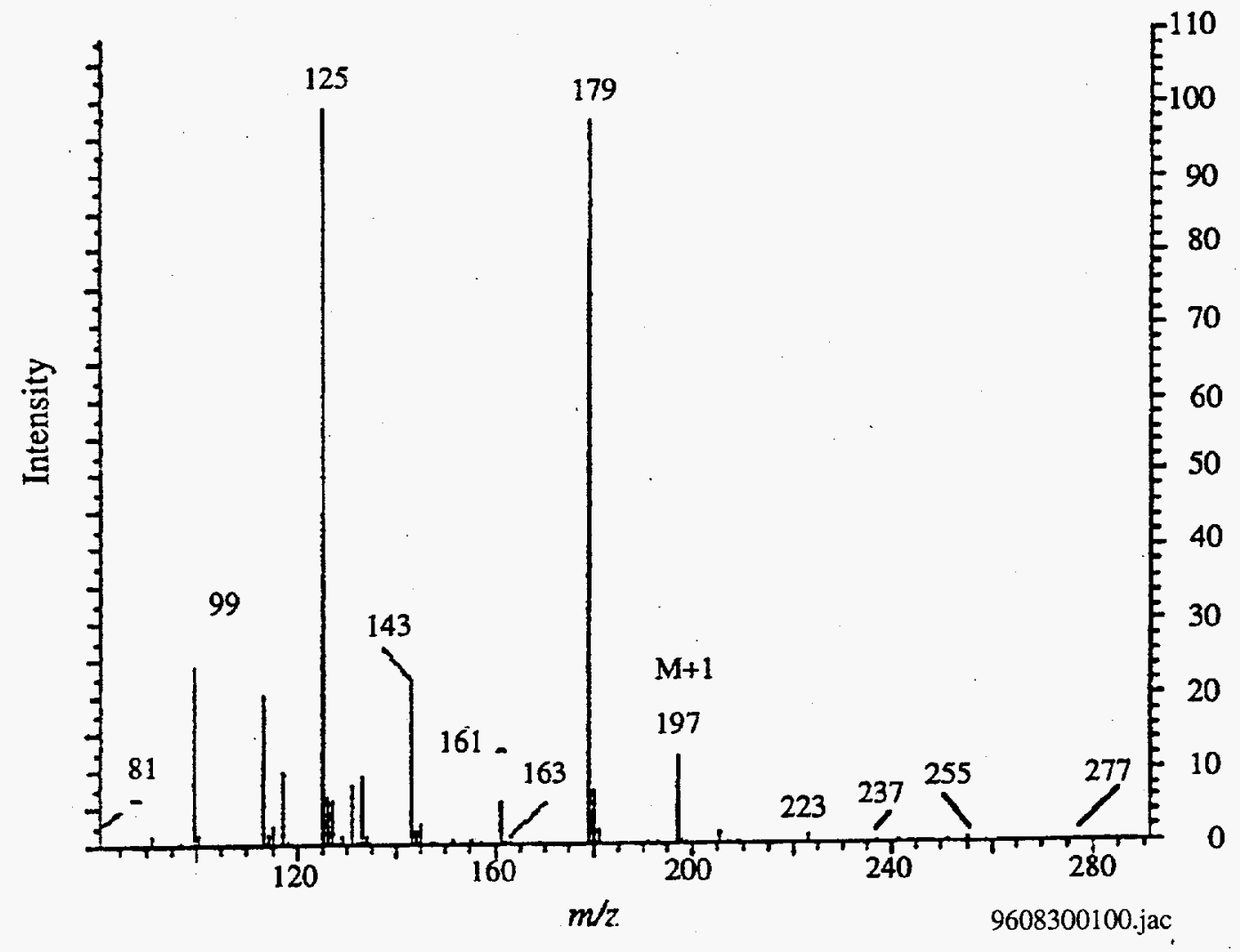

Figure 3. Total Ion Thermospray LC/MS Chromatogram of Tank 101-SY Composite Sample 


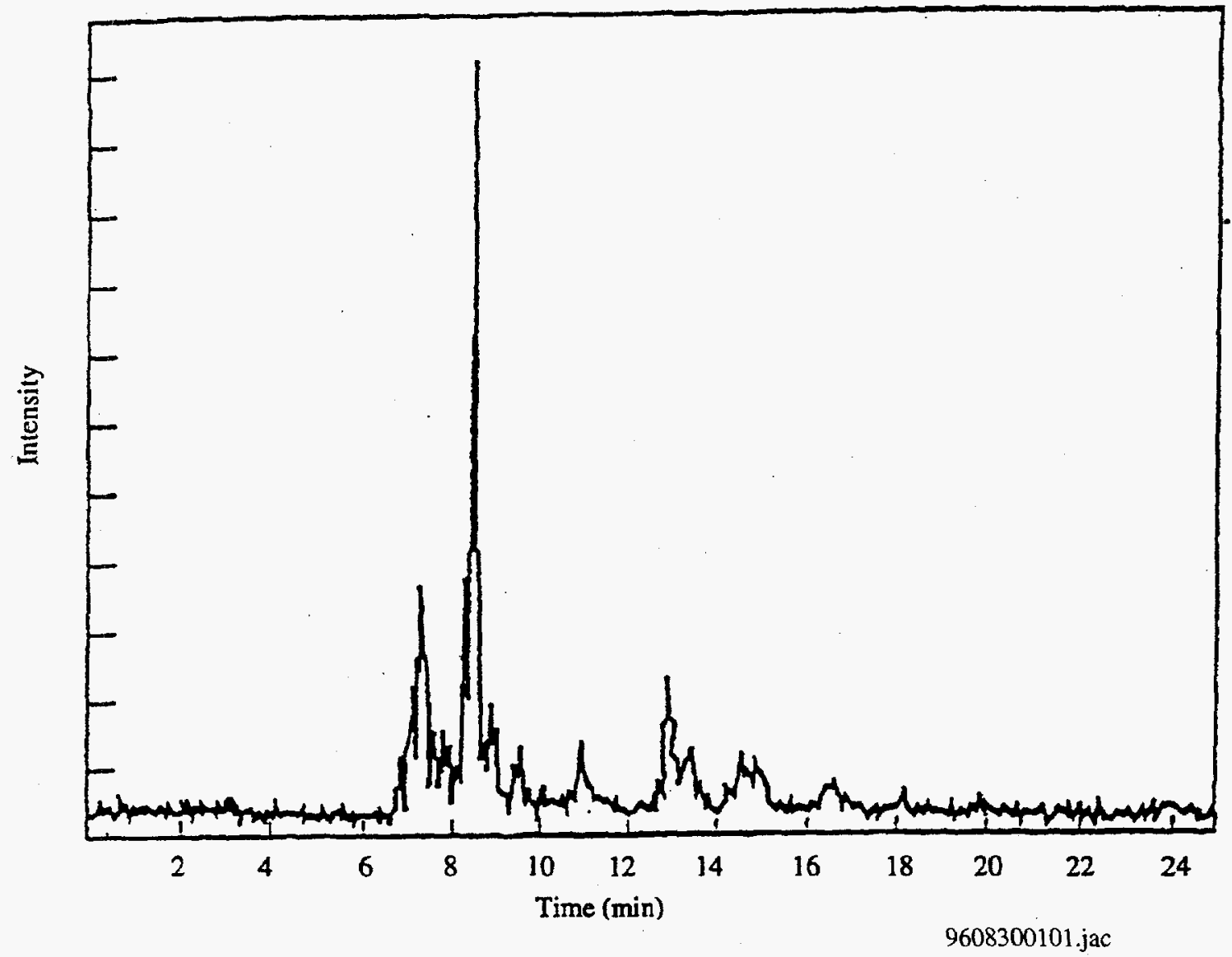

Figure 4. Thermospray LC/MS of (a) Composite Sample, (b) Extracted Ion Plot m/z 193 for Citric Acid, (c) m/z 95 for Glycolic Acid, and (d) m/z 97 for Acetic Acid 
(a)

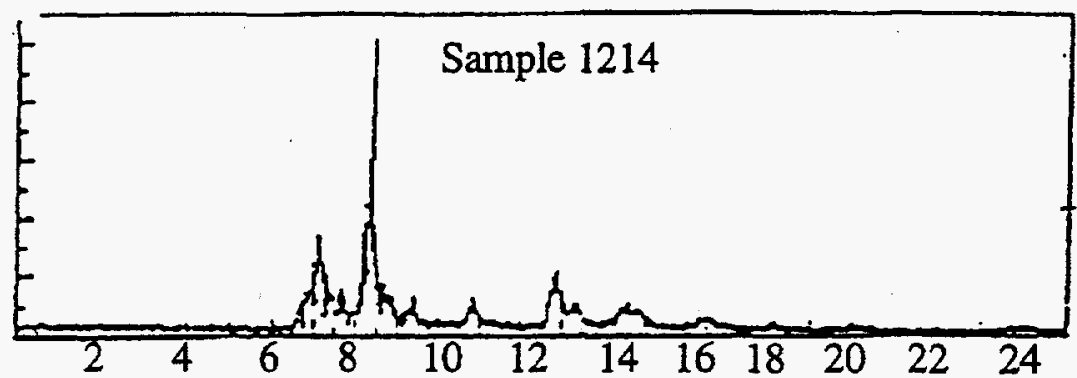

(b)

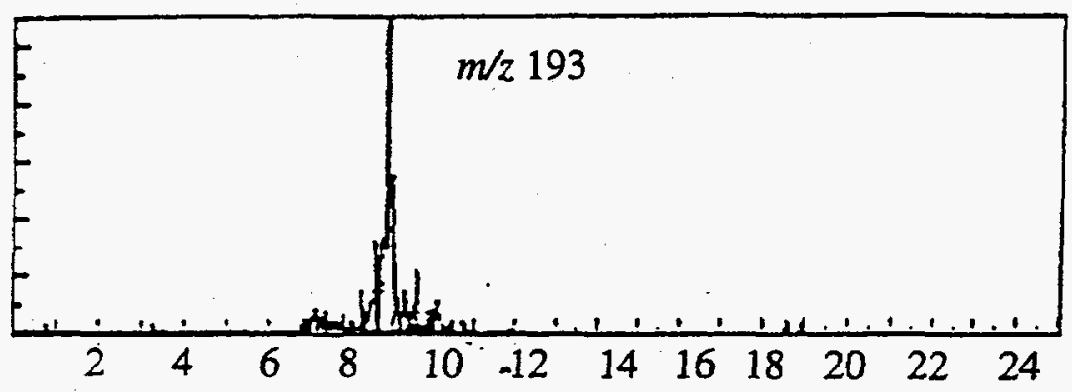

-

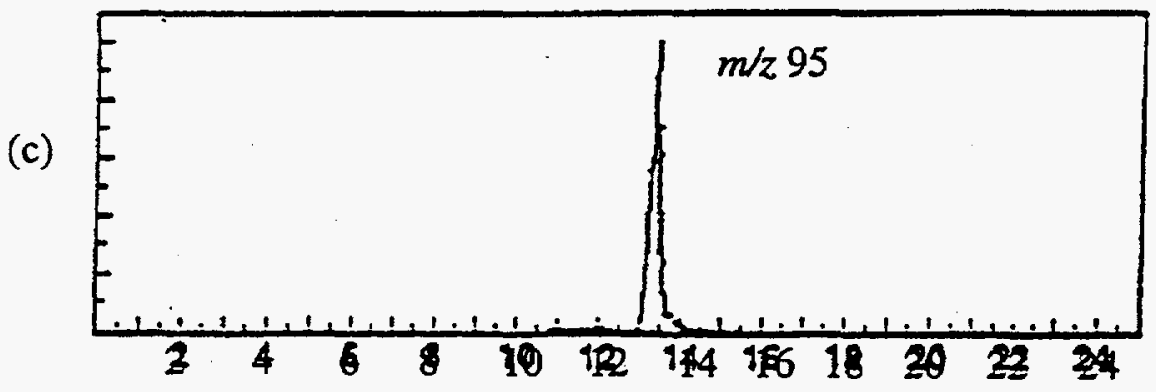

(d)

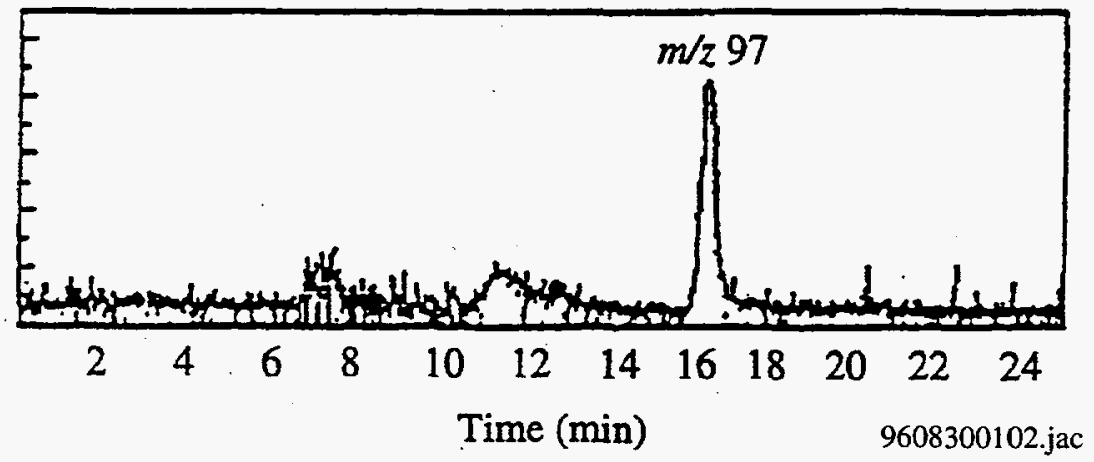

Figure 5. Thermospray Mass Spectrum of (a) Component at Retention Time of $8.0 \mathrm{~min}$ in Figure 4 and (b) Thermospray Mass Spectrum of NIDA 

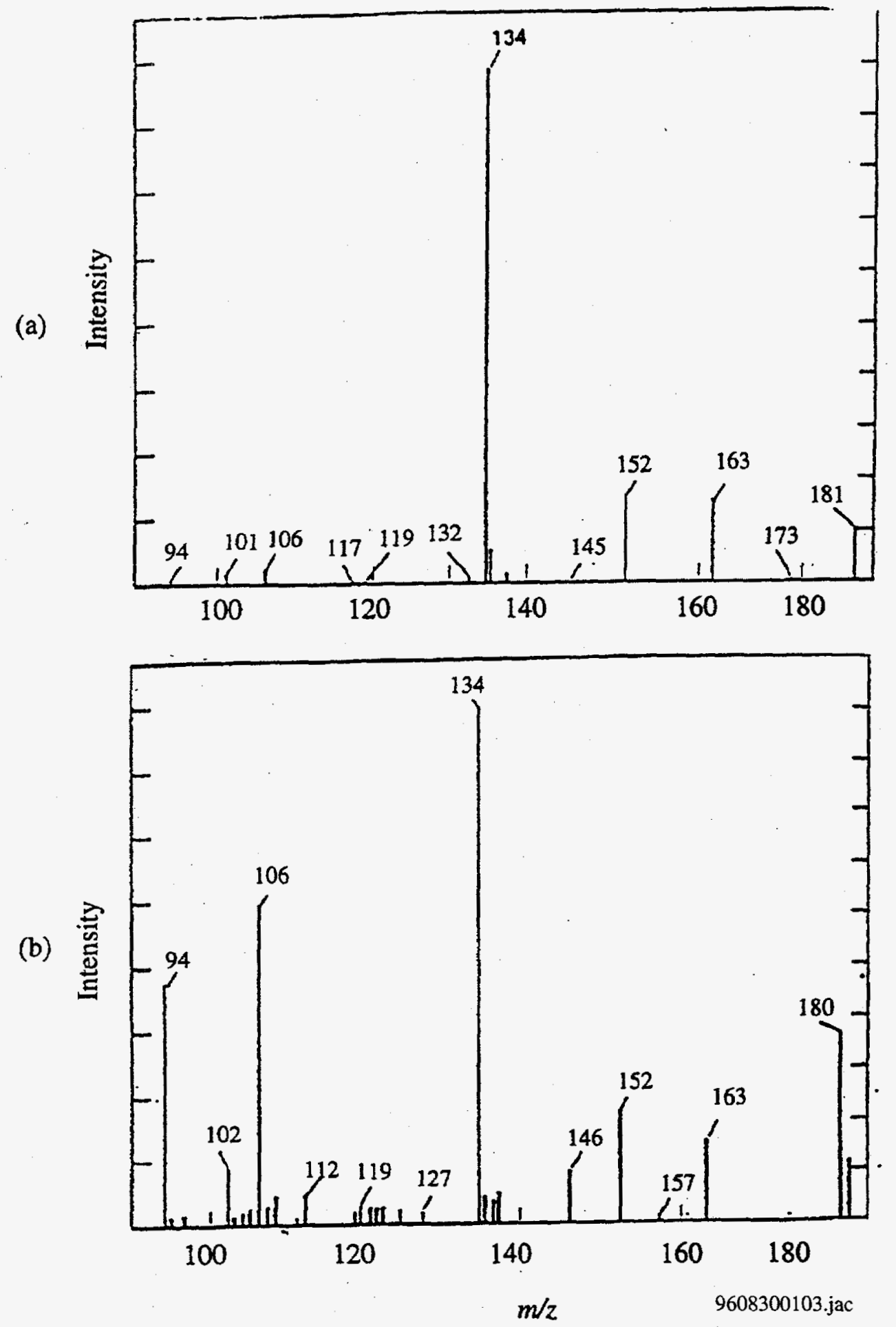

Figure 6. Thermospray Mass Spectrum Obtained Using a Basic Mobile Phase of (a) IDA and (b) NIDA 

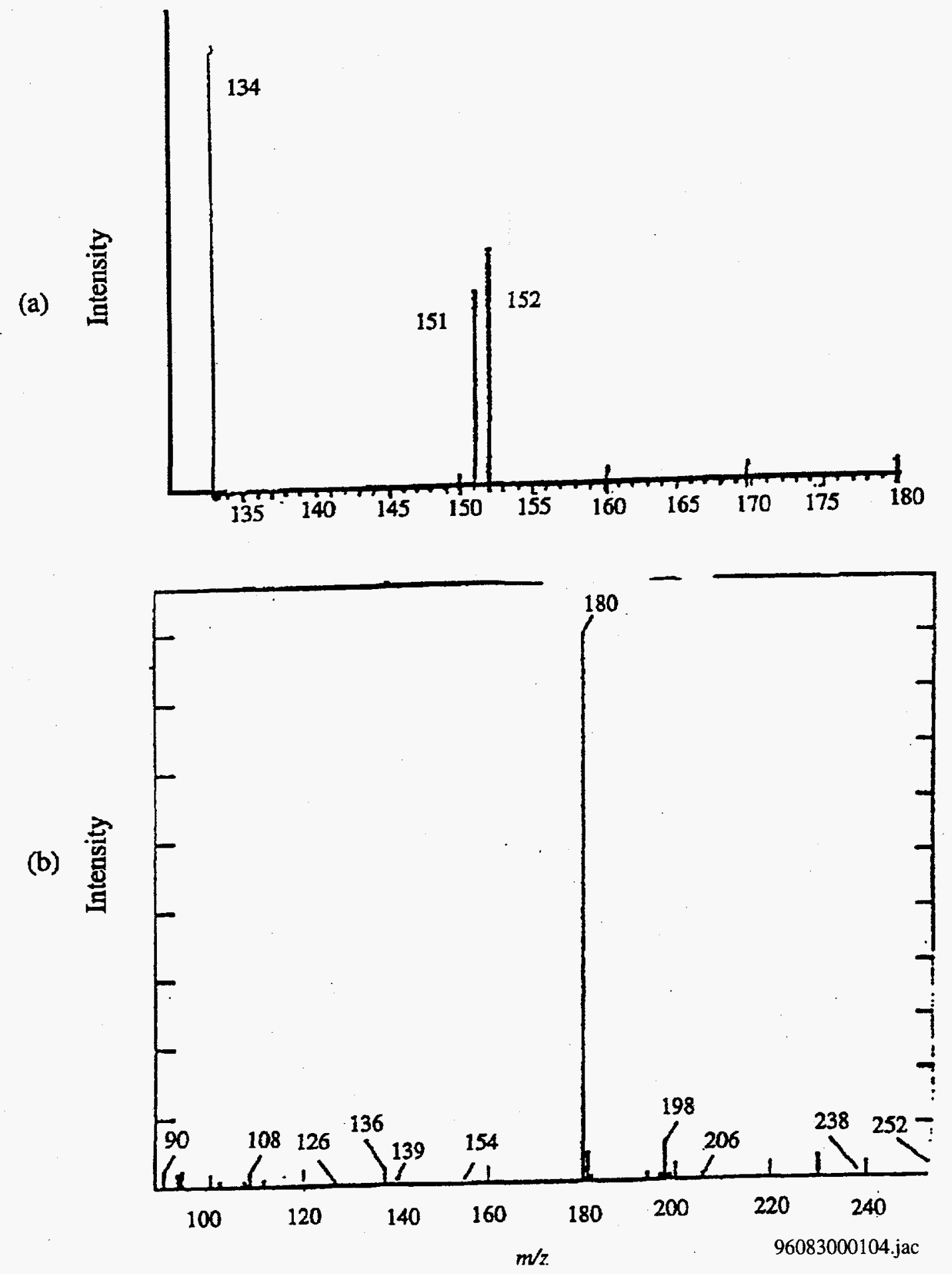

Figure 7. (a) Total Ion Chromatogram of Waste from Tank SY-101 Obtained Using a Basic Mobile Phase and (b) Spectrum of Component at Retention Time of $5.0 \mathrm{~min}$. Obtained Using 
(a)
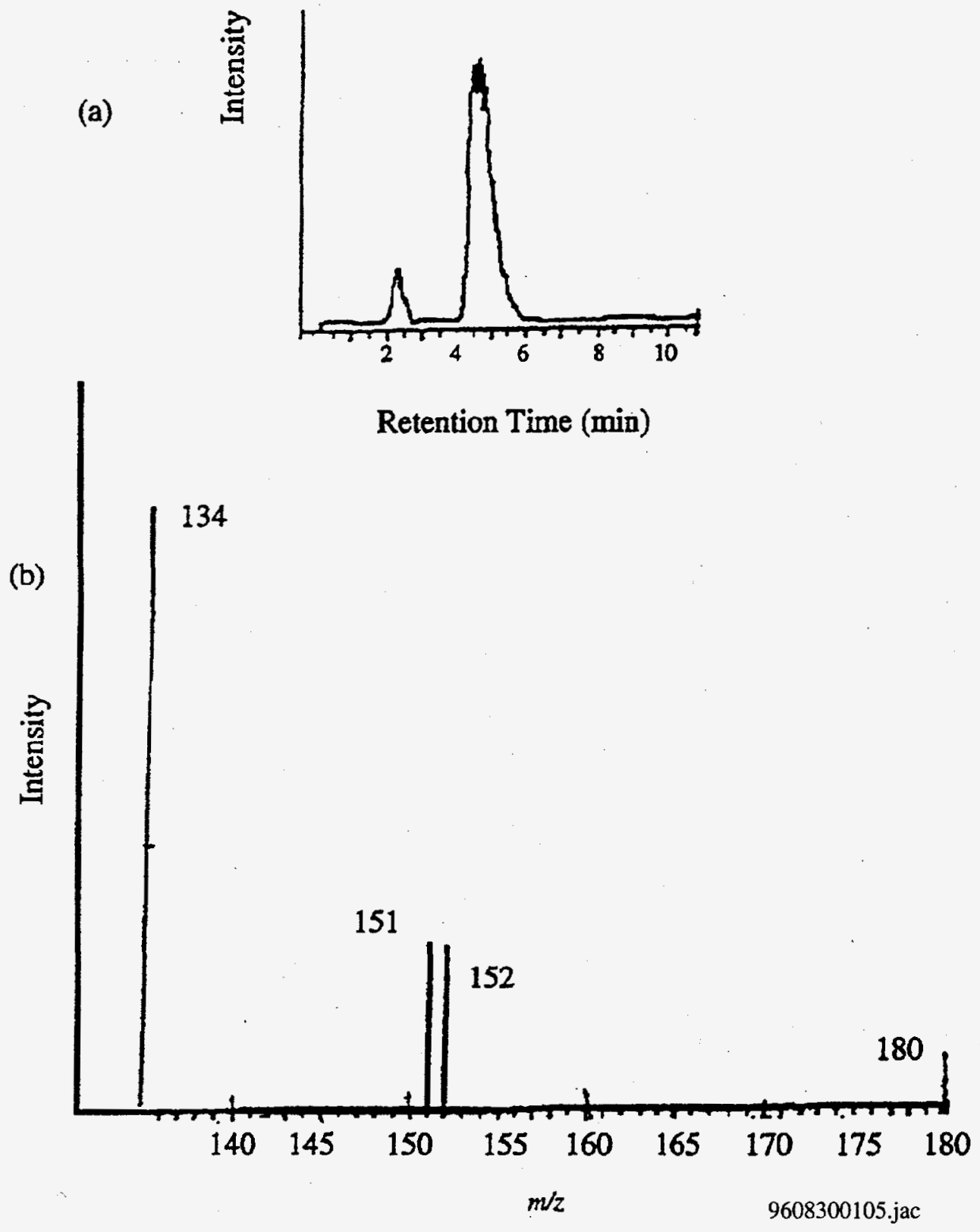

Figure 8. (a) Total Ion Chromatogram Obtained Under Basic Conditions, (b) Mass Spectrum of Peak at Retention Time 5.0 Min 


\section{Appendix B}

\section{Preprint}

DETERMINATION OF CHELATORS AND THEIR DEGRADATION PRODUCTS IN MIXED HAZARDOUS WASTES FROM TANK 241SY-101 USING DERIVATIZATION GC/MS 


\title{
DETERMINATION OF CHELATORS AND THEIR DEGRADATION PRODUCTS IN MIXED HAZARDOUS WASTES FROM TANK 241-SY-101 USING DERIVATIZATION GC/MS
}

\author{
K.E. Grant, G.M. Mong, R.B. Lucke, and J.A. Campbell(a) \\ Pacific Northwest National Laboratory \\ Richland, WA 99352
}

(a) Address correspondence to this author. 


\title{
DETERMINATION OF CHELATORS AND THEIR DEGRADATION PRODUCTS IN MIXED HAZARDOUS WASTES FROM TANK 241-SY-101 USING DERIVATIZATION GC/MS
}

\author{
K.E. Grant, G.M. Mong, R.B. Lucke, and J.A. Campbell(a) · \\ Advanced Organic Analytical Methods Development Group, \\ Pacific Northwest National Laboratory, \\ Box 999 , \\ Richland, WA 99352
}




\title{
QUANTITATIVE DETERMINATION OF CHELATORS AND THEIR DEGRADATION PRODUCTS IN MIXED HAZARDOUS WASTES FROM TANK 241-SY-101 USING DERIVATIZATION GC/MS
}

\author{
K.E. Grant ${ }^{1}$, G.M. Mong, R.B. Lucke, and J.A. Campbell* \\ Advanced Organic Analytical Methods Development Group, \\ Pacific Northwest National Laboratory, \\ Box 999, \\ Richland, WA 99352
}

\begin{abstract}
Considerable attention has been focused on chelators such as ethylene-diaminetetraacetic acid (EDTA) and N-(2-hydroxyethyl)ethylenediaminetriacetic acid (HEDTA), which form watersoluble complexes with most heavy metals. Most radionuclides are included in this class of constituents. As a result, chelator complexes have become very important environmentally because of their tendency to enhance the mobility of heavy metals through the soil and potentially contaminate groundwater. In addition, there is a correlation between chelator concentration and crust formation/gas release.

The chelators are a class of compounds whose low volatility and high polarity preclude analysis by gas chromatography/mass spectrometry (GC/MS) without prior derivatization. Waste samples from a double-shell storage tank at Hanford were derivatized with $\mathrm{BF}_{3} /$ methanol and analyzed using GC/MS. Results indicate the presence of EDTA, HEDTA, nitrilotriacetic acid (NTA), and citric acid. Nitrosoiminodiacetic acid was identified and determined to be an artifact of the derivatization procedure; it is assumed to arise from nitrosation of iminodiacetic acid in the waste sample.
\end{abstract}


1 AWU Faculty Member from Columbia Basin College, Pasco, WA

(a) Address correspondence to this author 


\section{INTRODUCTION}

Chelating compounds such as ethylenediaminetetracetic acid (EDTA), N-(2-

hydroxyethyl)ethylenediaminetriacetic acid (HEDTA), and nitrilotriacetic acid (NTA) are not part of the Environmental Protection Agency's (EPA) list of targeted, hazardous chemicals; nevertheless, they are receiving renewed environmental interest. The structures are shown below.

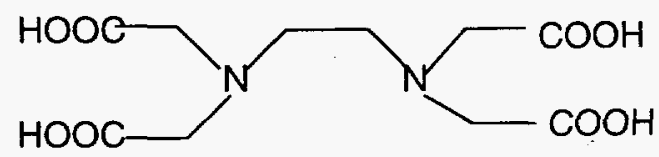

EDTA

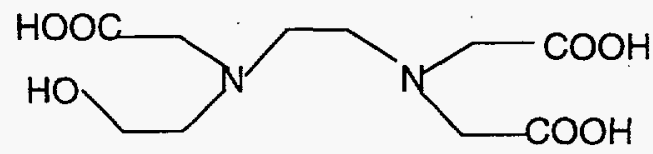

HEDTA

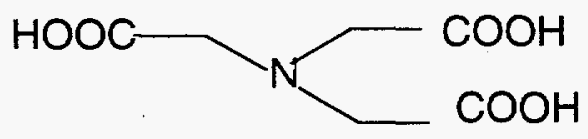

NTA

Large quantities of EDTA and HEDTA (approximately 240 and 1500 tons, respectively) have been used in defense-related activities at the Hanford site in south-eastern Washington State (1). These chelators are now part of the complex mixed wastes found in large storage tanks at Hanford. Mixed waste is defined as waste containing both hazardous chemicals and radionuclides. The chelators form water-soluble complexes with most heavy metals, thereby enhancing the migration of heavy metals in soils. For example, studies at Oak Ridge National Laboratory demonstrated that EDTA caused the low-level migration of ${ }^{60} \mathrm{Co}$ from intermediate-level liquid 
waste disposal pits and trenches (2). Another study at the Maxey Flats commercial low level waste disposal site revealed that Pu-EDTA and ${ }^{60} \mathrm{Co}$-EDTA migrated (3). In addition, after approximately 40 years of storage under radiolysis and favorable conditions for chemical degradation, other chelator fragments may have formed with equivalent or more complexing capability than the starting materials. Recent studies with simulated wastes indicate that chelator degradation is, in fact, quite vigorous (4,5). As a result, the presence of chelators is an important consideration when handling and storing mixed wastes.

The Hanford Site has 177 high-level waste storage tanks. Of these, 25 tanks are being watched closely because of the possibility that flammable gas mixtures will be produced from the mixed waste contained in the storage tanks. One tank in particular, Tank 241-SY-101(Tank SY101), has exhibited episodic releases of flammable gas mixtures since its initial filling in the late 1970s. Studies of simulated waste mixtures (SWM) have indicated that chelator concentration influences gas generation and retention. It was postulated that the chelators form hydrophobic surfaces on solids in the SWM. These hydrophobic surfaces are more conducive to bubble attachment, which causes solids to float and eventually crust to form (6). A knowledge of chelator types and concentration is important for understanding crust formation and gas release.

Several analytical techniques, including gas chromatography/mass spectrometry (GC/MS) and liquid chromatography (LC), have been utilized to analyze chelators. Derivatization GC/MS techniques that have been applied to the analysis of chelators, e.g., EDTA and NTA, include 1) reaction with boron trifluoride $\left(\mathrm{BF}_{3}\right) /$ methanol to form the methyl esters $(7)$ and 2$)$ reaction with propanol/HCl to form the propyl ester (8). Other analytical techniques exist for determining chelators and chelator-type compounds, among them, ion-pair chromatography (IPC) for separation and ultraviolet (UV) absorption of the copper(II) complex for detection (9-11). Another technique used reversed-phase chromatography with amperometric detection (12). Researchers have developed methods using reversed phase chromatography and have also examined several 
chelators, including both EDTA and HEDTA, by thermospray liquid chromatography/mass spectrometry (13). The base peak for most cases in that study was either $(\mathrm{M}+\mathrm{H})^{+}$or $(\mathrm{M}+\mathrm{H}$ $+18)^{+}$, indicative of ammonium adduction. Electrospray mass spectrometry has also been utilized to examine chelators such as EDTA, HEDTA, and NTA in the negative ion mode(14). The base peak in most cases was $(\mathrm{M}-\mathrm{H})^{-}$.

The chelators represent a class of compounds whose polarity and non-volatility preclude direct analysis by GC/MS. The majority of the chelators that were used in the chemical processes at the Hanford Site were organic acids containing one or more amine and/or alcohol functional groups. Over time, exposure to heat as well as chemical and radiolytic processes have degraded some of these compounds to smaller organic acids. Chemical derivatization is required because these compounds are not volatile enough to be determined by GC techniques. Derivatization also improves thermal stability and sensitivity in many cases. A derivatizing reagent, $\mathrm{BF}_{3} /$ methanol, has been used in the analysis of chelators in radioactive mixed hazardous wastes (15-21). Other potential derivatization techniques that have been evaluated include 1) reaction with butanol/ $\mathrm{HCl}$ to form the butyl esters; 2) reaction with diazomethane to form the methyl esters; 3 ) reaction with silylating reagents to form the trimethylsilyl derivatives; and 4) reaction with chloroethanol/HCl to form the chloroethyl esters (22). The most useful method appears to be a reaction with $\mathrm{BF}_{3} /$ methanol, with the other methods giving, at best, modest results. Radioactive waste samples were obtained from Tank SY-101, reacted with boron trifluoride/methanol, and analyzed using GC/MS. The results indicate the presence of EDTA, HEDTA, NTA, and citric acid. Nitrosoiminodiacetic acid (NIDA) was also observed; it is believed to originate from Lewis acid nitrosation reactions involving the nitrite native to the waste and the derivatizing reagent. This observation infers the presence of iminodiacetic acid (IDA) in the waste matrix. In addition, the multiple handling and analysis steps tank wastes are subjected to dictate that rugged surrogate compounds should be investigated that could be added to the matrix at any time past the sampling event to trace any net loss that might occur to the analytes of interest. A synthesis of $\mathrm{d}_{4}$ - EDTA 
(deuterated on the ethylenediamine bridge) was undertaken as a potential stable, non-exchangeable surrogate compound for future application.

\section{EXPERIMENTAL SECTION}

Derivatization of chelator standards, synthesis of deuterated EDTA, procedure for analysis of waste samples, yield experiments, synthesis of NIDA, and instrumental conditions will be discussed.

$\mathrm{BF}_{3} /$ methanol Methylation of Chelator Standards

Approximately $1 \mathrm{~mL}$ of a $12 \%$ w/v solution $\mathrm{BF}_{3} /$ methanol (Aldrich) was added to about 5 $\mathrm{mg}$ of the chelator in a reaction vial, and the mixture was vortexed and heated for varying lengths of time ( 1 to $2 \mathrm{~h}$ ) at $100^{\circ} \mathrm{C}$, depending on the chelator being derivatized. One $\mathrm{mL}$ of chloroform was added to the cooled reaction mixture and vortexed. A buffer solution $\left(0.4 \mathrm{M} \mathrm{KH}_{2} \mathrm{PO}_{4}\right)$ was made, and the $\mathrm{pH}$ was adjusted to 9.5 using sodium hydroxide. When this buffer solution was added to the contents of the vial, the solution separated into two layers, and an aliquot was removed from the chloroform layer for GC/MS analysis. Parent ion assignment was confirmed by using positive ion chemical ionization MS.

Synthesis of $\mathrm{d}_{4}$ - EDTA

Deuterated EDTA (for use as a yield tracer) was synthesized using the method of Vanyólòs (23). To a solution containing $0.25 \mathrm{M}$ chloroacetic acid in cold water was added $0.5 \mathrm{M} \mathrm{NaOH}$. The solution was maintained at less than $5^{\circ} \mathrm{C}$ in ice during the addition, then added dropwise with vigorous stirring to a cold aqueous solution of $0.06 \mathrm{M} \mathrm{d}_{4}$-ethylenediamine (Isotech). The solution was brought to $65^{\circ} \mathrm{C}$ and stirred for $2 \mathrm{~h}$, then acidified (pH 2) with concentrated $\mathrm{HCl}$. The 
resulting white solid (60\% yield) was washed and recrystallized from water. Derivatization using $\mathrm{BF}_{3} /$ methanol (above) yielded material that proved the product to be essentially pure. Dissolution of a sample in $\mathrm{D}_{2} \mathrm{O}$ and $200 \mathrm{MHz}$ proton nuclear magnetic resonance (NMR) revealed only signals attributable to entrained water and proton signals from the attached acetate groups.

Waste Samples

The waste samples represented several segments of actual waste obtained by core sampling the waste in Tank SY-101. This material was highly radioactive and contained high molar concentrations of nitrate and nitrite; the $\mathrm{OH}^{-}$concentration was at least $2 \mathrm{M}$. The total organic carbon (TOC) for these samples was $1.1-1.4 \%$.

For highly radioactive wastes, e.g. $3-11 \mathrm{R} / \mathrm{h}$, a hot cell facility must be used. This room is composed of thick walls $(\approx 1.3 \mathrm{~m}$ ) equipped with a sample entry port, viewing windows (leaded glass and oil-filled), and remote manipulators, which are operated by a highly-trained specialist. When a radioactive sample is remotely handled in the hot cell, the procedure is time consuming, difficult, and requires specialized, deft artistry to complete the tasks. Sample turnaround is much lower when using the hot cell facilities. Wastes with a low-to-moderate total radioactivity level, $\leq$ $1 \mathrm{R} / \mathrm{h}$, may be prepared and analyzed outside the hot cell in a radiation hood or glove box. The actual cutoff levels that differentiate lab bench work, glove box work, and hot cell work is usually based upon local practice or the judgment of the resident health physicist.

Approximately $2 \mathrm{~g}$ of the solids from the composite sample were stirred overnight with 20 $\mathrm{mL}$ of deionized water in a hot cell facility. The solution was then filtered to remove insoluble solids. Most of the radioactivity associated with the sample was removed by cation exchange by allowing the sample to percolate through a bed of AG50W-X8 resin (Biorad), 20-50 mesh, prepared in the sodium form. The resin must not be used in the usual $\mathrm{H}^{+}$form, since the chelator 
analytes tend to precipitate from solution as insoluble free acids when the matrix is exposed to the acid form of the resin. The sodium form of the cation exchange resin is conveniently prepared by stirring the resin with sufficient $6 \mathrm{~N} \mathrm{NaOH}$ until the solution remains basic to $\mathrm{pH}$ paper. The resin is then washed with deionized water. After elution through the cation exchange resin, the net reduction of fission products (chiefly ${ }^{137} \mathrm{Cs}$ and ${ }^{90} \mathrm{Sr}$ ) was sufficient $(2-3 \mathrm{mR} / \mathrm{h}$ per sample) that the sample could be removed from the hot cell environment and safely worked within a protected hood.

Measured aliquots of the sample, representing about $0.25 \mathrm{~g}$ of the original waste sample, were taken to dryness in reactivials (VWR Scientific) at ca. $75^{\circ} \mathrm{C}$ using a gentle stream of dry nitrogen . Two milliliters of a $12 \% \mathrm{BF}_{3} /$ methanol (Aldrich) was added, and the sample was heated to $100^{\circ} \mathrm{C}$ for $1 \mathrm{~h}$. The solution was cooled, and $2 \mathrm{~mL}$ of chloroform were added. The entire solution was then quenched in a vial containing $8 \mathrm{~mL}$ of $0.4 \mathrm{M} \mathrm{KH}_{2} \mathrm{PO}_{4}$ adjusted to $\mathrm{pH}$ 9.5. To ensure that the resulting solution maintained a $\mathrm{pH}$ between 7 and $8, \mathrm{pH}$ paper was used. The vial was vortexed, and the aqueous and chloroform layers were allowed to separate. The chloroform layer, containing the derivatized organics, was retained, and the aqueous layer was discarded. At this point, essentially all of the radioactivity remained with the aqueous layer. The chloroform solution was monitored for radioactivity and then removed for subsequent GC/electron impact MS analysis. The derivatized waste sample was also analyzed using positive ion chemical ionization MS to confirm parent ion assignment.

\section{Total Organic Carbon Measurements}

Total organic carbon was determined using the hot persulfate oxidation method (24). This procedure uses the wet oxidation/extraction method of hot acidic silver-catalyzed persulfate oxidation, followed by measurement of $\mathrm{CO}_{2}$ by coulometry detector. All carbon species, as 
liquids, acid-soluble sludges, or acid-soluble solids, are oxidized to $\mathrm{CO}_{2}$ by the silver-ion catalyzed persulfate reaction.

\section{Recovery Yield Experiments}

To determine the efficiency of the derivatization process in the waste matrix, a waste sample was spiked with a 3-5 fold concentration of chelators (EDTA, NTA, HEDTA) and related organics (citric acid, succinic acid) above the concentration found in the waste samples. An amount of $\mathrm{d}_{4}$ - EDTA similar to the total concentration of EDTA was added to the matrix. The sample was then derivatized as above, and the resulting data were analyzed in terms of net yield of the added chelators and acids.

Synthesis of N-Nitrosoiminodiacetic acid

To a 500-mL, four-necked flask equipped with an overhead stirrer, an addition funnel, and a thermometer were added $26.6 \mathrm{~g}$ ( $200 \mathrm{mmoles}$ ) of IDA (Aldrich) and $200 \mathrm{~mL}$ of $1 \mathrm{M}$ phosphoric acid. The contents of the flask were heated to $50^{\circ} \mathrm{C}$, and a solution of $27.6 \mathrm{~g} \mathrm{(} 400 \mathrm{mmoles}$ ) of sodium nitrite in $60 \mathrm{~mL}$ of water was added dropwise. The reaction was then stirred for $1 \mathrm{~h}$ and extracted with five $100-\mathrm{mL}$ portions of diethyl ether. The ethereal extract was dried $\left(\mathrm{MgSO}_{4}\right)$ and concentrated to yield a yellowish-white residue, which after recrystallization from ethyl acetatehexane afforded $13 \mathrm{~g}$ of $\mathrm{N}$-nitrosoiminodiacetic acid. $\mathrm{N}$-nitrosoiminodiacetic acid was methylated using $\mathrm{BF}_{3}$ /methanol, and the resulting methyl ester was analyzed using GC/MS (7,8). Accurate mass measurements of the methylated NIDA using a high resolution mass spectrometer (JEOL SX$102 / \mathrm{SX}-102$ ) indicated the structure to be $\mathrm{C}_{6} \mathrm{H}_{10} \mathrm{O}_{5} \mathrm{~N}_{2}$, which is the elemental formula for methylated NIDA. The structure for methylated-NIDA is shown below: 


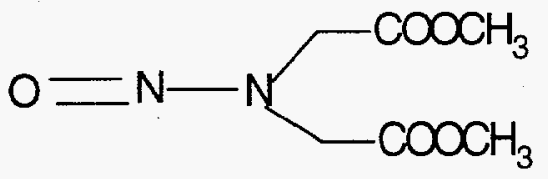

Instrumentation

\section{GC/MS Conditions}

A fused silica column (DB-5, $30 \mathrm{~m} \mathrm{X} 0.25 \mathrm{~mm}$ i.d., $0.25-\mu \mathrm{m}$ film thickness, J \& W Scientific) was used in the splitless mode. The oven temperature was typically programmed in the following manner: $50^{\circ} \mathrm{C}$ for $1 \mathrm{~min}, 8^{\circ} \mathrm{C} / \mathrm{min}$ to $300^{\circ} \mathrm{C}$, and hold at $300^{\circ} \mathrm{C}$ for $5 \mathrm{~min}$. The mass spectrometer was tuned daily with perfluorotributylamine (PFTBA). In these studies, the mass spectrometer was scanned from 50-500 amu and operated in the electron impact mode $(70 \mathrm{eV})$. The source temperature was $200^{\circ} \mathrm{C}$, the injector port temperature was $250^{\circ} \mathrm{C}$, and the interfaces were also at $250^{\circ} \mathrm{C}$.

Chemical ionization was carried out with both methane and isobutane in both positive ion and negative ion chemical ionization modes. The temperature of the source for positive ion chemical ionization MS was $200^{\circ} \mathrm{C}$ and $120^{\circ} \mathrm{C}$ for negative ion chemical ionization. The MS was scanned from 100-600 amu in the negative ion mode and 70-500 in the positive ion mode.

Accurate Mass Measurements

Accurate mass measurements were performed on a JEOL SX-102/SX-102 double-focusing MS equipped with a Unix data system. The instrument was tuned to a resolution of 5000 (10\% valley definition). Data were acquired by scanning over the mass range of 50-500 at a rate of $3 \mathrm{sec}$ per mass decade. Instrument tuning and real-time mass measurements were performed by leaking 
perfluorokerosene into the electron impact ion source from the septum inlet reservoir. Computerassisted accurate mass assignments and subsequent elemental compositions were made on data obtained from averaging four consecutive scans over the gas chromatographic elution profile of the analyte. The instrument was equipped with an HP $5980 \mathrm{GC}$. The GC was fitted with $30 \mathrm{~m} \mathrm{X}$ $0.25 \mathrm{~mm}$ i.d. DB-5 capillary column (J \& W Scientific, Folsom, CA). The GC oven temperature was held at $50^{\circ} \mathrm{C}$ for $2 \mathrm{~min}$., then programmed at $5^{\circ} \mathrm{C} / \mathrm{min}$ to $250^{\circ} \mathrm{C}$.

\section{RESULTS AND DISCUSSION}

The results from derivatization of standards, analysis of tank waste samples, and the use of deuterated surrogates as tracers, and the results of recovery studies will be discussed.

In the reaction of chelators with $\mathrm{BF}_{3} /$ methanol, methylation occurs at the carboxylic acid sites. The mass spectrum of methylated-EDTA is shown in Figure 1a. The parent ion is observed at $\mathrm{m} / \mathrm{z}$ 348. The chemical ionization mass spectrum is shown in Figure $1 \mathrm{~b}$.

However, methylation does not occur at hydroxy sites in the reaction of $\mathrm{BF}_{3} /$ methanol. The mass spectrum of methylated HEDTA shows a parent ion at m/z 288 in Figure 2a. The identification of $\mathrm{m} / \mathrm{z} 288$ for methylated HEDTA was initially surprising because the expected molecular weight of methylated HEDTA (Me ${ }_{3}$-HEDTA) should be 320 . Analysis of the $\mathrm{m} / \mathrm{z} 288$ species using GC/Fourier tansform infrared (FTIR) revealed the presence of a strong lactone absorbance. Consequently, the methylated lactone structure was derived and shown below. 


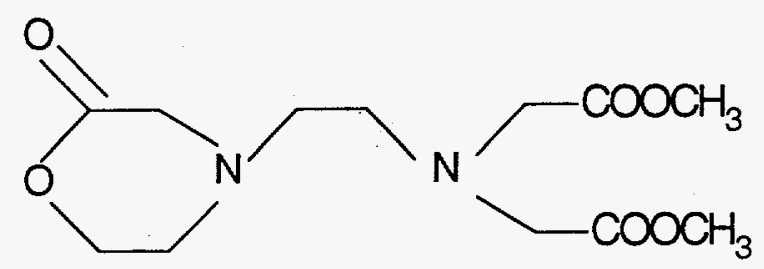

The hydroxyethyl group of HEDTA resists methylation by $\mathrm{BF}_{3} /$ methanol and, instead, forms a cyclic, or intramolecular lactone with one of the neighboring acetate ligands. The parent ion was confirmed with positive ion chemical ionization MS, and the mass spectrum is illustrated in Figure $2 b$.

Similarly, the mass spectrum of ethylenediaminetriacetic acid (ED3A, MW 234), derivatized with $\mathrm{BF}_{3} /$ methanol, shows the parent ion at $\mathrm{m} / \mathrm{z} 244$ (Figure 3), indicating formation of a lactam with the following structure.

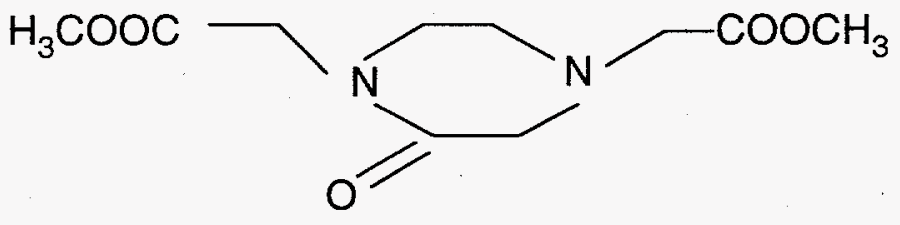

Ethylenediaminediacetic acid (EDDA) was predicted to be a major product of chelator degradation (25). Both symmetrical ethylenediaminediacetic acid (s-EDDA) and unsymmetrical ethylenediaminediacetic acid (u-EDDA), structures shown below, were derivatized with $\mathrm{BF}_{3}$ /methanol to form the methyl esters; however, the reaction of s-EDDA with $\mathrm{BF}_{3} /$ methanol is not reproducible. This may be due, at least in part, to the irreversible formation of boron trifluoride complexes with this isomer. 


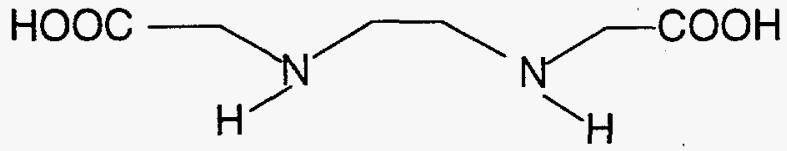

s-EDDA

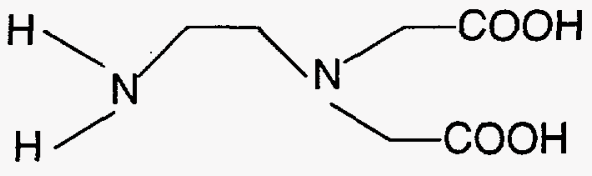

u-EDDA

The proposed structures for the corresponding lactams are shown below.

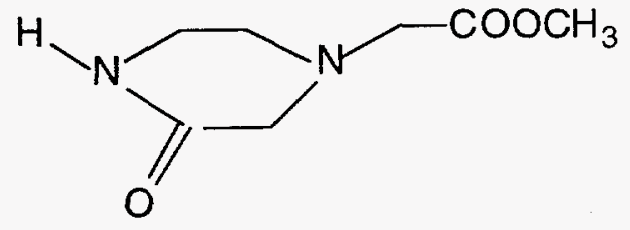

u

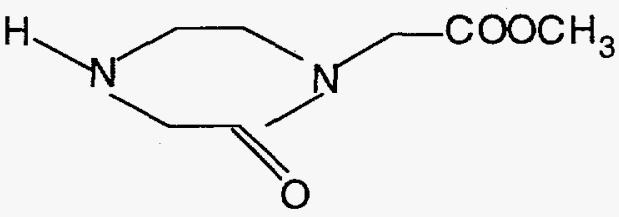

S

The corresponding electron impact mass spectra are shown in Figures $4 \mathrm{a}$ and $\mathrm{b}$. The base peak for derivatized $u-E D D A$ is $\mathrm{m} / \mathrm{z} 113$. The base peak for derivatized $s-E D D A$ is $\mathrm{m} / \mathrm{z} 85$ with fragment ions $\mathrm{m} / \mathrm{z} 143$ and 102. Accurate mass measurements indicate that $\mathrm{m} / \mathrm{z} 143$ is derived from loss of $\mathrm{CHO}$, presumably from the lactam ring.

\section{Waste Samples}

Six samples of core segments from Tank SY-101 were analyzed for organic constituents. Four of the samples were from the upper region, or convective layer, of the tank and two were from the lower layer, termed the nonconvective layer. The total ion chromatogram for a $\mathrm{BF}_{3} /$ methanol-derivatized tank waste sample is shown in Figure 5. The approximate concentrations of the major components expressed as mg carbon/g sample are listed in Table 1 as a function of segment number. These values are the average of two determinations. Errors in analysis are estimated to be $10 \%$ based on replicate analysis. A possible reason for wide 
variations between values for analytes in the same layer, e.g. EDTA at 1.30 in segment 6 and 3.90 in segment 11, may be the result of sample heterogeneity. Table 2 presents the structures of the major components identified in the actual waste sample.

The major components identified as methyl esters include butanedioic acid (succinic acid), citric acid, NTA, EDTA, ED3A, and HEDTA. The identification of component 12 of Figure 5 was confirmed using accurate mass high resolution MS. The structure of this component is shown below.

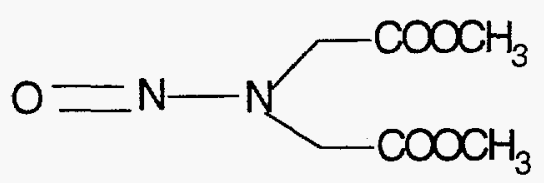

Nitroso compounds such as NIDA have been previously identified in the waste samples using derivatization (dimethyl sulfate under basic conditions) GC/MS; thermospray LC/MS with an acidic mobile phase, and LC under acidic conditions. The mass spectrum of the derivatized, synthesized standard was identical to that observed in the GC/MS total ion chromatogram, and the thermospray mass spectrum was identical to that of the major component in the total ion chromatogram. However, in both of these instances, the separation or derivatization involved acidic conditions or reaction with a Lewis acid. Studies by researchers at Georgia Institute of Technology showed that NIDA was a reactive intermediate and could not exist in appreciable quantities under basic conditions present in the waste tanks ${ }^{(21)}$. Our studies indicate that the formation and stability of NIDA under the acidic conditions of the derivatization process are both rapid and favorable.

To verify the presence of nitroso compounds in the tank waste, a procedure was developed to utilize thermospray LC/MS with ammonium carbonate as the mobile phase $(\mathrm{pH} \approx 10.0)$. The thermospray LC/MS results clearly indicate that the nitroso compounds identified in the 
derivatization GC/MS total ion chromatograms and LC chromatograms under acidic conditions are artifacts of the derivatization and separation processes. The nitroso compounds are formed under acidic conditions by the reaction of an analyte with a free active amine hydrogen, as in the case of IDA and ED3A, with a high concentration of nitrite present in the waste samples.

The chelators and chelator fragments make up approximately $20-50 \%$ of the TOC, depending on the sample. The remaining TOC was thought to be low-molecular- weight acids such as oxalic, glycolic, and formic acid, which may be the precursors or end products for hydrogen production in the waste tanks. This has been confirmed with subsequent LC analysis.

Deuterated EDTA as a Surrogate Tracer

The yield obtained for $\mathrm{d}_{4}$-EDTA from the waste matrix $(85 \%)$ suggests that this material would act as an effective surrogate component for determining organic acid loss/dilution error in the sampling and analysis of these wastes. To test the ruggedness of this material against deuterium exchange, a sample was exposed to $2 \mathrm{M}$ aqueous hydroxide overnight, then dried and derivatized with $\mathrm{BF}_{3} /$ methanol in the manner detailed above. The yield of derivatized $\mathrm{d}_{4}$ - EDTA and the absence of EDTA or partially deuterated EDTA in the mass spectrum was taken as evidence that the substrate did not readily undergo exchange to the hydroxide matrix or the derivatizing agent.. The recovery yields for the other components are illustrated in Table 3.

The observed yield for HEDTA was $30 \%$. The sensitivity or response factor of methylated-HEDTA was substantially lower than that of EDTA or NTA, 70\% less on a molar basis. This discrepancy was resolved by analyzing a sample of methylated HEDTA using direct probe/MS. The MW 288 lactone accounted for approximately $30 \%$ of the species detected. Trimethylated HEDTA with an unreacted, or free, hydroxyethyl group accounted for the remaining 
$70 \%$ of the HEDTA. It is speculated that the species is simply too polar to migrate through the GC columns.

To determine whether the trimethylated HEDTA was sorbed onto the GC column, two experiments were performed. First, HEDTA was silylated, and the product analyzed using MS and GC/MS. A single species, the tetratrimethylsilyl ether of HEDTA, chromatographed as a single GC peak. As a second test, methylated HEDTA was silylated using the silylating reagents $\mathrm{N}$-bis(trimethylsilyl)acetamine (BSA) and trimethylchlorosilane (TMCS). The reaction product was then analyzed using MS and GC/MS. Two species were identified as two distinct GC peaks: first, the MW 288 lactone and, second, the mixed derivative of HEDTA, the trimethyl ester, mono(trimethylsilyl)ether of HEDTA ${ }^{(8)}$. This confirmed that the underivatized hydroxyethyl group of HEDTA rendered any such derivative too polar to migrate through the GC column. Such chemical complexities are often encountered when analyzing chelating agents or their degradation products.

\section{CONCLUSIONS}

Derivatization with $\mathrm{BF}_{3}$ /methanol has been shown to be applicable for analyzing organic complexing agents and their degradation products. The current results have assisted in the chelator/gas generation connection. Further experimentation is underway with heating and radiolysis of the convective layer samples. These results should provide additional insight into the gas generation mechanism.

The reaction of the waste sample with $\mathrm{BF}_{3}$ /methanol was very useful in identifying and quantitating major components. The major components included citric acid, NTA, HEDTA, EDTA, and ED3A. It is inferred from the data that IDA is also present in the waste samples. The identity of the most concentrated component was verified with high resolution MS measurements. 
The chelators and chelator fragments constitute only $20-50 \%$ of the TOC; it has been shown that the remaining components are low-molecular-weight acids such as oxalic, glycolic, and formic $\operatorname{acid}^{(22)}$.

\section{ACKNOWLEDGMENTS}

The authors would like to thank Steve Goheen and Denis Strachan for many helpful suggestions. The authors would also like to acknowledge Westinghouse Hanford Company for support of this work. Pacific Northwest National Laboratory is operated for the Department of Energy under contract DE-AC06-76RLO 1830 by Battelle Memorial Institute. The authors would also like to thank Rick Steele, John Rau, and Vaughan Hoopes of the hot cell facilities. 


\section{REFERENCES}

1. 1. S. C. METCALF, Determination of EDTA and HEDTA in Hanford Defense Waste by High Performance Liquid Chromatography, RHO-SA-218, 1991, Rockwell Hanford Operations, Richland, Washington, pp. 1-32.

2. J. L. MEANS, D. A. CRERAR, J. O. DUGID, Science. 1978, 200, 1477-1482.

3. A. P. TOSTE, R. B. MYERS, "The Relation Contributions of Natural and Waste-Derived Organics to the Subsurface Transport of Radionuclide." In: The Effects of Natural Organic Compounds and of Micororganisms on Radionuclide Transport, 1986, pp. 57-76, RWM-6, Radioactive Waste Management Committee, OECD Nuclear Energy Agency, Paris, France.

4. A. P. TOSTE, J. Radioanaly. Nuc. Chem. 1992, 161, 549-559.

5. D. M STRACHAN, Minutes of the Tank Waste Science Panel, PNL-8278, March 25-27, Denver, Colorado, pp. K.1-K.75.

6. S. A. BRYAN, L. R. PEDERSON, R. D. SCHEELE, Synthetic Waste Studies Final Report $_{\mathbf{1}}$ 1992, PNL-8169, Pacific Northwest Laboratory, Richland, Washington, pp. 1-103.

7. L. RUDLING, Water Res. 1972, $\underline{6}, 871-874$.

8. D.R. KNAPP, In Handbook of Analytical Derivatization Reactions, John Wiley \& Sons, Inc., New York, 1979, pp. 21-23.

9. ORGANIC CHEMICAL DIVISION. General Procedure for the Determination of NTA, HEDTA, EDTA, and DTPA in Chelate and Metal Chelate Mixtures, RDSAP Number 0021, 1988, W.R. Grace and Company, Nashua, New Hampshire. pp. 1-19.

10. J. BAUER, D.HEATCOTE, S. KROGH, J. Chromatog. 1986, $\underline{369}, 422$.

11. M.E. UNGER, E. MAINKA, W. KNONIG, Fresenius A. Anal. Chem. 1987, 329, 50-54. 
12. J. DAI, G.R. HELZ,Anal. Chem. 1988, $\underline{60}$, 301-304.

13. J.A. CAMPBELL, R.B. LUCKE, S.A. CLAUSS, "Applications of LC/MS to the Study of Chelators in Mixed Hazardous Wastes." In: Proceedings of the 39th ASMS Conference on Mass Spectrometry and Allied Topics, Nashville, Tennessee, May 19-24, 1991, pp. 1334-1335.

14. J.A. CAMPBELL,H.R. UDSETH, R.B. LUCKE, "Application of Electrospray Mass Spectrometry to the Analysis of Chelator and Chelator Fragments in Mixed Hazardous Wastes." In: Proceedings of the 40th ASMS Conference on Mass Spectrometry and Allied Topics, 1992, Washington, D.C., May 24-June 2, 1992.

15. A.P. TOSTE, R.B. LUCKE, T.J. LECHNER-FISH, D.J. HENDREN, In: Proceedings, Waste Management '87, vol. 3, pp. 323-329. March 1-5, 1987, Tucson, Arizona.

16. R.B. LUCKE, J.A. CAMPBELL, K.L. MCKEETA, S.A. CLAUSS, "Analysis of Chelator and Chelator Fragments in Mixed Hazardous Wastes by Derivatization GC/MS." In: Proceedings of the 39th ASMS Conference on Mass Spectrometry and Allied Topics, Nashville, Tennessee, 1991, pp. 720-721.

17. A.P. TOSTE, F.T. HARA, D.J. HENDREN,T.J. LECHNER-FISH, Chemical and Radiochemical Analysis of Hanford Radioactive Wastes, 1987, PNL-6360, Pacific Northwest Laboratory, Richland, Washington.

18. R.O. LOKKEN, R.D. SCHEELE, D.M. STRACHAN, A.P. TOSTE, Complex Concentrate Pretreatment, FY 1986 Progress Report, PNL-7687, 1986, Pacific Northwest Laboratory, Richland, Washington.

19. J.A. CAMPBELL, R.W. STROMATT, M.R. SMITH, D.W. KOPPENAAL, R.M.BEAN, T.E. JONES, D.M. STRACHAN, H. BABAD, Anal. Chem. 1994, 66, 1207A-1215A.

20. G.M. MONG, J.A. CAMPBELL, R.B. LUCKE, B.D. LERNER, K.L. WAHL, S.A. CLAUSS, K.E. GRANT, "Progress in the Analysis and Speciation of Organic Chelator Compounds in Hanford Waste Tanks." In: Waste Management 95, February 27-March 3, 1995, Tucson, Arizona, In Press. 
21. J.A. CAMPBELL, S.A. CLAUSS, K.E. GRANT, V. HOOPES, B.D. LERNER, R.B. LUCKE, G.M. MONG, J. RAU, R. STEELE, Flammable Gas Safety Program, Analytical Methods Development: FY 1994 Progess Report, PNL-10127, Pacific Northwest Laboratory, Richland, Washington.

22. J.A. CAMPBELL, S.A. CLAUSS, K.E. GRANT, V. HOOPES, B.D. LERNER, R.B.LUCKE, G.M. MONG, J. RAU, R. STEELE, Flammable Gas Safety Program, Analytical Methods Development: FY 1993 Progess Report, PNL-9062, Pacific Northwest Laboratory, Richland, Washington.

23. A. VANYOLOS, Rev. Chim. (Bucharest), 1955, $\underline{6}, 378-9$.

24. D.L. BALDWIN, R.W. STROMATT, W.I. WINTERS, "Comparative Study of Total Organic Carbon Methods for High-Level Waste," PNL-SA-23718, Pacific Northwest National Laboratory, Richland, Wa, June 1994.

25. E.C. ASHBY, E.K. BAREFIELD,C.L. LIOTTA, H.M.NEUMANN, D. BOATRIGHT, F. DOCTORVICH, A.DESHPANDE, C.F. YAO, "Mechanisms of the Chemical Decomposition of Complexants in Hanford HLW Simulants." Presented at the 208th American Chemcial Society National Meeting, Washington, D.C., August 21-25, 1994. 
Table 1. Results of Derivatization(a) GC/MS Analyse's on Tank 101-SY Window E Core Segment Samples Concentration of Major Components (mg C/g Sample)

\begin{tabular}{|c|c|c|c|c|c|c|c|c|c|c|}
\hline Sample\# & & NIDA & NTA & $\mathrm{CA}$ & $\underline{\mathrm{ED}} 3 \mathrm{~A}^{(\mathrm{b})}$ & EDTA & $\mathrm{HEDTA}^{(\mathrm{c})}$ & $\mathrm{SA}$ & $\begin{array}{c}\text { TOC } \\
\text { Accounted For } \\
\text { (d) }\end{array}$ & $\begin{array}{r}\% \mathrm{TO} \\
\text { Accounte }\end{array}$ \\
\hline $\mathrm{R} 4258 / \mathrm{C}$ & $4(e)$ & 1.30 & 0.40 & 0.44 & 0.19 & 2.00 & . & 0.07 & 4.8 & 44 \\
\hline $\mathrm{R} 4259 / \mathrm{C}$ & 6 & 0.88 & 0.32 & 0.22 & 0.18 & 1.30 & . & 0.05 & 3.3 & 33 \\
\hline $\mathrm{R} 4260 / \mathrm{C}$ & 9 & 1.00 & 0.30 & 0.38 & 0.50 & 1.70 & - & 0.08 & 5.0 & 46 \\
\hline $\mathrm{R} 4261 / \mathrm{C}$ & 11 & 0.97 & 0.29 & 0.23 & 0.34 & 3.90 & - & 0.08 & 6.4 & 52 \\
\hline $\mathrm{R} 4262 / \mathrm{NC}$ & 16 & 0.24 & 0.06 & 0.14 & 0.32 & 0.81 & - & 0.02 & 2.2 & 20 \\
\hline R4263/NC & 17 & 1.40 & 0.37 & 0.47 & 0.24 & 0.79 & - & 0.08 & 3.5 & 32 \\
\hline
\end{tabular}

\footnotetext{
(a) Derivatization performed in fume hood

(b) Assuming response similar to EDTA

(c) HEDTA was found in window $\mathrm{E}$ composite samples, but not in the segment subsamples.

(d) Total includes minor components not included in this summary table.

(e) Represents segment number.

C Convective layer

NC Nonconvective layer

NIDA- nitrosoiminodiacetic acid

NTA- nitrilotriacetic acid

CA- citric acid

ED3A- ethylenediaminetriacetic acid

EDTA- ethylenediaminetetraacetic acid

HEDTA- N-(2-hydroxyethyl)ethylenediaminetriacetic acid

SA- succinic acid
} 
Table 2. Molecular Structures Determined by High Resolution Mass Spectrometry

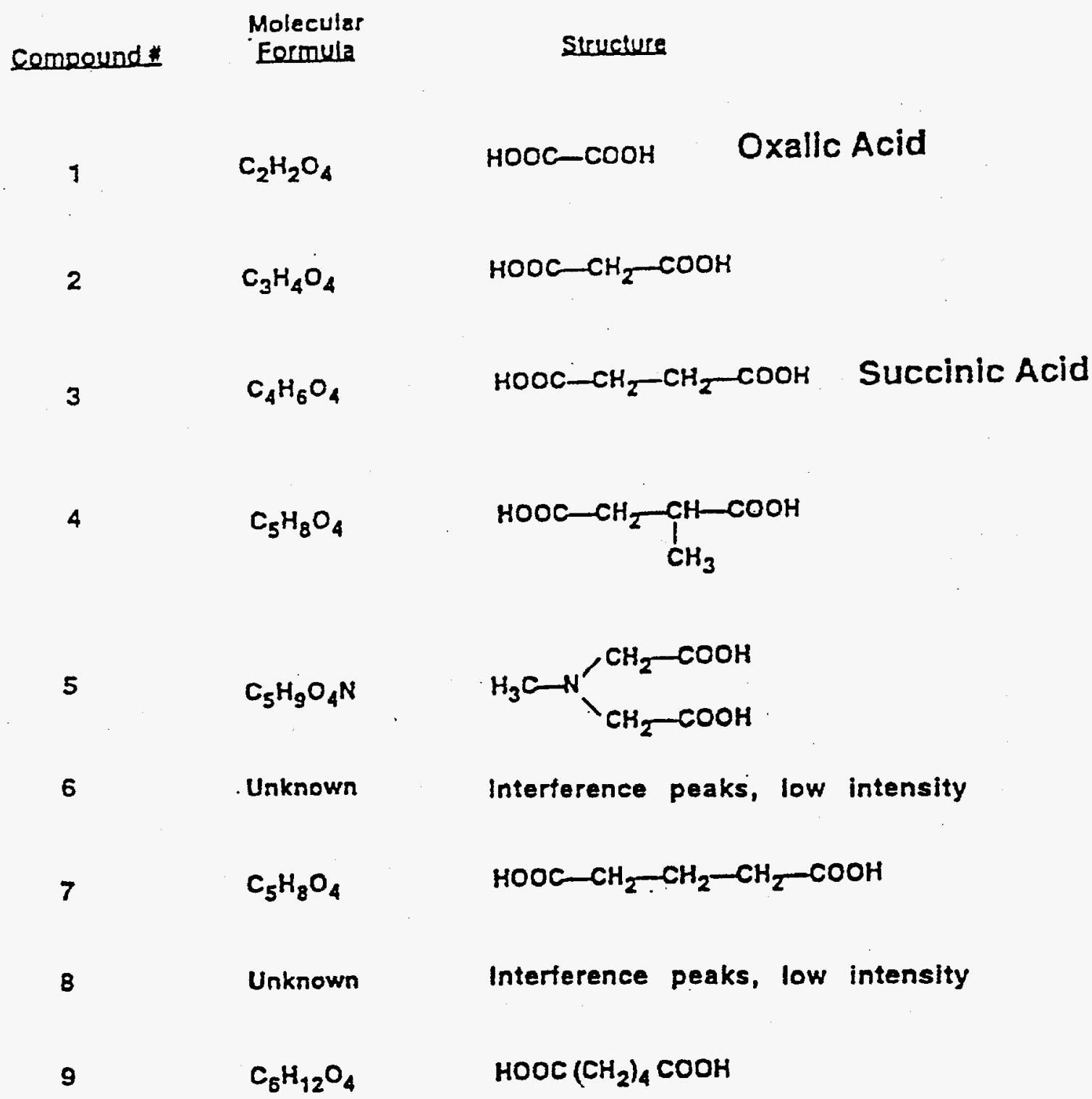




Eompound:
10
11

13

$\mathrm{C}_{6} \mathrm{H}_{9} \mathrm{O}_{7}$<smiles>O=C(O)CC(CC(=O)O)C(=O)O</smiles>

14

$\mathrm{C}_{6} \mathrm{H}_{9} \mathrm{O}_{5} \mathrm{~N}$<smiles>O=C(O)CN(CC(=O)O)CC(=O)O</smiles>

15

$\mathrm{C}_{7} \mathrm{H}_{13} \mathrm{O}_{5} \mathrm{~N}_{3}$<smiles>CN(CCN(CC(=O)O)CC(=O)O)N=O</smiles>

16

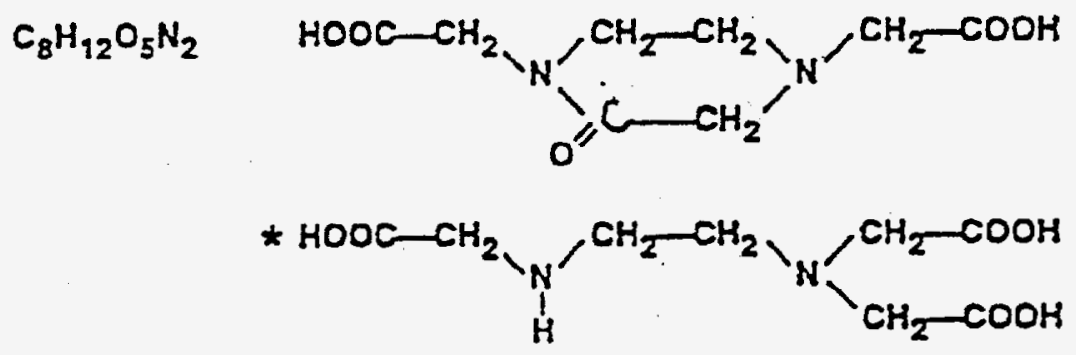

393090323 


$$
\begin{aligned}
& \text { Molecular } \\
& \text { Eermula Structure }
\end{aligned}
$$
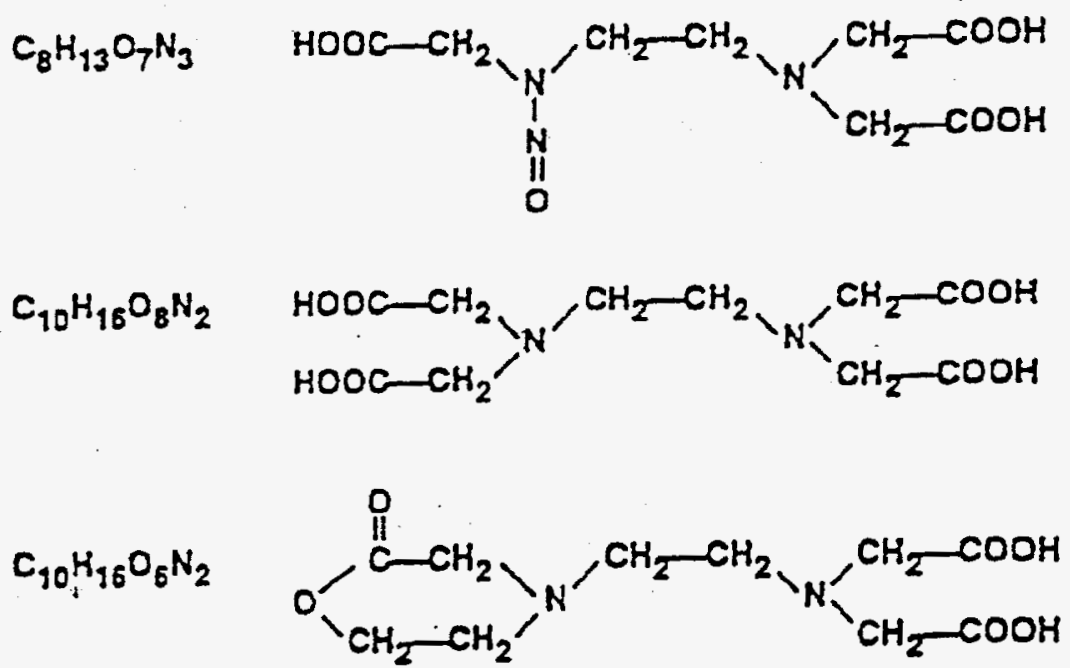

* Indicate components detected as intramolecular lactones or lactams 
Table 3. Recovery Yields for Analytes in Tank SY-101 Matrix

Target Compound

Succinic Acid

Citric Acid

NTA

EDTA

d4-EDTA

HEDTA
Yield

$101 \%$

$108 \%$

$111 \%$

$117 \%$

$85 \%$

$27 \%$ 


\section{Figure Captions}

Figure 1. (a) Electron Impact Mass Spectrum of Methylated EDTA and (b) Chemical Ionization Mass Spectrum of Methylated EDTA.

Figure 2. (a) Electron Impact Mass Spectrum of Methylated HEDTA and (b) Chemical Ionization Mass Spectrum of HEDTA

Figure 3. (a) Electron Impact Mass Spectrum of Methylated ED3A and (b) Chemical Ionization Mass Spectrum of ED3A.

Figure 4. Electron Impact Mass Spectrum of Methylated (a) u-EDDA and (b) s-EDDA.

Figure 5. Total Ion Chromatogram of Derivatized Waste Sample from Tank SY-101. 


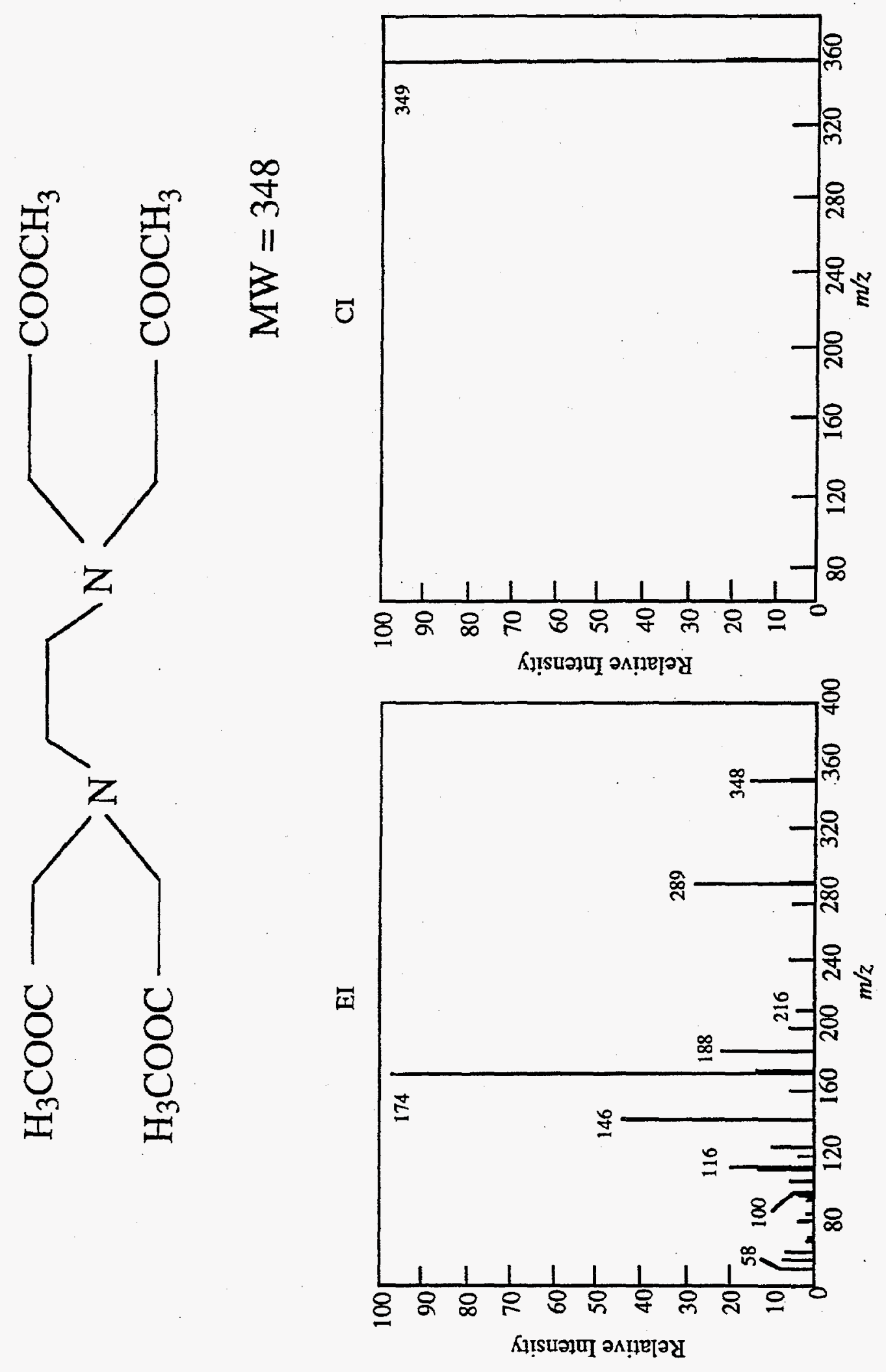




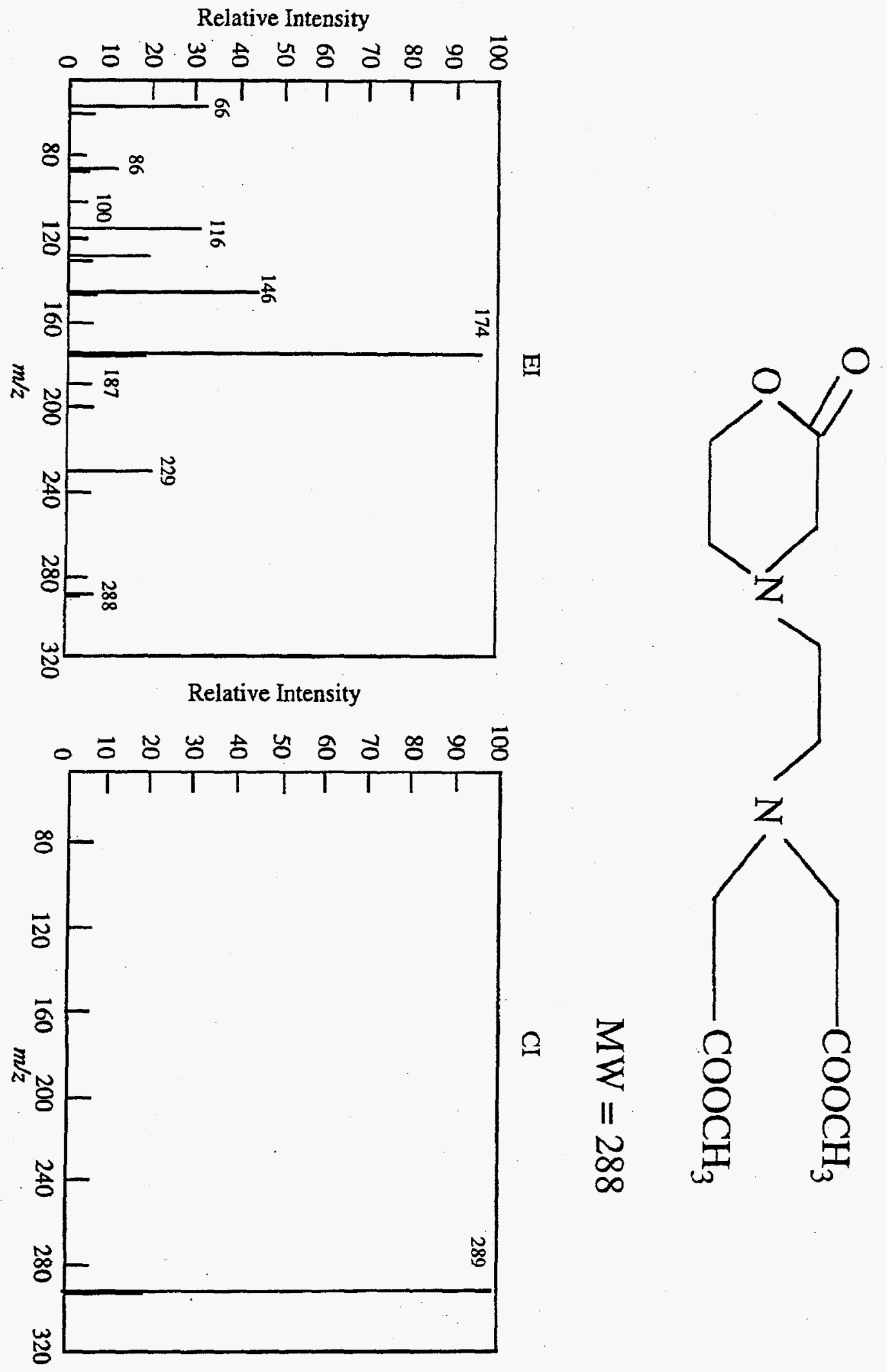



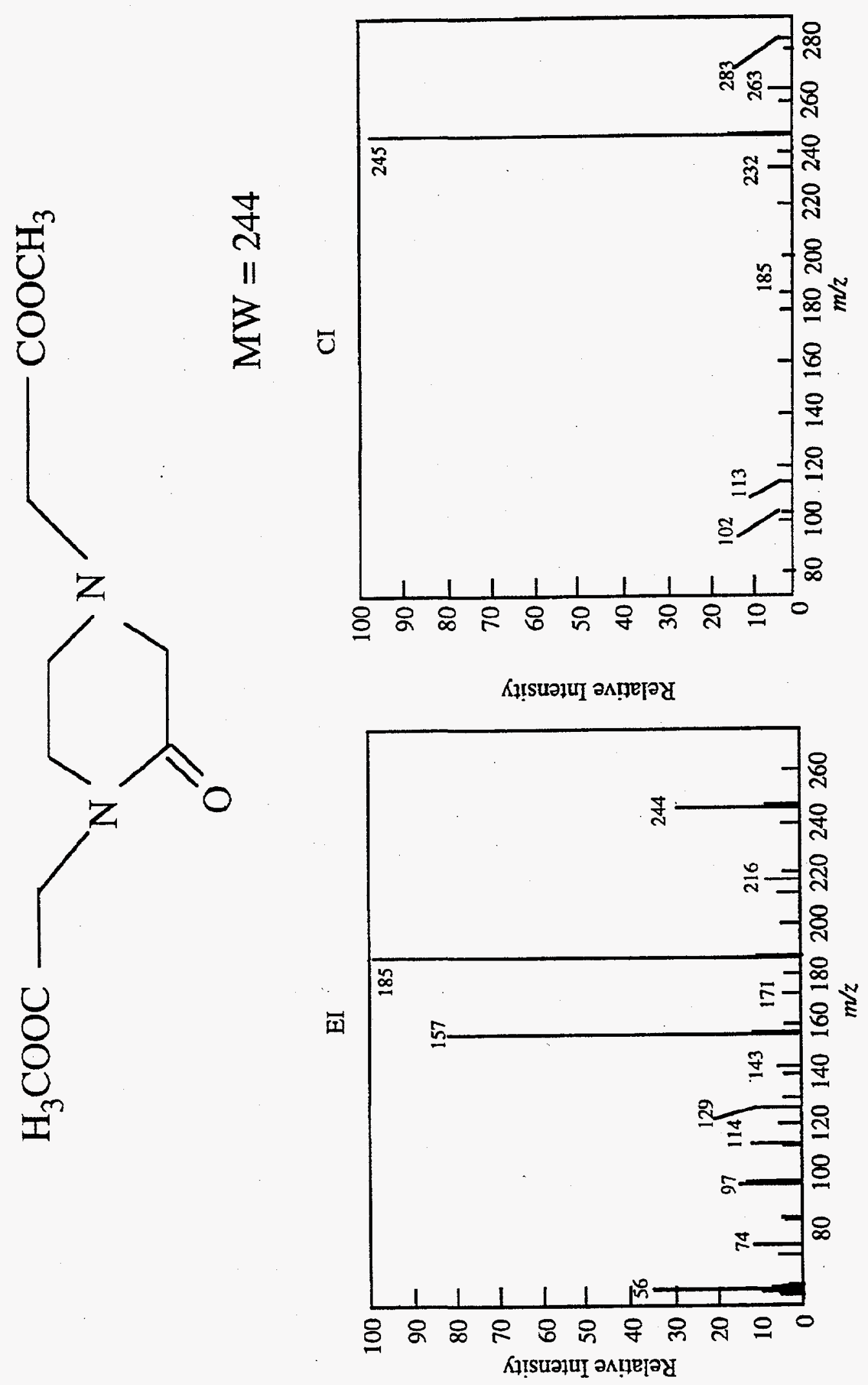

B. 32 


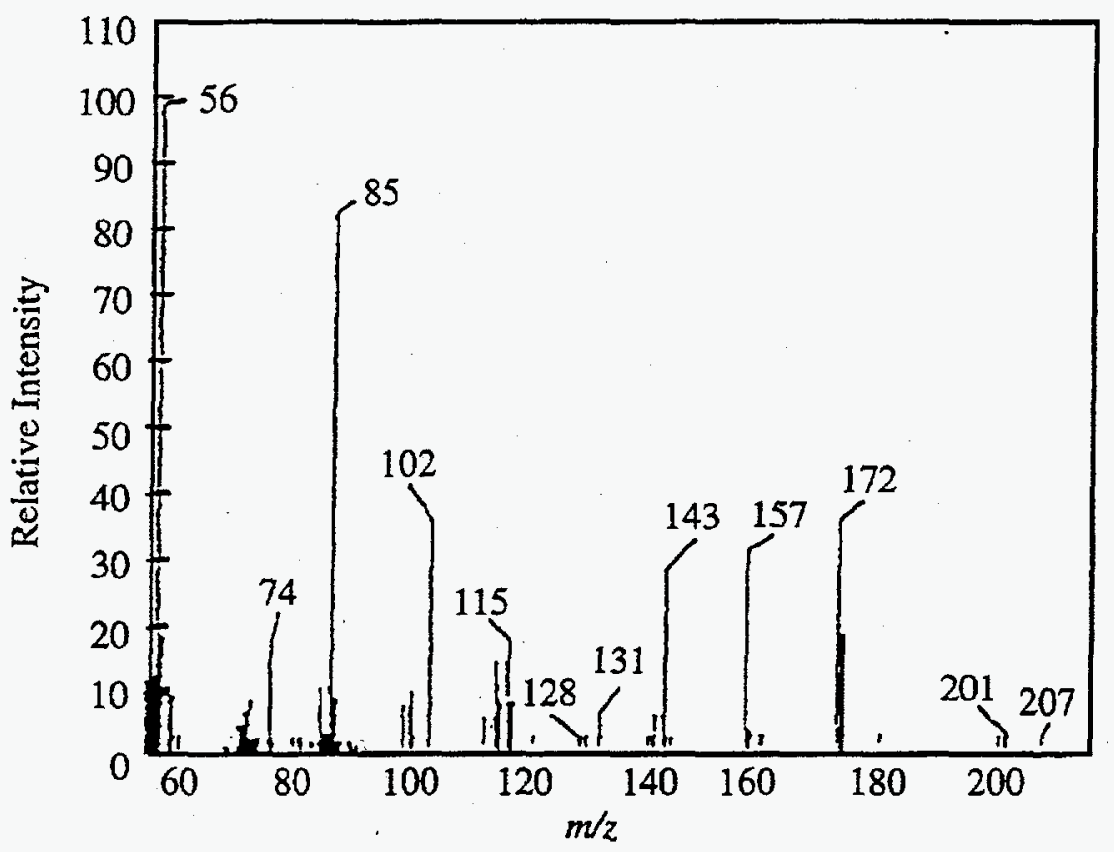

(a) Unsymmetrical

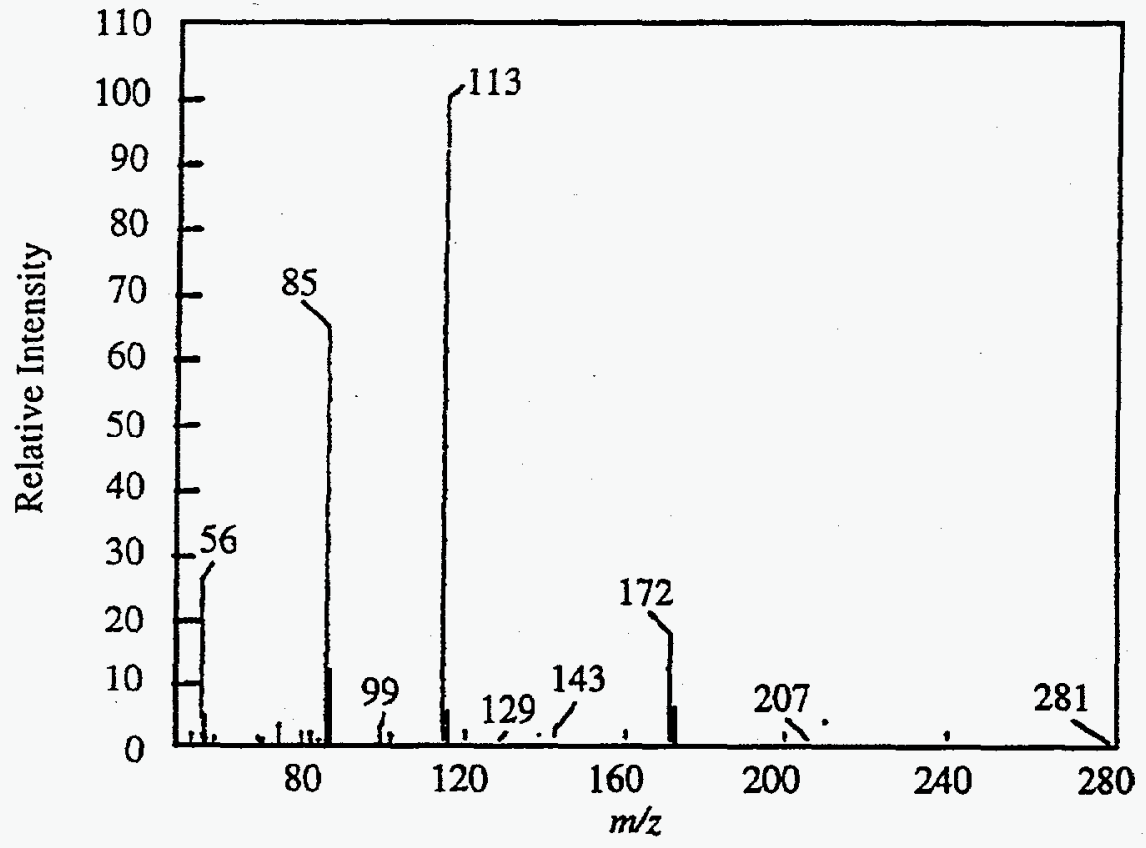

(b) Symmetrical 


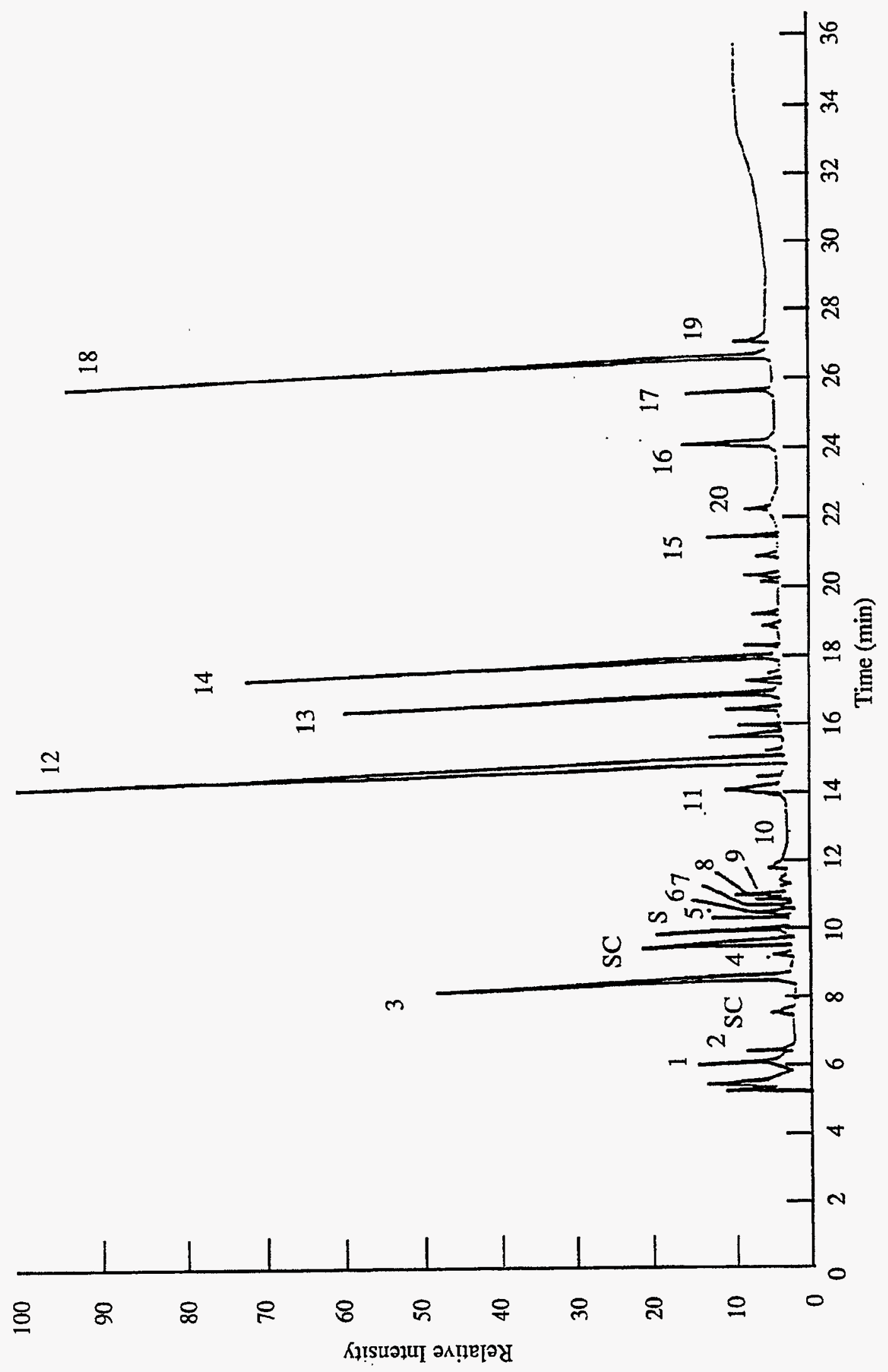




\section{Appendix C}

\section{Preprint}

Activity Reduction of Radioactive Mixed Wastes for Subsequent Carboxylate Determinations

C.1 


\title{
Activity Reduction of Radioactive Mixed Wastes for Subsequent Carboxylate Determinations
}

\author{
G. M. Mong, J. A. Campbell*, R. D. Orr, S. A. Clauss, K. L. Wahl, and F. V. Hoopes \\ Advanced Organic Analytical Methods Group \\ Pacific Northwest National Laboratory \\ Richland, Wa 99352
}

* Address correspondence to this author. 


\title{
Activity Reduction of Radioactive Mixed Wastes for Subsequent Carboxylate Determinations
}

\author{
G. M. Mong, J. A. Campbell*, R. D. Orr, S. A. Clauss, K. L. Wahl, and F. V. Hoopes \\ Advanced Organic Analytical Methods Group \\ Pacific Northwest National Laboratory \\ Richland, Wa 99352
}

\begin{abstract}
Tank wastes are usually very basic, $\mathrm{pH}>12$, and extremely radioactive. An ion exchange method for removing most of the radioactive components has been developed. The sample can then be removed from the hot cell facility to be analyzed for chelator, chelator fragments, and lowmolecular weight acids. The use of cation exchange resin in the sample preparation does not introduce or remove any organic carbon.
\end{abstract}




\title{
Activity Reduction of Radioactive Mixed Wastes for Subsequent Carboxylate Determinations
}

\author{
G. M. Mong, J. A. Campbell*, R. D. Orr, S. A. Clauss, K. L. Wahl, and F. V. Hoopes \\ Advanced Organic Analytical Methods Group \\ Pacific Northwest National Laboratory \\ Richland, Wa 99352
}

\section{Introduction}

The 560 square mile Hanford Site (Washington State) and its associated 177 underground storage tanks (USTs) contain large quantities of highly radioactive mixed wastes. Several of these tanks contain significant amounts of organic materials, notably complexants such as ethylenediaminetetraacetic acid (EDTA), nitrilotriacetic acid (NTA), and N-

hydroxyethylethylenedamianetriacetic acid (HEDTA) that were once part of the aqueous waste streams. The structures are shown below.

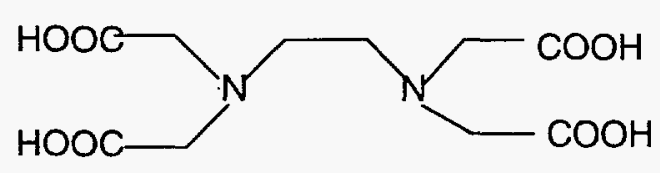

EDTA

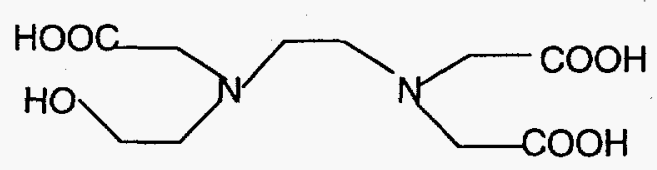

HEDTA

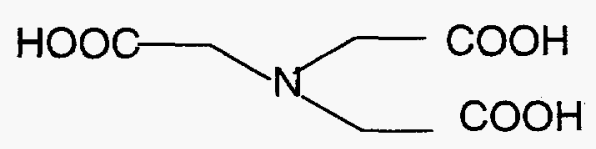

NTA

Most of the organic chelators and non-volatile organics contained in these wastes are not designated as U.S. Environmental Protection Agency target compounds; therefore, special methods are required for their determination. These components are of environmental interest, primarily due to their ability to form water-soluble compounds with most heavy metals and radionuclides. Chelators enhance the migration of heavy metal complexes through the soil 
column. ${ }^{(1,2)}$ Hundreds of tons of the chelators HEDTA and EDTA were used in processing activities at the Hanford Site. ${ }^{(3)}$

Certain of these chelator components in the radioactive environment of the waste tanks degrade rapidly. This creates an organic mix of unaffected chelator components along with an array of chelator-related fragments. The composition of typical chelator degradation products has been detailed elsewhere. ${ }^{(4,5)}$ Besides degrading to smaller organic components, these materials have been strongly implicated in the production of hydrogen gas in a number of the USTs. A convenient quantification method is necessary to study these materials and their fate in the radioactive matrix.

Of the techniques available to study chelators and their decomposition fragments, the best analysis technique appears to be derivatization with boron trifluoride $\left(\mathrm{BF}_{3}\right) /$ methanol followed by gas chromatography (GC) or GC/mass spectrometry (GC/MS) analysis. ${ }^{(5)}$ Reacting the carboxylates with diazomethane and other reagents has been attempted, but without success. Analyzing chelators and chelator fragments directly by high performance liquid chromatography (HPLC) has not proven fruitful due to the complexity of the material. However, HPLC ion chromatography (IC) methods have successfully quantitated the low-molecular-weight degradation carboxylates such as acetate, formate, and oxalate, which are formed by the decomposition process. ${ }^{(5)}$

Hot cells (shielded facilities equipped with remote manipulation equipment) have been used previously for working with highly radioactive waste samples. ${ }^{(5)}$ However, shielded hot-cell work can be very time consuming; additionally, any work that involves rapid manual control is severely limited. Instruments and analysis equipment are frequently too bulky and expensive to commit to use in the hot-cell. The procedure developed ${ }^{(4,5)}$ for analyzing chelators in radioactive wastes has been used in the hot-cell environment, but chemical yields for spiked samples were found to be low in cases where the sample matrix contained residual water. Therefore, it is better to have access to the samples to ensure a scrupulously dry and evenly dispersed matrix in the sample container before derivatization.

In this paper, we discuss an ion-exchange method for removing most of the radioactive components from Hanford-related tank matrices; the wastes can then be analyzed for carboxylates and chelator components. Tests have been conducted to ensure that the ion exchange medium has not reduced the desired analytes significantly or augmented the total organic carbon (TOC) by leaching. The analyst can use elution through cation exchange resin in the sample-preparation 
procedure to reduce the radioactivity to a sufficient level and remove the tank waste sample safely from the hot-cell facility for subsequent drying and derivatization. This single step has significantly increased the amount of organic carbon accounted for.

\section{Experimental}

Tank waste materials are generally very basic; the $\mathrm{pH}$ is usually greater than 12 . For samples that we have encountered, it is not necessary to add base to the samples to ensure that carboxylate moieties remain soluble in the matrix. However, for samples that display a $\mathrm{pH}$ less than 10 , adding sodium hydroxide can ensure the analytes remain in solution.

We converted cation exchange resin (AG 50W-X8, Biorad) from the hydrogen form to the sodium form with $6 \mathrm{~N} \mathrm{NaOH}$. The caustic was added in portions to a water slurry of the resin until the slurry remained basic ( $\mathrm{pH} 8-9$ ). The resin was allowed to equilibrate for an hour to ensure complete conversion to the sodium form; then it was filtered and rinsed with deionized water to remove excess sodium hydroxide.

The resin was loaded in plastic disposable columns (Econo-Pac, Biorad) using a bed volume of $18 \mathrm{~mL}$ of resin. The columns were used immediately upon loading, without allowing the resin an opportunity to dry. Blanks were run by passing $15 \mathrm{~mL}$ of $6 \mathrm{~N} \mathrm{NaOH}$ through the column, followed by washing with $15 \mathrm{~mL}$ of deionized water. The blank solution was submitted for TOC analysis.

We prepared radioactive storage tank waste samples by dissolving 3-5 grams of the waste in $20 \mathrm{~mL}$ of water and stirring overnight. The $\mathrm{pH}$ was checked and adjusted if necessary. Insoluble solids were removed by passing through a $0.45 \mu \mathrm{M}$ filter (Acrodisc, Gelman). A measured aliquot was removed for TOC and radiochemical analysis.

The samples were passed through two pre-loaded columns arranged in series. The columns were rinsed by passing a column volume of $1 \mathrm{~N} \mathrm{NaOH}(19 \mathrm{~mL})$ to collect sample holdup, and the eluents were combined. Samples of the eluent were taken for TOC and radiochemical analysis. All of the sample preparation is performed in the hot cell facility. For highly radioactive wastes, e.g. 3-11 R/h, a hot cell facility must be used. This room is composed of thick walls ( $\approx$ $1.3 \mathrm{~m}$ ) equipped with a sample entry port, viewing windows (leaded glass and oil-filled), and remote manipulators, which are operated by a highly-trained specialist. When a radioactive sample is remotely handled in the hot cell, the procedure is time consuming, difficult, and requires 
specialized, deft artistry to complete the tasks. Sample turnaround is much lower when using the hot cell facilities. Wastes with a low-to-moderate total radioactivity level, $\leq 1 \mathrm{R} / \mathrm{h}$, may be prepared and analyzed outside the hot cell in a radiation hood or glove box. The actual cutoff levels that differentiate lab bench work, glove box work, and hot cell work is usually based upon local practice or the judgment of the resident health physicist.

\section{Radiochemical Analysis}

The samples were assayed for fission products $\left({ }^{90} \mathrm{Sr},{ }^{137} \mathrm{Cs}\right)$ and for actinide content. Gamma energy analysis for ${ }^{137} \mathrm{Cs}$ was done on a high-purity Ge detector ( $80 \%$ efficiency) with efficiency calibrated geometries.

Alpha measurements were determined by pipetting aliquots onto stainless steel planchettes, drying over a flame, and counted using a standard alpha proportional counter.

We determined ${ }^{90} \mathrm{Sr}$ by separating $\mathrm{Sr}$ and using liquid scintillation counting (LSC) and counted the ingrowth of ${ }^{90} \mathrm{Y}$ by Cherenkov counting. Samples and comparative standards were spiked with identical aliquots of ${ }^{85} \mathrm{Sr}$ and loaded onto $\mathrm{SrSpec}{ }^{\circledR}$ columns (EICHROM Industries) with $8 \mathrm{M} \mathrm{HNO}_{3}$. They were rinsed free of ${ }^{90} \mathrm{Y}$ and other fission products with $8 \mathrm{M} \mathrm{HNO}_{3}$, and the purified ${ }^{90} \mathrm{Sr}$ was eluted with water. The chemical yield for $\mathrm{Sr}$ was calculated based on a gamma assay of the ${ }^{85} \mathrm{Sr}$ activity in each sample as compared to observed ${ }^{85} \mathrm{Sr}$ activity in identical geometries. The samples were then counted without delay by LSC (Quantalus, Wallac Oy). The samples were counted in water using the Cherenkov radiation emitted as an effect from ${ }^{90} \mathrm{Y}$ decay. The Cherenkov emission efficiency of ${ }^{85} \mathrm{Sr}$ was calculated from the comparator standards containing only ${ }^{85} \mathrm{Sr}$. The ${ }^{90} \mathrm{Sr}$ Cherenkov efficiency was determined from ${ }^{90} \mathrm{Sr}$ freshly purified from the ${ }^{90} \mathrm{Y}$ daughter, and ${ }^{90} \mathrm{Y}$ Cherenkov efficiency was determined by counting known activities of ${ }^{90} \mathrm{SrY}$ at equilibrium The ${ }^{90} \mathrm{Sr}$ activity was then calculated from several counts of the samples over a suitable ingrowth period. Activity at secular equilibrium was calculated by computational software.

In all radiochemical assays, background efficiency calibrations and system controls were done to ensure that the data were valid.

\section{Total Organic Carbon Determination}


Samples, blanks, standards, and spiked samples were prepared and analyzed using a UIC Coulometrics 5300 Carbon System with coulometry detector. Acidification with sulfuric acid (4N) allows determination of total inorganic carbon; introduction of potassium persulfate and a silver nitrate catalyst followed by heating the sample to $600^{\circ} \mathrm{C}$ permits oxidation of most organic carbon species. The system is purged with purified oxygen to pass the $\mathrm{CO}_{2}$ to the coulometric cell. The entire analysis system is committed to the hot-cell environment with only the read-out being outside of the shielded facility.

Samples, blanks, and standards were done in duplicate. A spiked sample is prepared by adding a known amount of standard glucose to a random sample. Recoveries were generally 9095\% of the spiked material. The hot persulfate oxidation to determine TOC and total carbon has been shown to be valid for samples containing high concentrations of sodium nitrite, sodium nitrate, and sodium hydroxide typical of the radioactive waste matrices encountered.

\section{Results and Discussion}

Figure 1 is a schematic illustrating the sample preparation procedure and analysis scheme for tank wastes. Briefly, the solid sample is leached with water overnight and eluted through the cation exchange column to reduce the radioactivity level; the sample preparation procedure occurs in the hot cell facility. The column is eluted with $\mathrm{NaOH}$ to remove any organic carbon and combined with the water solution. The sample is then measured for radioactivity and then removed from the hot cell. An aliquot of the water solution is then dried in the fume hood for derivatization. Another aliquot is prepared for analysis of the low-molecular weight organic acids using liquid chromatography or ion chromatography. To determine the organically-soluble carbon, an aliquot of the starting waste is extracted with methylene chloride or chloroform and analyzed using GC/MS.

Table 1 lists the typical results of TOC determinations for Tank 241-SY-101(Tank SY101) samples. The convective layer is the upper-most layer, and the nonconvective layer refers to the lower layer samples. The segment numbers are related to the depth of the sample. Hot persulfate TOC determination has been shown to be effective in estimating many organic species; it is relatively insensitive to organic compounds lacking functionality, such as n-paraffins and elemental carbon. The relative response for carboxylates has been found to be an effective probe for carbon content in the types of wastes that have been examined to date. Results from analyses of other tank samples indicate that TOC increases as a function of depth. ${ }^{(6)}$ 
Table 2 shows the results of TOC measurements of waste samples from Tank 241- SY101 (Tank SY-101) before and after elution through cation exchange resin. The results represent a portion of the total sample analyzed for TOC in the bulk sample. The results clearly indicate no addition or reduction of organic components occurs with elution through the cation exchange resin. In addtion, the use of the hydrogen form significantly reduces the amount of organic carbon.

Table 3 lists the results from ${ }^{137} \mathrm{Cs},{ }^{90} \mathrm{Sr}$, and gross alpha analyses in samples from Tank 241-SY-103 (Tank SY-103), a tank waste similar in composition to Tank SY-101, before and after using cation exchange. The results of radiochemical removal from samples indicate a manifold decrease in radioactivity, primarily noted in ${ }^{137} \mathrm{Cs}$. The radioactivity level for ${ }^{137} \mathrm{Cs}$ was reduced by a factor of approximately 221 while ${ }^{90} \mathrm{Sr}$ was reduced by a factor of 10-15. Complexation of ${ }^{90} \mathrm{Sr}$ to waste chelators may represent a competitive process with the ion-exchange, limiting the removal of ${ }^{90} \mathrm{Sr}$. Current research is exploring this area.

The analysis of the organic components in radioactive tank wastes is related to an accurate accounting of the various organic compounds in the waste versus the values obtained from TOC analysis. This provides a check on the various quantitation methods that are used to determine the compounds found in the waste. If TOC measurements are far higher than the total carbon represented in the GC, IC, or GC/MS quantitation, then additional analyses are warranted to determine the identity of any additional organic components. Table 4 lists the concentration of chelators, chelator fragments, low-molecular-weight acids, and amount of TOC accounted for in samples from Tank SY-101. The results clearly indicate that elution through cation exchange as part of the sample preparation did not significantly affect the amount of organic carbon identified. Developing this procedure was extremely important in increasing the amount of TOC accounted for by speciation. However, the TOC of the sample should be measured before and after elution through the cation exchange resin to confirm the TOC is not altered. In other words, the cation exchange elution should neither introduce nor remove any organic carbon.

Removing the principle fission products by ion-exchange allows the sample to be removed from the shielded laboratory for work in a standard fume hood. The samples in their ionexchanged form are sufficiently stripped of their fission products that the analyst can manipulate the samples without risk of exposure to excessive radioactivity. In the derivatization steps used in this laboratory to determine chelators such as EDTA, the sample size, sample dryness, and sample dispersion in the reaction vessel are found to be critical for obtaining a good conversion to the methyl esters. It is not possible to manipulate the samples in the hot cell to obtain these conditions. 


\section{Acknowledgments}

This work was performed at Pacific Northwest National Laboratory, which is operated for the U.S. Department of Energy by Battelle under Contract DE-AC06-76RLO 1830.

\section{References}

1. A.P. TOSTE, L.J. KIRBY, T.R. PAHL. 1984. Proceedings of the 5th Annual Participants' Informational Meeting DOE Low-Level Waste Management Program; Denver, Colorado.

2. J.L. MEANS, D.A. CRERAR, J.O. DUGUID. Science. 1978, 200, 1477-82.

3. M.J. KLEM. 1988. Inventory of Chemicals Used at Hanford Productions Plants and Support Operations (1944-1980), WHC-EP-0172.Westinghouse Hanford Company, Richland, Washington.

4. J.A. CAMPBELL, R.W. STROMATT, M.R. SMITH, D.W. KOPPENAAL, R.M. BEAN, T.E. JONES, D.M. STRACHAN, H. BABAD. "Organic Analysis at the Hanford Nuclear Site," Anal. Chem. 1994, 66, 1208A-1215A.

5. J.A. CAMPBELL, R.M. BEAN, G.M. MONG, S.A. CLAUSS, R.B. LUCKE, B.D. LERNER, K.E. GRANT, R. STEELE, V. HOOPES, J. RAU. 1994. Flammable Gas Safety Program. Analytical Methods Development: FY 1993 Progress Report. PNL-9062, Pacific Northwest Laboratory, Richland, Washington.

6. J.A. CAMPBELL,G.M. MONG, S.A. CLAUSS, K.L.WAHL, B.D. LERNER, K.E. GRANT, R. STEELE, V. HOOPES, J. RAU. 1994. Flammable Gas Safety Program. Analytical Methods Development: FY 1994 Progress Report. PNL-10127, Pacific Northwest Laboratory, Richland, Washington. 


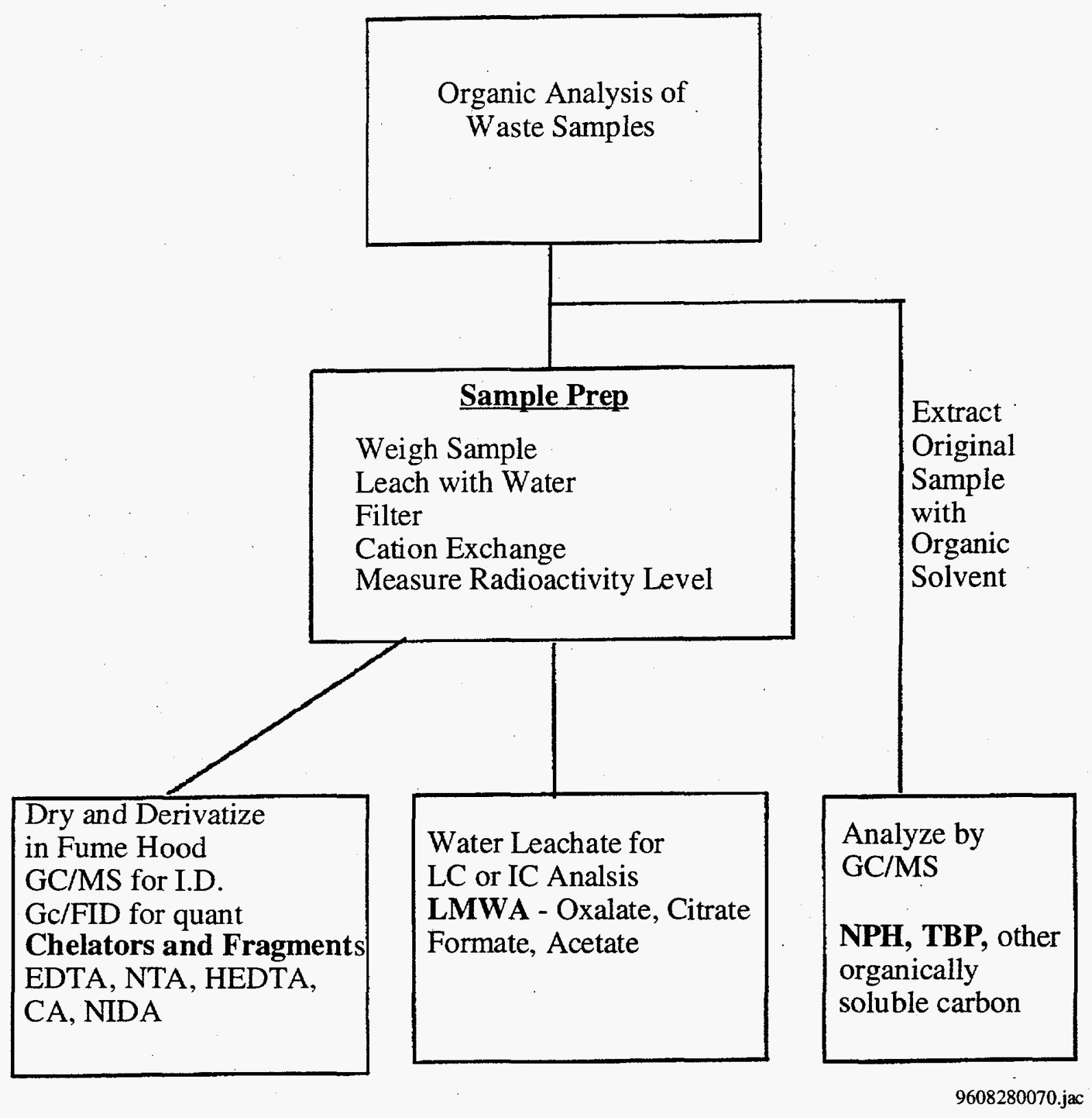

Figure 1. Schematic Illustrating Sample Preparation and Analysis Scheme 
Table 1. Typical Total Organic Data (mg C/g) for Tank SY-101 Core Segment Samples

Sample

$\mathrm{R} 4258 / \mathrm{C}$

$\mathrm{R} 4259 / \mathrm{C}$

$\mathrm{R} 4260 / \mathrm{C}$

$\mathrm{R} 4261 / \mathrm{C}$

$\mathrm{R} 4262 / \mathrm{NC}$

$\mathrm{R} 4263 / \mathrm{NC}$ $\underline{\text { Segment \# }}$

4

6

9

11

16

17
TOC(a)

$11.0(1.4)^{(b)}$

$10.1(6.4)$

$10.6(6.9)$

$10.9(7.0)$

$11.4(7.0)$

$11.0(12.0)$

(a) Based on the average of duplicate analyses

(b) Relative percent difference in parentheses

C Convective Layer

NC Nonconvective Layer 
Table 2. Total Organic Measurements of Waste Sample from Tank SY-101

Sample $\mathrm{TOC}(\mu \mathrm{g} / \mathrm{mL})$

\begin{tabular}{ll}
\hline Trial \#1 & Trial \#2
\end{tabular}

Tank Sample SY-101 2100 1995

After Separation Through $\quad 2200$ 2170 Sodium Form of Resin

After Separation Through $\quad 470$ 490 Hydrogen Form of Resin

Blank of Hydrogen Form 9.5 8

Blank of Sodium Form $<0.5$ $<0.5$ 
Table 3. Results of ${ }^{137} \mathrm{Cs},{ }^{90} \mathrm{Sr}$, and Gross Alpha Analyes from Tank SY-103 Sample Before and After Elution Through Cation Exchange for Radioactivity Reduction

\section{$\underline{\text { Sample }}$}

Convective

Nonconvective

$$
\begin{gathered}
\text { Isotope } \\
{ }^{137} \mathrm{Cs} \\
{ }^{90} \mathrm{Sr} \\
\text { gross alpha }
\end{gathered}
$$

$$
\begin{gathered}
{ }^{137} \mathrm{Cs} \\
{ }^{90} \mathrm{Sr}
\end{gathered}
$$

gross alpha
Before $(\mu \mathrm{Ci} / \mathrm{g})$

273

6.92

0.007

260.80

4.75

0.002

\section{After $(\mu \mathrm{Ci} / \mathrm{g})$}

\subsection{3}

0.55

0.0000061

0.29

0.033

0.00000143 
Table 4. Total Organic Carbon (TOC) Accounted for by Chelators, Chelator Fragments, Low Molecular Weight Organic Acids, and Normal Paraffin Hydrocarbon in Tank SY-101 Segment Samples (mg C/g sample)

\begin{tabular}{|c|c|c|c|c|}
\hline Sample & Segment \# & Chelators & $\begin{array}{l}\text { Low Molecular } \\
\text { Weight Acids }\end{array}$ & $\begin{array}{c}\% \text { TOC } \\
\text { Accounted For }\end{array}$ \\
\hline $\mathrm{R} 4258 / \mathrm{C}$ & 4 & $4.7(44 \%)^{(\mathrm{c})}$ & $3.3(30 \%)$ & $87^{(\mathrm{d})}$ \\
\hline $\mathrm{R} 4259 / \mathrm{C}$ & 6 & $3.3(33 \%)$ & $4.5(44 \%)$ & 77 \\
\hline $\mathrm{R} 4260 / \mathrm{C}$ & 9 & $4.8(46 \%)$ & $4.4(41 \%)$ & 91 \\
\hline $\mathrm{R} 4261 / \mathrm{C}$ & 11 & $6.4(52 \%)$ & $2.5(23 \%)$ & 81 \\
\hline $\mathrm{R} 4262 / \mathrm{NC}$ & 16 & $2.2(20 \%)$ & $5.8(53 \%)$ & 73 \\
\hline $\mathrm{R} 4263 / \mathrm{NC}$ & 17 & $3.6(32 \%)$ & $6.8(61 \%)$ & 93 \\
\hline
\end{tabular}

(a) Includes chelators, chelator fragments, nitrosated chelator material, and several carboxylic acids

(b) Low molecular weight acids include acetic, formic, glycolic, and oxalic

(c) Numbers in parentheses are percent of TOC accounted for by analyte category

(d) Includes contribution from normal paraffin hydrocarbon 


\section{Distribution}

No. of

Copies

\section{Offsite}

2 DOE/Office of Scientific and

Technical Information

Steve F. Agnew

Los Alamos National Laboratory

P. O. Box 1663

CST-4MS-J586

Los Alamos, NM 87545

J. Antizzo

U.S. Department of Energy

EM-36/Trevion II

Germantown, MD 20874

Dr. E. C. Ashby

School of Chemistry/Biochemistry

Georgia Institute of Technology

Atlanta, GA 30332-0400

Dr. E. K. Barefield

School of Chemistry/Biochemistry

Georgia Institute of Technology

Atlanta, GA 30332-0400

Ned Bibler

Westinghouse Savannah River

P. O. Box 616

Aiken, SC 29802

Jack Edwards

Los Alamos National Laboratory

P. O. Box 1663

Los Alamos, NM 87545

L. Kovach

NUCON

P. O. Box 29151

Columbus, OH 43229-0151
No. of

Copies

B. R. Kowalski

Chemistry Department, BG-10

University of Washington

Seattle, WA 98195

C. L. Liotta

School of Chemistry/Biochemistry

Georgia Institute of Technology

Atlanta, GA 30332-0400

\section{Offsite}

Dr. D. Meisel

Chemistry Division

Argonne National Laboratory

9700 South Cass Avenue

Argonne, IL 60439

H. M. Neumann

School of Chemistry/Biochemistry

Georgia Institute of Technology

Atlanta, GA 30332-0400

C. O'Dell

U. S. Department of Energy

EM 36/Trevion II

Germantown, MD 20874

H. Sutter

SAIC

20300 Century Boulevard

Germantown, MD 20874

\section{Onsite}

7 DOE Richard Operations Office

S. O. Branch

S7-54

R. F. Christensen,

S7-54

M. F. Jarvis,

S7 $7-54$

G. W. Rosenwald,

S7-54

Public Reading Room

RL Docket File (2)

B3-11 
No. of

Copies

Onsite

FAI

M. G. Plys

H4-62

2 MACTEC

M. H. Campbell,

S7-73

S. T. Murff

S7-73

17 Westinghouse Hanford Company

H. Babad

S7-14

G. S. Barney

G. A. Barnes

D. B. Bechtold

B. A. Crawford

G. T. Dukelow

K. A. Gasper

D. L. Herting

J. D. Hopkins

J. R. Jewett

G. D. Johnson

N. W. Kirch

J. C. Person

F. R. Reich

D. A. Reynolds

L. M. Stock

D. A. Turner
No. of

Copies
Onsite

Pacific Northwest National Laboratory

B. D. Lerner

M. A. Lilga

P. K. Melethil

G. M. Mong

L. R. Pederson

W. D. Samuels

R. D. Scheele

L. A. Schienbein

A. K. Sharma

C. W. Stewart

M. R. Thompson

$\mathrm{J} . \mathrm{M}$. Tingey

J. J. Toth

K. L. Wahl (10)

Organic Tank Project File

Publishing Coordination

Technical Report Files (5)
P8-08

P8-38

P7-22

P8-08

K2-44

$\mathrm{K} 2-44$

$\mathrm{P} 7-25$

$\mathrm{K} 5-20$

P8-08

K7-15

K2-50

P7-25

K7-94

P8-08

K9-89

\section{Pacific Northwest National}

\section{Laboratory}

G. H. Beeman

J. W. Brothers (5)

P7-75

I. E. Burgeson

K9-20

S. A. Bryan

P7-25

D. M. Camaioni

J. A. Campbell (10)

P7-25

K2-44

C. D. Carlson

S. A. Clauss

P8-08

P7-25

P. A. Gauglitz

P8-08

M. A. Gerber

P7-41

S. C. Goheen

P8-38

R. T. Hallen

P8-08

L. K. Holton

P8-38

D. W. Koppenaal

K9-73

P7-07 